\title{
INTELLIGENT BIOREACTOR MANAGEMENT INFORMATION SYSTEM (IBM-IS) FOR MITIGATION OF GREENHOUSE GAS EMISSIONS
}

\section{Final Project Report}

Reporting Period Start Date: June 1, 2005

Reporting Period End Date: March 30, 2010

Principal Author

Paul T. Imhoff, Associate Professor, Department of Civil and Environmental Engineering, University of Delaware, Newark, Delaware

Co-Authors

Ramin Yazdani, Senior Civil Engineer, Yolo County, Planning and Public Works Department Division of Integrated Waste Management, Woodland, California

Don Augenstein, Scientist/Technical Director, I E M (Institute for Environmental Management, Inc.), Palo Alto, California

Harold W. Bentley, Principle Scientist, Hydro Geo Chem, Inc., Tucson, Arizona

Pei Chiu, Professor, Department of Civil and Environmental Engineering, University of Delaware, Newark, Delaware

Date Report Issued

January 3, 2011

Department of Energy Award Number

DE-FC26-05NT42432

Name and Address of Submitting Organization

Department of Civil and Environmental Engineering

Attn: Paul T. Imhoff, PhD, Associate Professor

University of Delaware

Newark, DE 19716 
$\underline{\text { Names and Addresses of Sub-Recipients }}$

1. County of Yolo

Planning and Public Works Department

Division of Integrated Waste Management

Attn: Ramin Yazdani, PhD, Senior Civil Engineer

44090 County Road 28H

Woodland, CA 95776

2. Hydro Geo Chem, Inc.

Attn: Harold W. Bentley, PhD, Principal Scientist

51 West Wetmore Road, Suite 101

Tucson, AZ 85705-1678

3. Institute for Environmental Management, Inc. (I E M)

Attn: Don Augenstein

4277 Pomona Avenue

Palo Alto, CA 94306 


\section{Disclaimer}

This report was prepared as an account of work sponsored by an agency of the United States Government. Neither the United States Government nor any agency thereof, nor any of their employees, makes any warranty, express or implied, or assumes any legal liability or responsibility for the accuracy, completeness, or usefulness of any information, apparatus, product, or process disclosed, or represents that its use would not infringe privately owned rights. Reference herein to any specific commercial product, process, or service by trade name, trademark, manufacturer, or otherwise does not necessarily constitute or imply its endorsement, recommendation, or favoring by the United States Government or any agency thereof. The views and opinions of authors expressed herein do not necessarily state or reflect those of the United States 


\section{Abstract}

Methane is an important contributor to global warming with a total climate forcing estimated to be close to $20 \%$ that of carbon dioxide (CO2) over the past two decades. The largest anthropogenic source of methane in the US is "conventional" landfills, which account for over $30 \%$ of anthropogenic emissions. While controlling greenhouse gas emissions must necessarily focus on large $\mathrm{CO} 2$ sources, attention to reducing $\mathrm{CH} 4$ emissions from landfills can result in significant reductions in greenhouse gas emissions at low cost. For example, the use of "controlled" or bioreactor landfilling has been estimated to reduce annual US greenhouse emissions by about 15-30 million tons of $\mathrm{CO} 2$ carbon (equivalent) at costs between $\$ 3-13 /$ ton carbon. In this project we developed or advanced new management approaches, landfill designs, and landfill operating procedures for bioreactor landfills. These advances are needed to address lingering concerns about bioreactor landfills (e.g., efficient collection of increased $\mathrm{CH} 4$ generation) in the waste management industry, concerns that hamper bioreactor implementation and the consequent reductions in $\mathrm{CH} 4$ emissions. Collectively, the advances described in this report should result in better control of bioreactor landfills and reductions in $\mathrm{CH} 4$ emissions. Several advances are important components of an Intelligent Bioreactor Management Information System (IBM-IS). 


\section{Table of Contents}

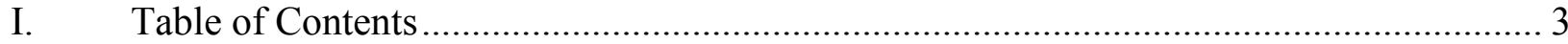

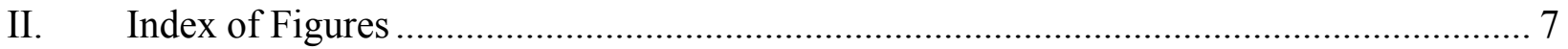

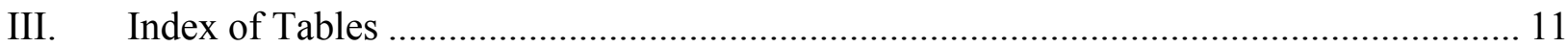

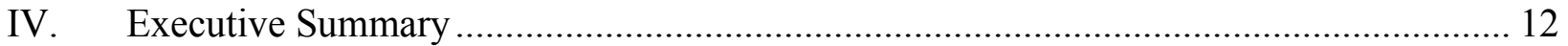

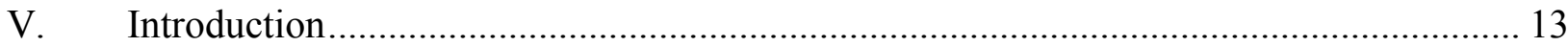

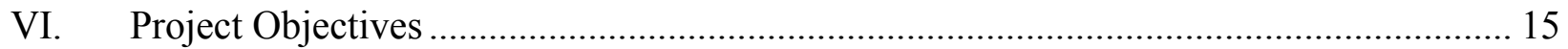

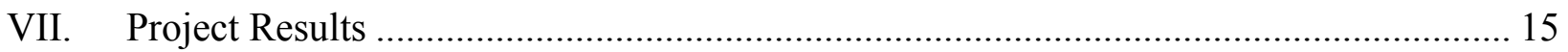

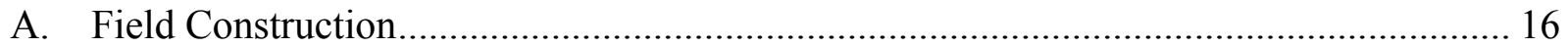

1. New Anaerobic Test Cell 16

2. Gas Pressure and Composition Measurement 18

B. Intelligent Control of Aerobic Bioreactor Operations ...................................................... 19

1. Field Testing to Design IBM-IS 19

2. Modeling to Design IBM-IS for Aerobic Operations 24

3. Field Tests of IBM-IS for Aerobic Operations 26

a) Materials and Methods $\quad 26$

(1) Landfill design and instrumentation 26

(2) Landfill cell operation and testing 30

(3) In-situ aerobic respiration tests $\quad 32$

(4) Partitioning gas tracer tests 33

b) Results and discussion $\quad 33$

(1) Fluid pressure and gas composition 33

(2) In-situ aerobic respiration test results $\quad 39$

(3) Partitioning gas tracer tests 40

c) Findings 43

C. Intelligent Control of Anaerobic Bioreactor Operations .................................................... 43

1. Performance of a Near-Surface High Permeability Layer 44

a) Gas Flow in Landfills $\quad 47$

(1) Landfill gas collection systems $\quad 47$

(2) Diffusion of multicomponent gas mixtures in porous media 48 
b) Methodology $\quad 51$

c) Results $\quad 57$

(1) Effect of permeable layer - Base case simulation 57

d) Discussion $\quad 66$

e) Conclusions $\quad 68$

2. Inverse Modeling to Estimate Gas Permeability Field and Landfill Gas Generation

$\begin{array}{ll}\text { Rate } & 69\end{array}$

$\begin{array}{ll}\text { a) Background } & 72\end{array}$

(1) Baro-pneumatic method $\quad 72$

b) Methods $\quad 74$

(1) Overview $\quad 74$

(2) Baro-pneumatic Method Evaluation $\quad 75$

c) Results $\quad 82$

(1) Parameter Estimation $\quad 82$

(2) Performance of Calibrated Models $\quad 88$

d) Conclusions 92

3. Performance of Near-Surface High Permeability Layer and Automated System for Landfill Gas Collection $\quad 94$

a) Performance of Near-Surface High Permeability Layer $\quad 94$

b) Performance of Automated System for Gas Collection 99

VIII. Conclusions ..................................................................................................... 103

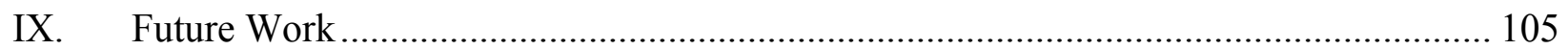

X. Products Produced and Technology Transfer Activities .......................................... 108

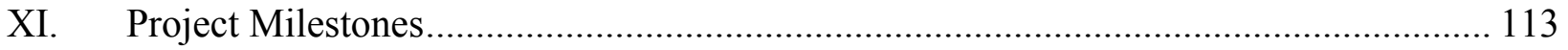

XII. References..................................................................................................... 115 


\section{Index of Figures}

FIGURE 1. SIDE VIEW OF NEW ANAEROBIC CELL, LOOKING SOUTHEAST. 16

FIGURE 2. SIDE VIEW OF NEW ANAEROBIC CELL, LOOKING EAST. 17

$\begin{array}{ll}\text { FIGURE 3. SHREDDED TIRE LAYER IN NEW ANAEROBIC CELL. } & 17\end{array}$

FIGURE 4. SWITCHING VALVES (BLACK BOX-LIKE ITEMS) AND THE MODEL 270 SETRA PRESSURE TRANSDUCER FOR THE AUTOMATIC PRESSURE MEASUREMENT SYSTEM.

FIGURE 5. COMPUTER FOR OPERATING AUTOMATIC PRESSURE MEASUREMENT SYSTEM, AND LINES CONNECTING SWITCHING VALVES WITH TUBES RUNNING TO LOCATIONS INSIDE LANDFILL CELLS.

FIGURE 6. LAYOUT OF NUMERICAL GRID FOR SIMULATING THE PUMP TESTS IN THE AEROBIC LANDFILL CELL.

FIGURE 7. CROSS SECTION THROUGH THE MIDDLE OF THE LANDFILL ILLUSTRATING THE FOUR REGIONS (OR MATERIAL TYPES) NEEDED TO FIT THE PUMP TEST DATA.

FIGURE 8. GAS PRESSURE DATA AND BEST-FIT MODEL PREDICTIONS FOR TWO MEASUREMENT LOCATIONS IN PUMP TEST 1.

FIGURE 9. GAS PRESSURE DATA AND BEST-FIT MODEL PREDICTIONS FOR THREE MEASUREMENT LOCATIONS IN PUMP TEST 1.

FIGURE 10. DISTRIBUTION OF AIR IN A CROSS-SECTION THROUGH THE AEROBIC BIOREACTOR AFTER 24 HOURS OF EXTRACTION OF GAS FOR CASE 1. DOTTED LINES ILLUSTRATE THE TOP SURFACE OF THE LANDFILL.

FIGURE 11. DISTRIBUTION OF AIR IN A CROSS-SECTION THROUGH THE AEROBIC BIOREACTOR AFTER 24 HOURS OF EXTRACTION AND INJECTION OF GAS FOR CASE 4. DOTTED LINES ILLUSTRATE THE TOP SURFACE OF THE LANDFILL. 25

FIGURE 12. PLAN AND CROSS SECTIONAL VIEW OF YOLO COUNTY AEROBIC BIOREACTOR LANDFILL CELL ILLUSTRATING THE LOCATION OF INSTRUMENTATION, GAS COLLECTION AND LEACHATE RECIRCULATION LINES, RESPIRATION TESTS LOCATIONS, AND PARTITIONING GAS TRACER TESTS.

FIGURE 13. CUMULATIVE SUPPLEMENTAL LIQUID ADDED AND LEACHATE RECIRCULATED DURING THE OPERATIONAL PERIOD. 
FIGURE 14. PERCENT ANAEROBIC ACTIVITY AND TOTAL FLUID PRESSURE IN INSTRUMENTATION LAYERS 1 AND 2. MEASUREMENTS REPORTED FOR LAYER 1 AND 2 ARE AVERAGES OF ALL READINGS IN EACH LAYER. PERIODS WHEN THE BLOWER WAS OFF FOR LONGER THAN 2 DAYS ARE INDICATED. 32

FIGURE 15. CONTOURS OF GAS COMPOSITION IN LAYER 1 ON 8/23/06. SOLID LINES CORRESPOND TO OUTLINE OF LANDFILL. (A) PERCENT ANAEROBIC ACTIVITY. DASHED LINES REPRESENT REGIONS WHERE $P \geq 50 \%$ AND DOTTED LINES WHERE $P<50 \%$. (B). OXYGEN CONCENTRATION. DASHED LINES REPRESENT REGIONS WHERE OXYGEN CONCENTRATION $<10 \%$. (C) WASTE TEMPERATURE. DASHED LINES REPRESENT REGIONS WHERE LANDFILL TEMPERATURE $>70^{\circ} \mathrm{C}$.

FIGURE 16. DATA FROM IN-SITU RESPIRATION TESTS IN AEROBIC BIOREACTOR LANDFILL CELL

FIGURE 17. SIMPLIFIED CROSS SECTION OF GAS COLLECTION SYSTEMS. (A) CONVENTIONAL VERTICAL PUMPING WELL. (B) PUMPING WELL WITH PERMEABLE LAYER.

FIGURE 18. ONE HALF OF CROSS SECTION FOR BASE-CASE SIMULATIONS. THE THICKNESSES OF LAYERS 1 TO 5 ARE 2.1, 2.4, 2.3, 2.0, AND $2.0 \mathrm{M}$, RESPECTIVELY.

FIGURE 19. METHANE AND OXYGEN GAS MOLAR FLUX VECTORS FOR ONE HALF OF THE COVER SOIL. THE LENGTH AND DIRECTION OF THE ARROWS INDICATE THE MAGNITUDE AND DIRECTION OF GAS FLOWS. (A) WITH UPPER HORIZONTAL PERMEABLE LAYER INSTALLED. (B) WITHOUT UPPER HORIZONTAL PERMEABLE LAYER INSTALLED.

FIGURE 20. OXYGEN (PERCENT BY MASS) THROUGHOUT ONE HALF OF THE PROBLEM DOMAIN. (A) WITH UPPER HORIZONTAL PERMEABLE LAYER INSTALLED. (B) WITHOUT UPPER HORIZONTAL PERMEABLE LAYER INSTALLED.

FIGURE 21. VARIATION OF METHANE EMISSIONS AND REFUSE VOLUME WITH $>3$ $\%$ OXYGEN CONCENTRATION ABOVE THE PUMPING WELL.

FIGURE 22. VARIATIONS OF METHANE EMISSIONS AS A FUNCTION OF THE GAS PERMEABILITY AND WASTE ANISOTROPY RATIO. RESULTS ARE SHOWN FOR CASES WITH OR WITHOUT THE HORIZONTAL PERMEABLE LAYER.

FIGURE 23VARIATIONS IN METHANE EMISSIONS ASSOCIATED WITH ATMOSPHERIC PRESSURE CHANGES OVER A 24-HOUR PERIOD. RESULTS ARE SHOWN FOR A LANDFILL WITH AND WITHOUT A HORIZONTAL PERMEABLE LAYER INSTALLED AT THE TOP OF THE LANDFILL. (A) VARIATIONS IN ATMOSPHERIC PRESSURE. (B) METHANE EMISSIONS. 
FIGURE 24. SCHEMATIC OF THE MODEL DOMAIN FOR SYNTHETIC EXAMPLE. (A) GEOMETRY OF OBSERVATION (+) AND PILOT POINTS (๘) AND (B) THE TRUE HORIZONTAL GAS PERMEABILITY DISTRIBUTION IN A LOGARITHMIC SCALE. THE NUMBERS IN THE BOX INDICATE OBSERVATION POINTS (E.G., OBS6). 76

FIGURE 25. VARIATION OF ATMOSPHERIC PRESSURE AND THE CORRESPONDING PRESSURE RESPONSES AT OBSERVATION POINTS OBS6 AND OBS8 DURING THE PNEUMATIC PUMP TEST. THE PUMPING SCHEDULE IS ALSO SHOWN, WHERE "PUMP ON" IS WHEN THE GAS EXTRACTION RATE WAS INCREASED BY A FACTOR OF THREE AND "PUMP OFF" IS WHEN THE GAS EXTRACTION RATE RETURNED TO 80\% OF THE LFG GENERATION RATE OF THE LANDFILL.

FIGURE 26. ESTIMATED HORIZONTAL GAS PERMEABILITY FIELD WHEN THE LOG GAS PERMEABILITY WAS THE ONLY UNKNOWN PARAMETER: (A) ONE REALIZATION AMONG THE 20 ESTIMATED GAS PERMEABILITY FIELDS, (B) THE MEAN OF THE PREDICTED DISTRIBUTIONS, AND (C) THE STANDARD DEVIATION OF THE PREDICTED DISTRIBUTIONS. THE RESULTS ARE SHOWN IN A LOGARITHMIC SCALE.

FIGURE 27. MATCH OF PNEUMATIC PRESSURES DURING THE BARO-PNEUMATIC TEST AT DIFFERENT LOCATIONS IN CASE 1 FOR ONE EXAMPLE REALIZATION: (A) OBS6, (B) OBS11, AND (C) OBS15.

FIGURE 28. VERTICAL PROFILES OF THE ESTIMATED HORIZONTAL GAS PERMEABILITY FIELDS AT (A) $\mathrm{X}=35 \mathrm{M}$ AND (B) $\mathrm{X}=70 \mathrm{M}$ FOR ONE REALIZATION FOR EACH CASE USING THE SAME SEED NUMBER.

FIGURE 29. PRESSURE DISTRIBUTIONS AT THE BEGINNING (LEFT COLUMN) AND THE END (RIGHT COLUMN) OF THE PUMPING PERIOD IN WHICH THE FLOW RATE WAS TRIPLED IN THE TRUE MODEL (A), AND PREDICTED PRESSURE DISTRIBUTIONS FOR THE HETEROGENEOUS CASE WITH THE (B) MINIMUM AND (C) MAXIMUM OBJECTIVE FUNCTION AMONG 20 DIFFERENT INVERSIONS FOR CASE 1. CONTOUR LINES DELINEATE CHANGES IN PRESSURE OF 125 PA.

FIGURE 30. PRESSURE DISTRIBUTIONS AT THE BEGINNING (LEFT COLUMN) AND THE END (RIGHT COLUMN) OF THE PUMPING PERIOD IN WHICH THE FLOW RATE WAS TRIPLED: (A) HO1 AND (B) HO3. . CONTOUR LINES DELINEATE CHANGES IN PRESSURE OF 125 PA.

FIGURE 31. PREDICTED BTCS FOR (A) TEST 1 AND (B) TEST 2. TRUE BTCS ARE SHOWN WITH SOLID CIRCLES. THE MEAN PREDICTED BTCS IN CASE 1 ARE SHOWN WITH THICK SOLID LINES, AND THE PREDICTION BOUNDS (THE MEAN SURFACE +/-2 TIMES THE STANDARD DEVIATIONS) ARE SHOWN WITH SHADE. 
FIGURE 32. TOP VIEW OF WELL DESIGN AND PERMEABLE LAYER COMPONENTS.

FIGURE 33. WELL DESIGN AND PERMEABLE LAYER COMPONENTS IN PROFILE VIEW.

FIGURE 34. PLACEMENT OF ADDITIONAL COVER SOIL ON SIDE SLOPE OF ANAEROBIC TEST CELL WITH NEAR-SURFACE HIGH PERMEABILITY LAYER.

FIGURE 35. LOCATIONS OF SURFACE PROBES FOR MEASURING GAS PRESSURE AT THE TOP SURFACE OF THE LANDFILL BENEATH THE COVER SOIL. PROBE LOCATIONS ARE INDICATED BY “X” AND ARE NUMBERED 1-15.

FIGURE 36. DATA FROM SETTING 1 FOR CONTROL OF GAS COLLECTION WELL 2G9: FIXED VALVE POSITION.

FIGURE 37. DATA FROM SETTING 2 FOR CONTROL OF GAS COLLECTION WELL 2G9: FIXED GAS FLOW RATE. 


\section{Index of Tables}

TABLE 1. CONDITIONS FOR PUMP TESTS IN AEROBIC BIOREACTOR IN JANUARY 2006

TABLE 2. BEST-FIT PARAMETERS FROM PUMP TEST 1 FOR AEROBIC BIOREACTOR.

TABLE 3. GENERAL PROPERTIES OF MODEL DOMAIN FOR BASE SIMULATIONS

TABLE 4. SUMMARY OF VARIOUS CASES ANALYZED

TABLE 5. ASSUMED PARAMETERS FOR VARIOUS CASES TESTED

TABLE 6. COMPARISON OF MODEL PERFORMANCE WITH HETEROGENEOUS GAS PERMEABILITY FIELD A

TABLE 7. COMPARISON OF MODEL PERFORMANCE WITH HOMOGENEOUS GAS PERMEABILITY APPROXIMATION 


\section{III.Executive Summary}

Methane is an important contributor to global warming with a total climate forcing estimated to be close to $20 \%$ that of carbon dioxide (CO2) over the past two decades. The largest anthropogenic source of methane in the US is "conventional" landfills, which account for over $30 \%$ of anthropogenic emissions. One means of mitigating methane emissions is to operate landfills as "controlled landfills" or "bioreactors." Here, biological conditions in the waste are optimized allowing more rapid and complete waste decomposition. In "anaerobic bioreactors" methane generation is enhanced through liquid addition. High efficiency capture of methane is utilized to maximize fuel energy recovery and minimize fugitive emissions. In "aerobic bioreactors" air and liquid are introduced in the landfill and the combined effects of heat and oxygen inhibit methane formation. Both "controlled" landfill operations hold promise for mitigating fugitive methane emissions from landfills.

A recent NETL sponsored economic study of anaerobic controlled landfilling estimated that such landfilling could reduce annual US greenhouse emissions by about 15-30 million tons of CO2 carbon (equivalent) at costs between $\$ 3-13 /$ ton carbon. Given the promise of this technology, several bioreactor landfills have been constructed in the United States, although most are fieldscale research landfills. While a few commercial bioreactor landfills have been built, the waste management industry has yet to embrace this technology because of lingering concerns about the capture of fugitive greenhouse gases, how to manage liquid addition to maintain optimal moisture contents while avoiding seeps from landfill sidewalls, and the potential for fires (aerobic bioreactor).

In this work we developed and/or advanced new management approaches, landfill designs, and landfill operating procedures for bioreactor landfills that we believe can alleviate many of the concerns listed above. These included (1) advancing a gas tracer technology for measuring gas flow and water content in landfills, (2) evaluating the amount of methane generated during aerobic bioreactor operations and factors causing its generation, (3) testing a new type of landfill design to increase methane capture in anaerobic bioreactors, (4) using pneumatic pump tests and baro-pneumatic tests to estimate the gas permeability field and landfill gas generation rate of landfills, (5) and developing an automated system for adjusting gas collection in response to barometric pressure changes to reduce fugitive methane emissions from landfills. Several of these are components of an Intelligent Bioreactor Management Information System (IBM-IS).

If the advances we made are combined with innovations developed by others (e.g., engineered biocovers for oxidizing fugitive methane emissions), less methane will be emitted from landfills in the United States and other countries. To encourage application of the management approaches, landfill design features, and landfill operating procedures developed in this project we disseminated our work by co-hosting a workshop in 2008 on "Models for Landfills," presenting project results in 16 conference presentations, and publishing our work in 11 manuscripts thus far. This report summarizes advances made in our project that we believe aid in intelligent control of bioreactor landfills and the reduction of greenhouse gas emissions. 


\section{IV.Introduction}

Methane is an important contributor to global warming with a total climate forcing estimated to be close to $20 \%$ that of carbon dioxide (CO2) over the last two decades. Because methane has an atmospheric lifetime of 12 years compared to 50-200 years for CO2 and a global warming potential 21 times larger than CO2 over a 100-year period [IPCC, 2001], it is a prime candidate for emissions reduction. A decrease in methane emissions will have a more immediate effect on climate warming than similar reductions in $\mathrm{CO} 2$ emissions.

The largest anthropogenic source of methane in the United States is "conventional" landfills, which account for over $30 \%$ of anthropogenic emissions [USEPA, 2008]. Organic wastes placed in sanitary landfills (also waste dumps) initially sequester photosynthetically fixed carbon in amounts sufficient to significantly reduce atmospheric $\mathrm{CO} 2$. However, much of this waste organic material decomposes over time to methane. In an uncontrolled landfill or a landfill with a gas collection system with gas extraction efficiency of $70 \%$ to $80 \%$ (efficiencies achieved with best available technology for gas collection and removal), methane generated from waste decomposition is emitted into the atmosphere and acts as a greenhouse gas. If, however, methane can be captured and used for energy generation rather than released into the atmosphere, methane emissions are reduced with the added benefit of offsetting fossil $\mathrm{CO} 2$ emissions from energy generating facilities. In fact, for organic waste that decomposes, the methane energy benefit is comparable to the initial sequestration of carbon in the decomposing waste.

Controlled "bioreactor" landfilling entails controlling and optimizing biological conditions in the waste to allow more rapid and complete waste decomposition. The two bioreactor options are anaerobic, in which air is excluded, and aerobic, in which air is passed 
through the waste. Both options require moisture. In the anaerobic bioreactor, rapid, controlled methane generation is combined with high efficiency methane capture. This maximizes fuel energy recovery and $\mathrm{CO} 2$ offsets, while minimizing fugitive methane emissions. By contrast, the aerobic bioreactor process introduces air and liquid into landfilled waste, with the combined effects of heat and oxygen inhibiting methane formation. While there is no energy recovery with aerobic bioreactor landfills, waste degrades significantly faster than in anaerobic bioreactors. This faster destruction of waste materials allows reclamation of landfill space vacated by decomposing organic waste sooner than for anaerobic bioreactors.

While bioreactors landfills at Yolo County and elsewhere show much promise, this technology is still primarily conducted at research landfills, with only a few commercial applications of bioreactor landfilling found in the United States. There are several reasons for this including potential increases in greenhouse gas emissions if the enhanced methane produced cannot be captured; seepage of liquids through side walls of landfills associated with difficulties in predicting and measuring the movement of added liquids; and the potential for fires in aerobic bioreactor landfills, if the injection of liquid and air are not sufficient to maintain optimal moisture conditions and air distribution, respectively. Each of these concerns (as well as others) for bioreactor landfills relate to the control of gas and liquid flows in bioreactors. If such flows can be "controlled" in an intelligent system, then risks associated with bioreactor operation would be significantly reduced. While intelligent control of engineered systems using automated sensors and control points is common in many fields, it is virtually unknown in the field of solid waste management and represents a revolutionary change in thinking. 


\section{Project Objectives}

The overall goal of this work was to develop and demonstrate an Intelligent Bioreactor Management and Information System (IBM-IS) for control of landfill gas extraction, air injection, and liquid addition in bioreactor landfills. To achieve this overall goal, this work had two objectives. First, an IBM-IS was to be developed and tested for mitigating fugitive methane emissions from a new anaerobic cell with a near-surface high permeability cover. Without an IBM-IS, typically from 15 to over $30 \%$ of the methane generated from a traditional anaerobic landfill is emitted to the atmosphere. The IBM-IS was intended to mitigate methane emissions associated with barometric pressure fluctuations, potentially reducing fugitive methane emissions to below $10 \%$. Second, an IBM-IS was to be developed and tested for controlled injection of air and liquids to maintain optimal conditions for suppression of methane generation in the aerobic landfill cell. Suboptimal moisture contents and air injection rates increase risks of fires, decrease suppression of methane generation, and increase risks associated with leachate seeps from landfill sidewalls.

While these were the primary objectives of the project, the IBM-IS includes many components, most of which had to be tested independently to aid in IBM-IS operations. These included the development of advanced data inversion techniques to determine the spatial variability of gas permeability in landfills, the evaluation of photoacoustic spectroscopy for conducting gas tracer tests in real-time to quantify gas flow patterns and water content in landfills, and the construction and testing of a near-surface high permeability layer for enhanced collection of landfill gas.

\section{VI.Project Results}

The project results are presented in the following sections. We begin with a summary of field construction activities at the Yolo County Landfill, where all field testing was performed. Next, we present in results from IBM-IS operations for aerobic bioreactors, followed by IBM-IS 
operations of anaerobic bioreactors. Within each of these subsections we present some of the contributions made in the development and testing of each IBM-IS system.

\section{A. Field Construction}

\section{New Anaerobic Test Cell}

A new anaerobic test cell was constructed (1) to evaluate the performance of a nearsurface high permeability layer for enhancing landfill gas collection and (2) to test an automated IBM-IS for collecting landfill gas during periods of barometric pressure change. While funds from a separate project on peaking-power operations were used to construct this new anaerobic cell, this cell was critical to this project.

Photographs of the constructed anaerobic cell are shown in Figures 1 and 2.

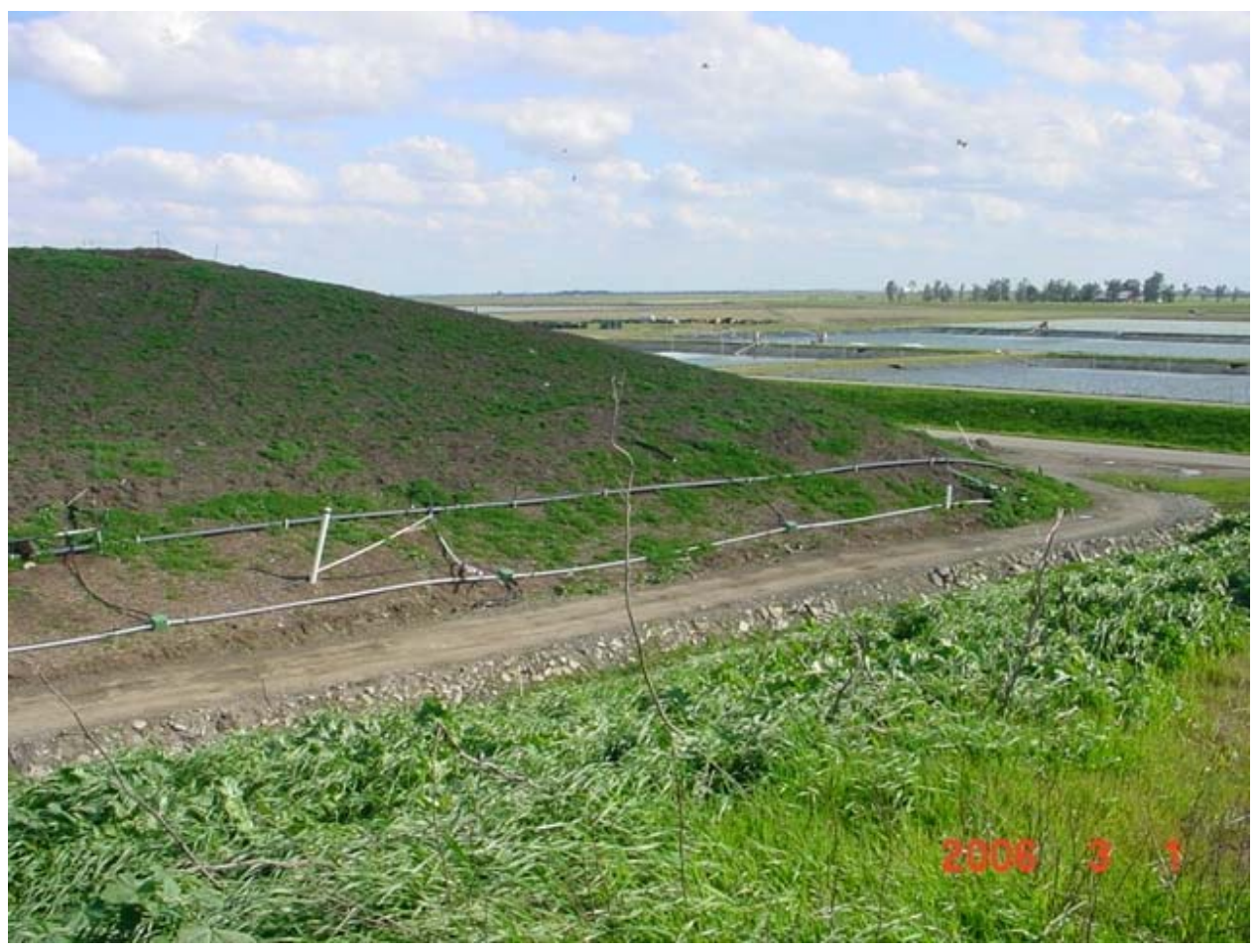

Figure 1. Side view of new anaerobic cell, looking southeast. 


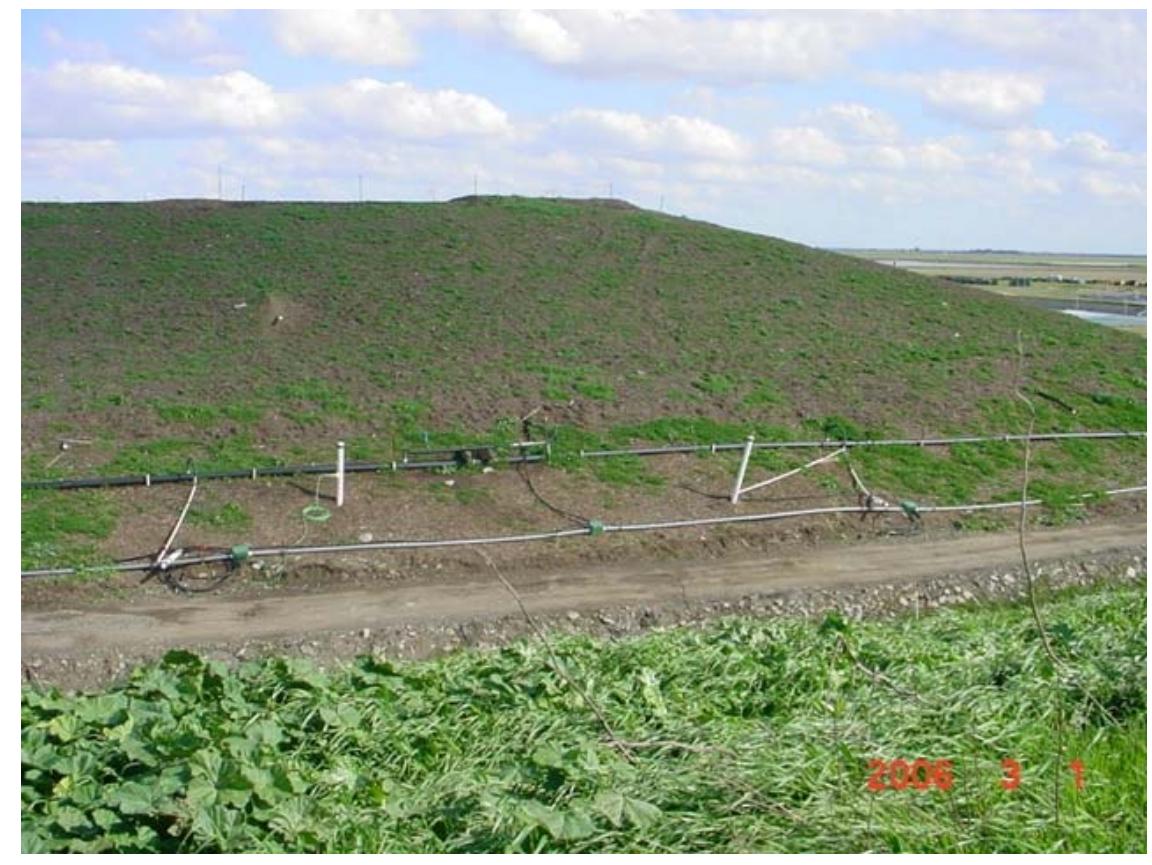

Figure 2. Side view of new anaerobic cell, looking east.

A key feature of this cell is a near-surface high permeability layer that was constructed to enhance collection of landfill gas. This layer is constructed of shredded tires, similar to that shown below in Figure 3 .

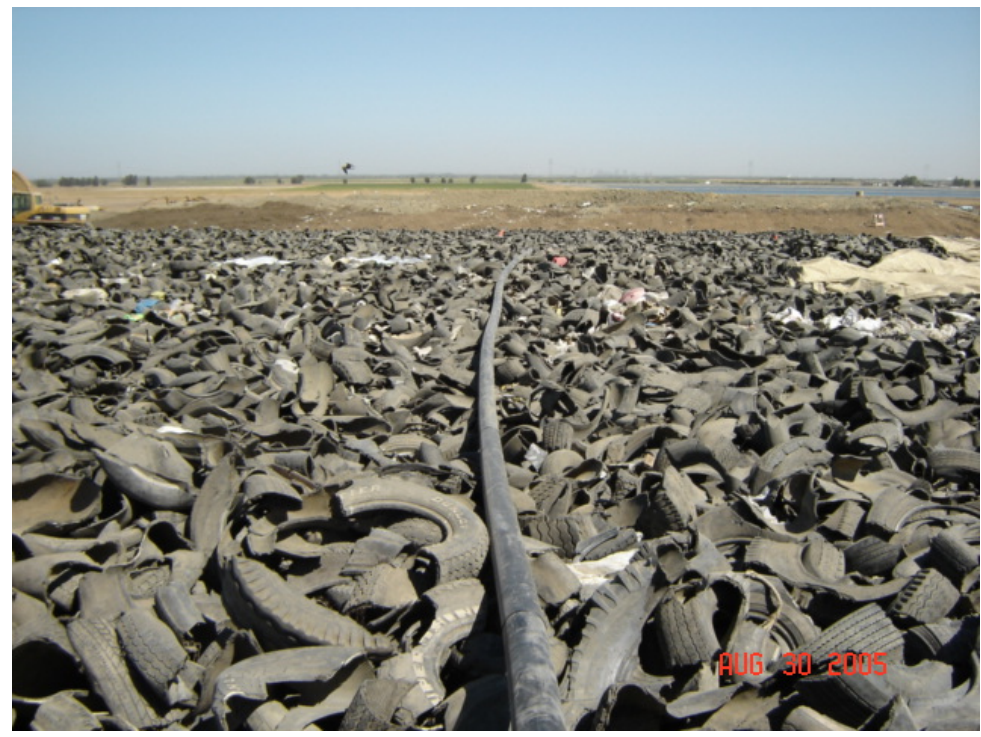

Figure 3. Shredded tire layer in new anaerobic cell. 


\section{Gas Pressure and Composition Measurement}

The anaerobic test cell was instrumented with sensors to measure moisture locally, and

tubes that were routed to a nearby instrument shed. There, a system was constructed to automatically measure gas composition and gas pressure with these tubes. Photographs of this system are shown below in Figures 4 and 5.

Setra Model 270 Pressure Transducer

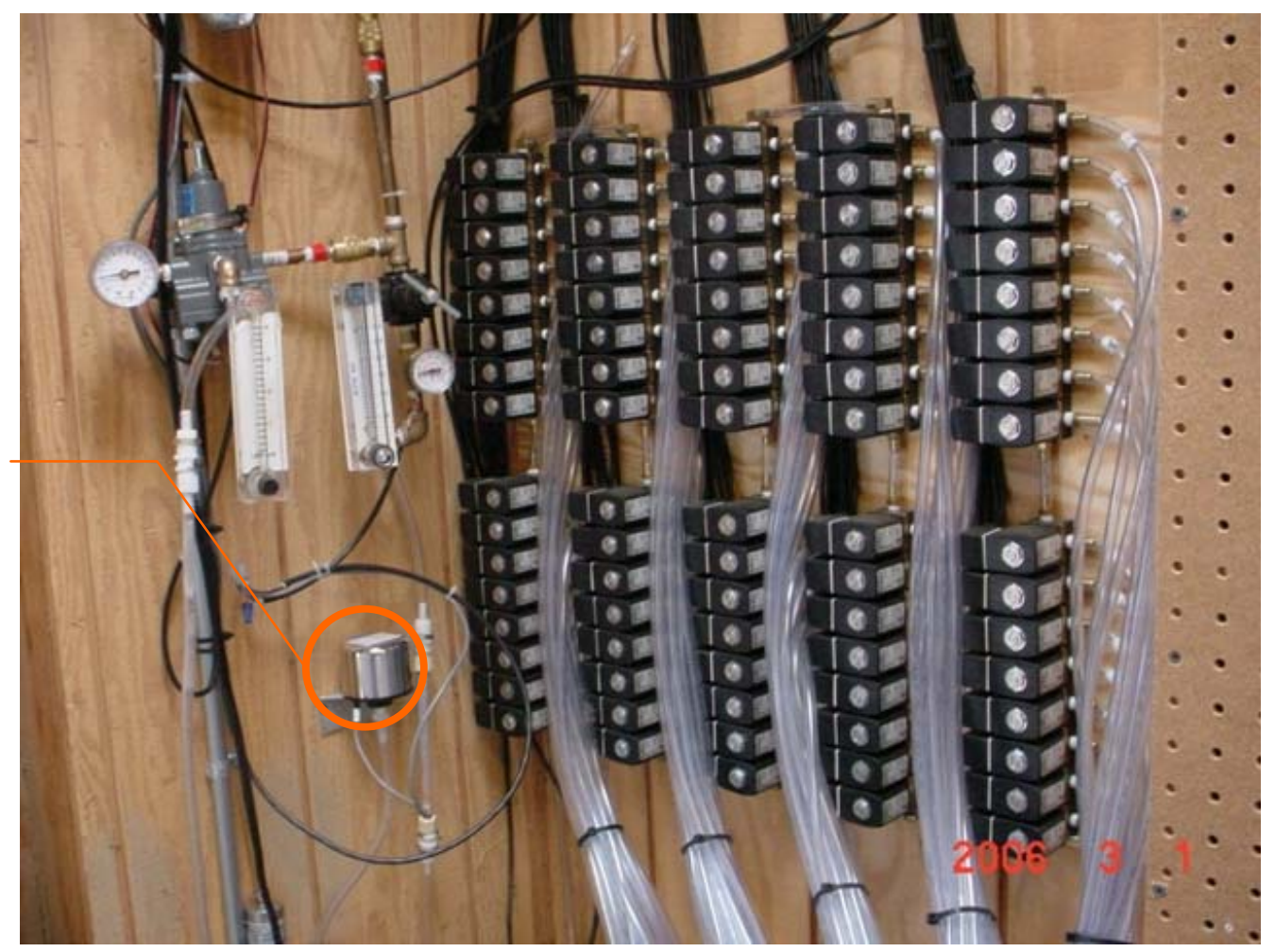

Figure 4. Switching valves (black box-like items) and the Model 270 Setra pressure transducer for the automatic pressure measurement system. 


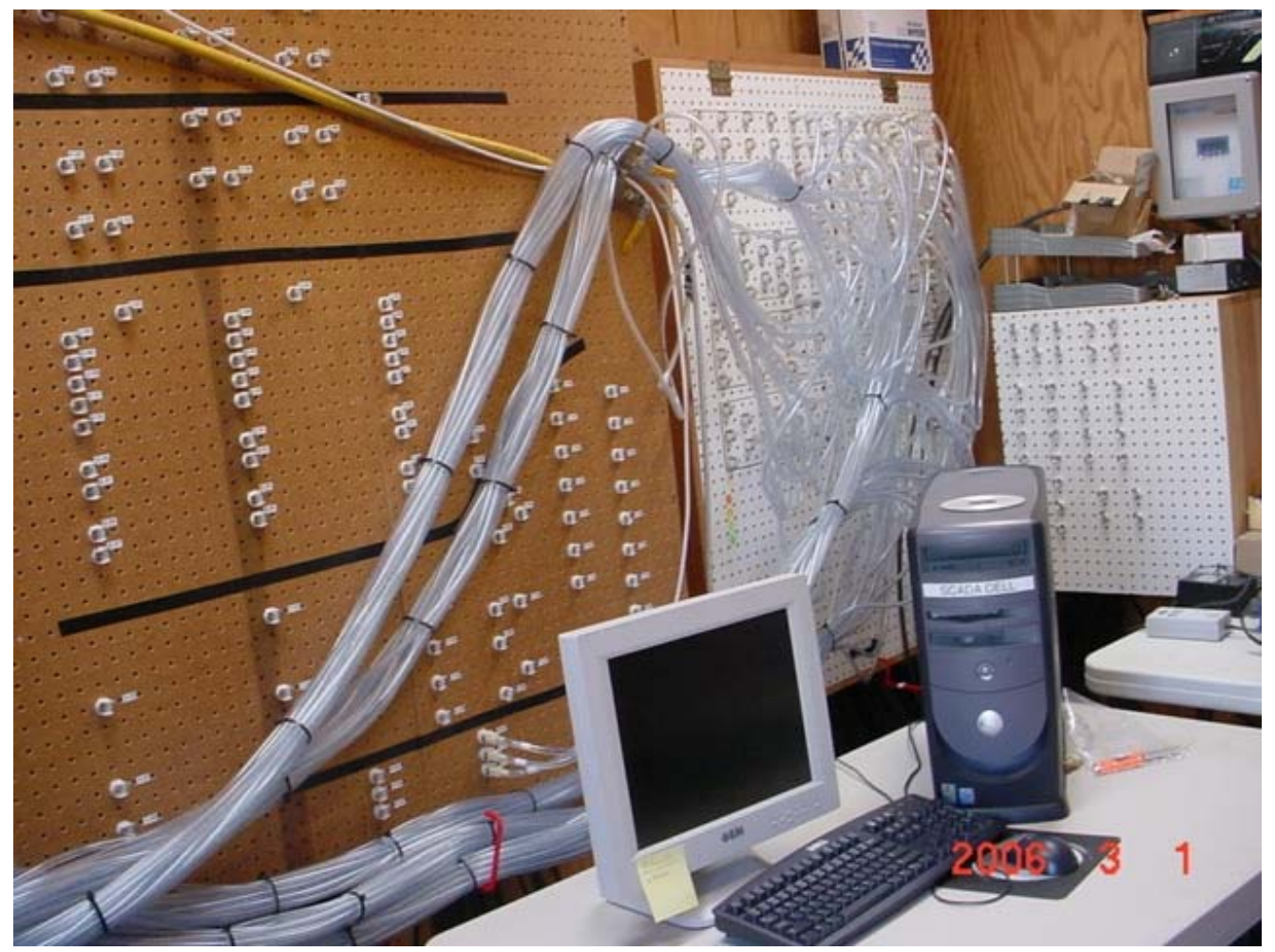

Figure 5. Computer for operating automatic pressure measurement system, and lines connecting switching valves with tubes running to locations inside landfill cells.

\section{B. Intelligent Control of Aerobic Bioreactor Operations}

\section{Field Testing to Design IBM-IS}

Field experiments were conducted to determine the gas permeability in the aerobic

bioreactor, which was constructed at Yolo County Central Landfill as part of a previous NETL-

sponsored project. This permeability was used to develop a three-dimensional gas flow model of the landfill so that an intelligent selection of wells and gas flow rates could be made for assuring optimal air injection conditions for operation of this cell. Previous attempts of operating this cell as an aerobic bioreactor resulted in localized regions were temperatures were elevated, which indicated that air injection was not sufficient to remove excess heat associated with aerobic 
biodegradation of refuse. This operational problem has prevented this cell from being operated continuously as an aerobic bioreactor.

Six pump tests were conducted in the aerobic bioreactor using three existing horizontal wells in the landfill. Two wells were in layer 1 and one well in layer 2 . The pump tests were conducted using the following procedures:

- Test well was pumped at an extraction rate that was $15 \%$ higher than the pumping rate for the pump test, for approximately 15 minutes.

- Test well was turned off and pressures allowed to return to background

- Automatic pressure measurement system turned on.

- Pump test started at specified flow rate and continued for approximately 60 minutes.

Table 1 lists the locations of the pumping wells used in the tests and the pumping rates.

Table 1. Conditions for Pump Tests in Aerobic Bioreactor in January 2006

\begin{tabular}{|c|c|c|}
\hline Pump Test & Pumping Well & $\begin{array}{c}\text { Pumping Rate } \\
\text { (SCFM) }\end{array}$ \\
\hline 1 & $2-\mathrm{A} 3-\mathrm{SE}$ & $321-337$ \\
\hline 2 & $2-\mathrm{A} 3-\mathrm{SE}$ & $162-169$ \\
\hline 3 & $1-\mathrm{A} 3-\mathrm{SE}$ & 343 \\
\hline 4 & $1-\mathrm{A} 3-\mathrm{SE}$ & $188-200$ \\
\hline 5 & $2-\mathrm{A} 2-\mathrm{SE}$ & $326-329$ \\
\hline 6 & $2-\mathrm{A} 2-\mathrm{SE}$ & $203-210$ \\
\hline
\end{tabular}

The pump tests were analyzed by first developing a three-dimensional gas flow model for the aerobic bioreactor. This model consists of a rectangular grid that is $98 \times 50 \times 30$ cells to represent this 2.5 acre landfill. The model layout is shown below in Figures 6 and 7 . 

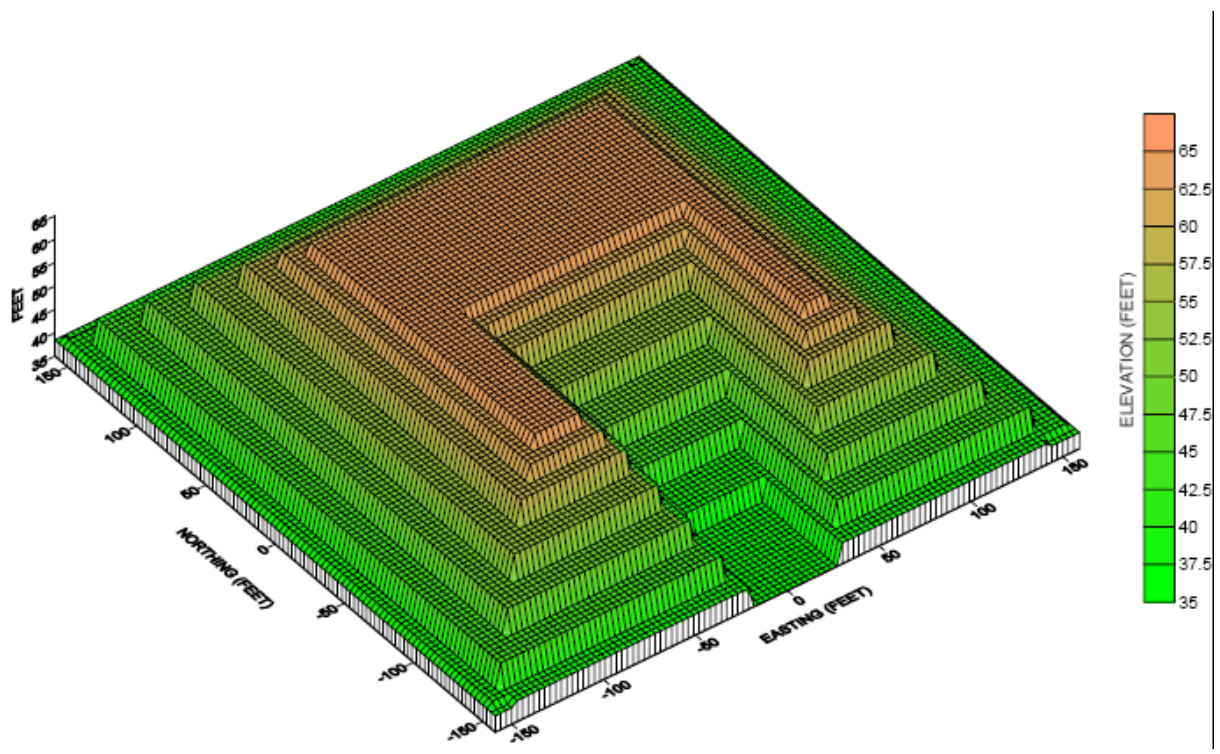

Figure 6. Layout of numerical grid for simulating the pump tests in the aerobic landfill cell.

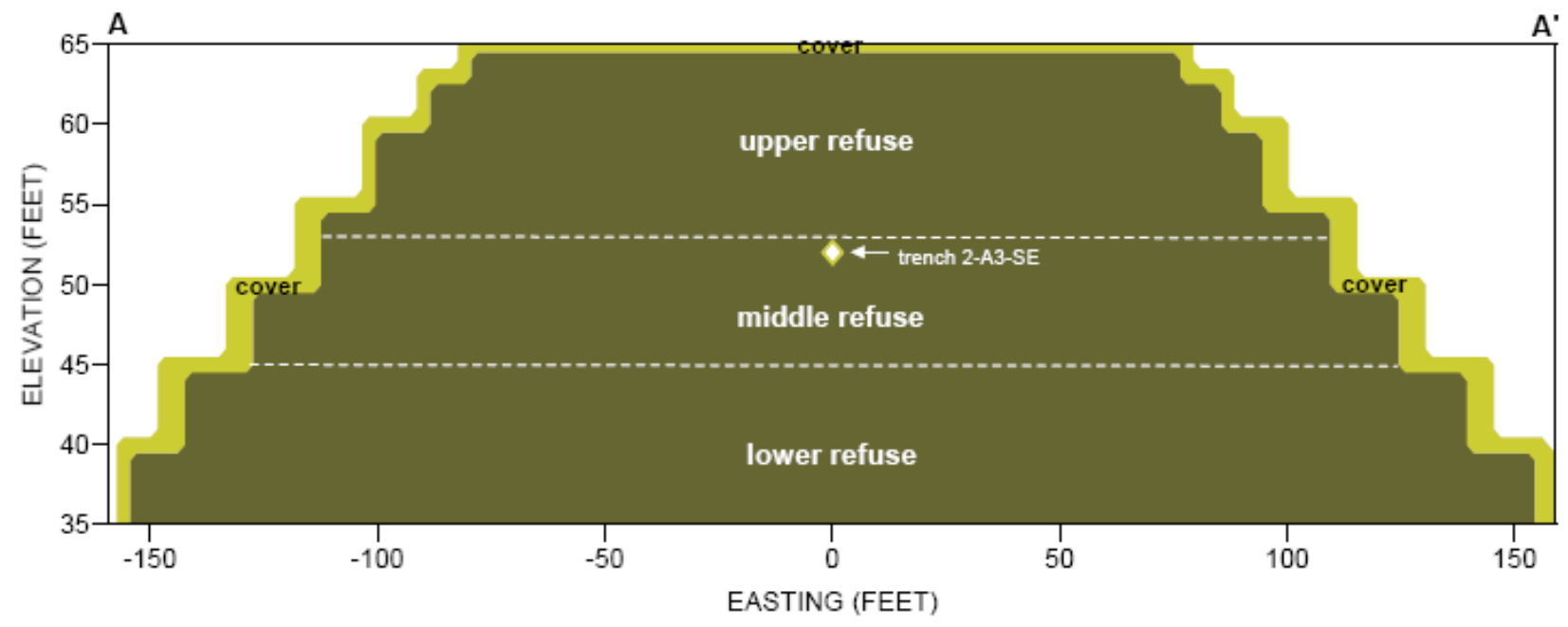

Figure 7. Cross section through the middle of the landfill illustrating the four regions (or material types) needed to fit the pump test data.

The multiphase flow and transport code TRACRN was used to fit the intrinsic gas permeability of the waste and the gas-filled porosity to the pump test data. In addition to measurements of changes in gas pressures in each pumping well, numerous gas pressure measurements were made simultaneously throughout the landfill. In fitting these data, it was 
necessary to divide the landfill into four different porous media each with different flow properties: a lower refuse zone, a middle refuse zone, an upper refuse zone, and two types of cover material. For each material type, the horizontal and vertical permeabilities and the gasfilled porosity were adjusted until the best match could be found between the gas pressure data and the model predictions. Typical fitted profiles of changing pressure within the landfill for Pump Test 1 are shown in Figures 8 and 9. Similar plots were developed for the other pump tests.

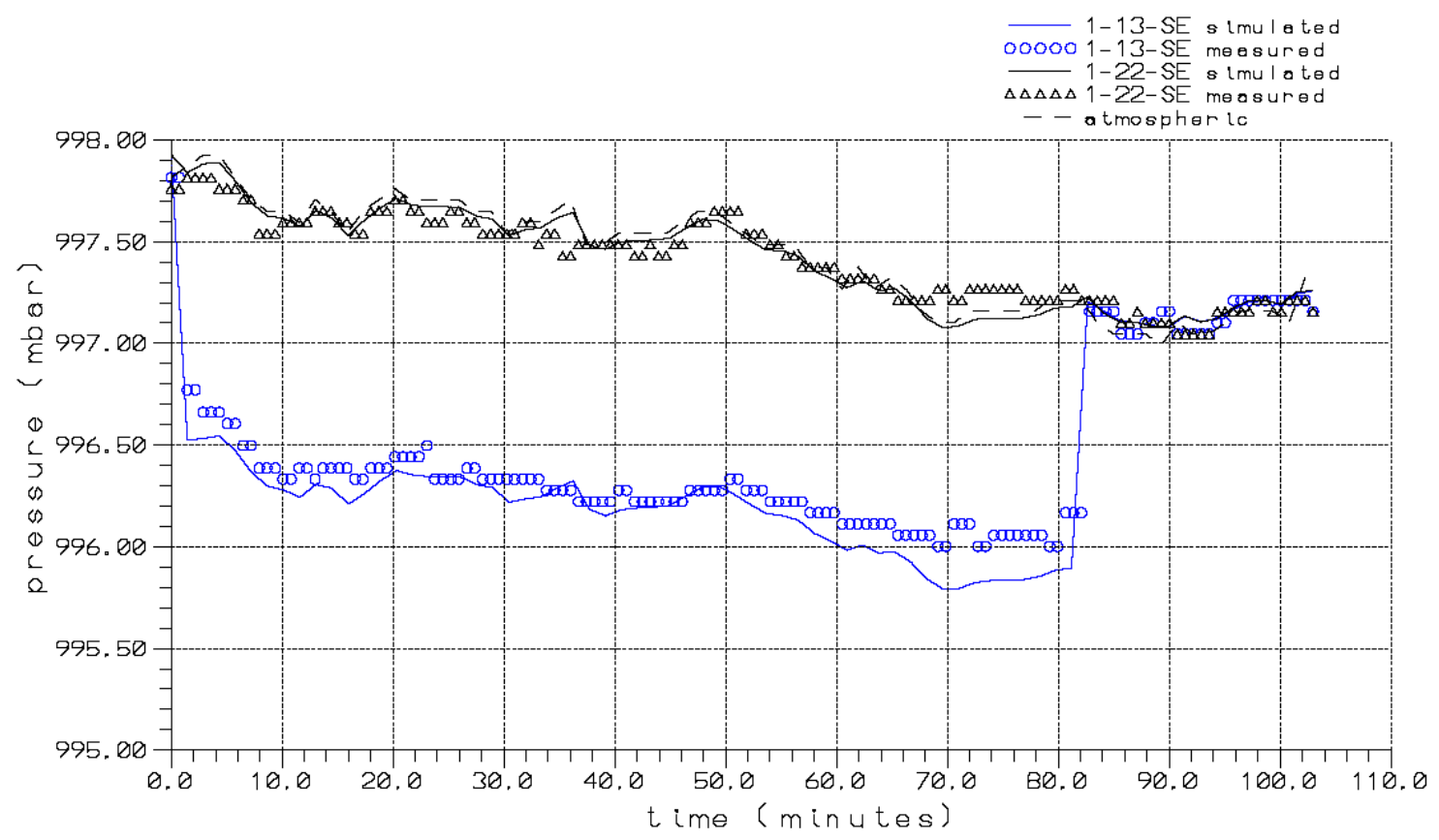

Figure 8. Gas pressure data and best-fit model predictions for two measurement locations in Pump Test 1. 


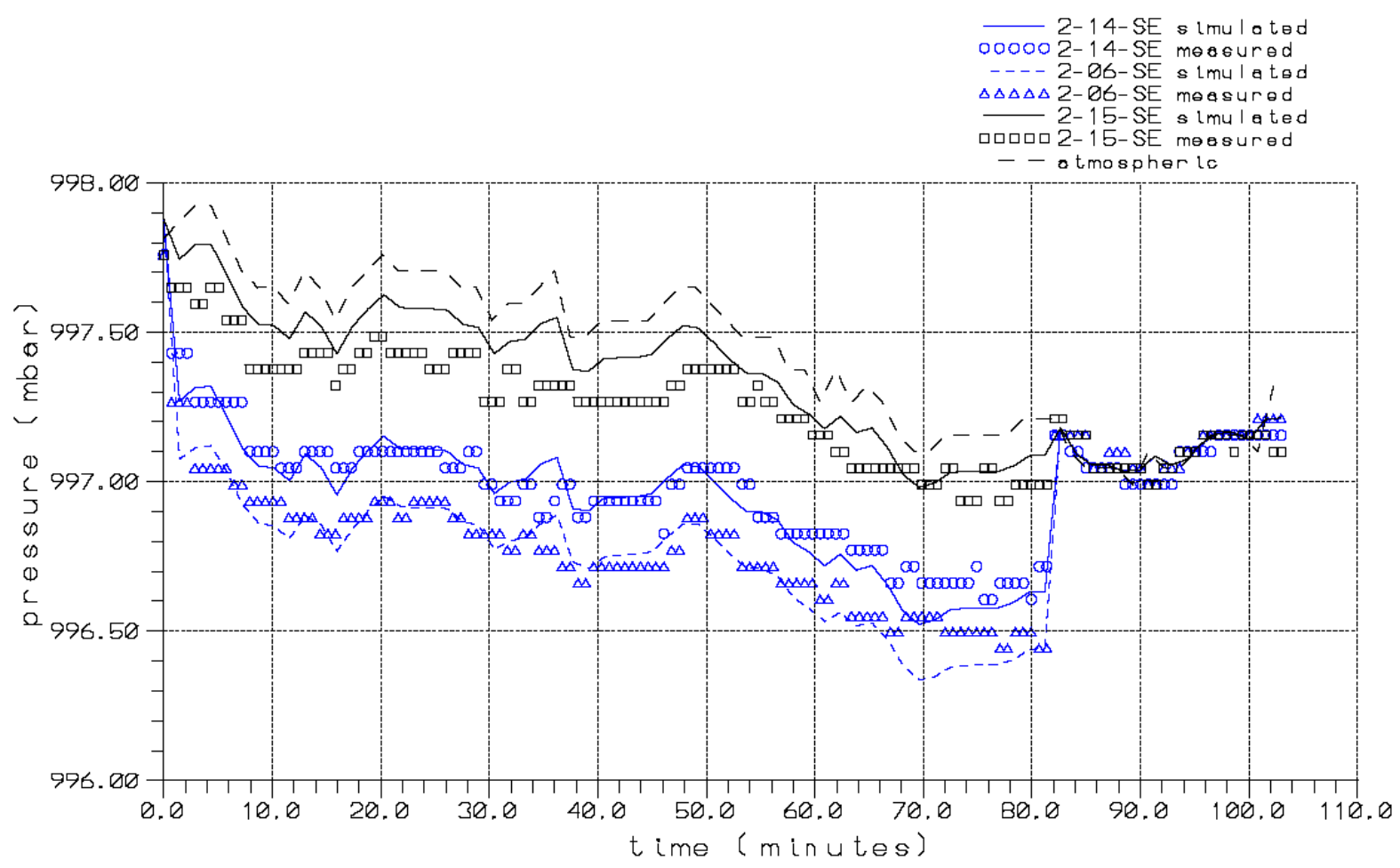

Figure 9. Gas pressure data and best-fit model predictions for three measurement locations in Pump Test 1.

Based on these pump test results, the gas flow parameters shown in Table 2 were developed for the aerobic bioreactor. These parameters are based on fits to data from Pump Test 1, which we believe provide the best overall estimates for waste properties in different regions of the landfill.

Table 2. Best-fit parameters from Pump Test 1 for aerobic bioreactor.

\begin{tabular}{|c|c|c|c|}
\hline Layer & $\begin{array}{c}\text { Horizontal Gas Permeability } \\
\text { (darcies) }\end{array}$ & $\begin{array}{c}\text { Vertical Gas Permeability } \\
\text { (darcies) }\end{array}$ & $\begin{array}{c}\text { Gas-filled Porosity } \\
(-)\end{array}$ \\
\hline Cover Material 1 & 2 & 2 & 0.10 \\
\hline Cover Material 2 & 20 & 20 & 0.10 \\
\hline Upper Refuse & 250 & 40 & 0.10 \\
\hline Middle Refuse & 150 & 4 & 0.10 \\
\hline Lower Refuse & 100 & 2 & 0.10 \\
\hline
\end{tabular}




\section{Modeling to Design IBM-IS for Aerobic Operations}

Using the results from the pump tests shown above, a three-dimensional gas flow model was developed that represents conditions in the aerobic bioreactor in January 2006. This model was used to explore how the gas extraction wells currently installed and used in this bioreactor may be operated in an "optimal" fashion to achieve efficient distribution of oxygen and dissipation of heat in the landfill cell.

A cross-section through the three dimensional model was selected for this analysis, which is shown in Figure 10. Four different test cases were run

- Case 1: extraction only at constant vacuum from all horizontal wells

- Case 2: extraction only at constant flow (all wells same extraction rate)

- Case 3: extraction in level 2 trenches (upper trenches) and injection in level 1 trenches (lower trenches), with the total extraction rate equal to the total injection rate (total injection $=100 \mathrm{scfm}$, total extraction $=100 \mathrm{scfm}$ )

- Case 4: extraction in level 2 trenches and injection in level 1 trenches, with the total extraction rate greater than the total injection rate (total extraction rate $=112 \mathrm{scfm}$, total injection rate $=88 \mathrm{scfm}$ )

These four cases were run to evaluate the distribution of air in the cell. In the aerobic bioreactor, air is injected or "pulled" into the cell from the landfill boundaries to create aerobic conditions for waste degradation. In Figure 10 results are shown after operating the cell for one day under Case 1. The air concentration is indicated by the degree of green. Air is distributed relatively uniformly in the cell, with the exception of the bottom center, where after one day of extracting gas and thus pulling air in from the boundaries, a "dead" zone still exists which is anaerobic. This simulation illustrates gas flow in the aerobic bioreactor under the standard operating conditions at Yolo County. 


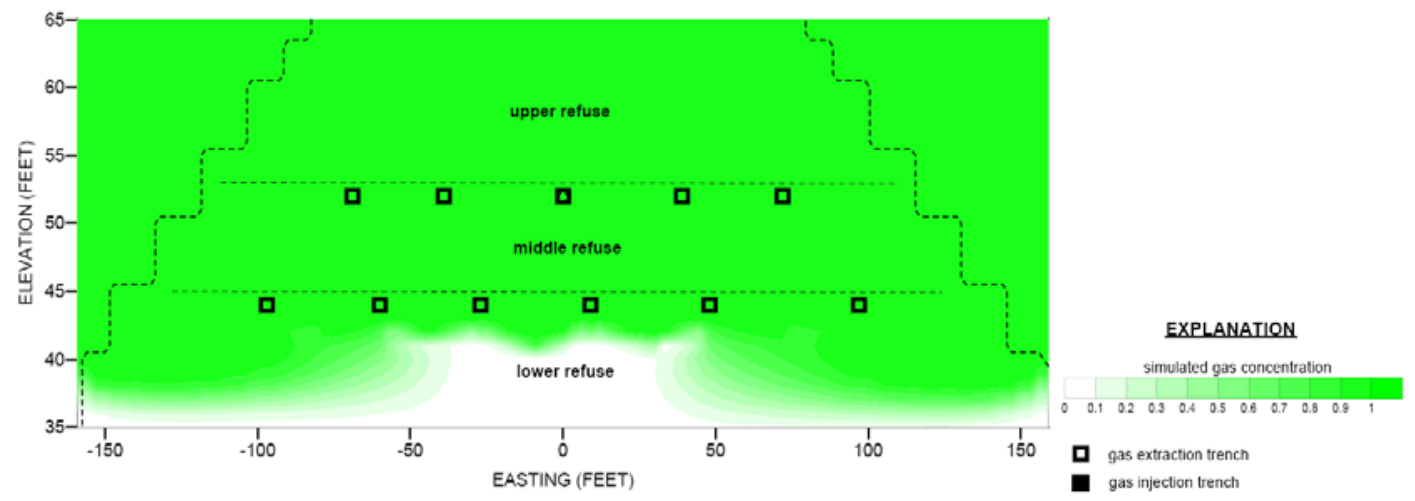

Figure 10. Distribution of air in a cross-section through the aerobic bioreactor after 24 hours of extraction of gas for Case 1. Dotted lines illustrate the top surface of the landfill.

Based on these simulation results, Cases 2-4 were conducted to explore ways to improve the gas flow. Case 4 produced the best results and is shown in Figure 11 after one day of operation. Here, gas was extracted from layer 2 wells but injected in layer 1 wells. In this case, the gas flow is much more uniform throughout the cell and the dead zone near the bottom center has almost disappeared.

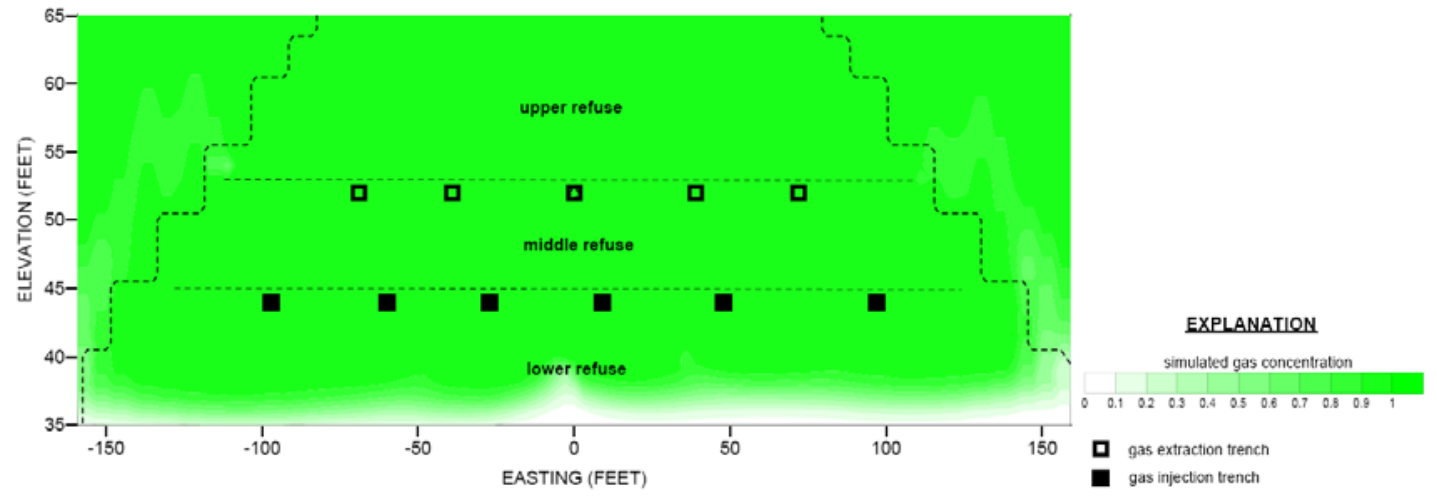

Figure 11. Distribution of air in a cross-section through the aerobic bioreactor after 24 hours of extraction and injection of gas for Case 4. Dotted lines illustrate the top surface of the landfill.

The results from these simulations illustrate the dramatic improvement in gas distribution in this landfill cell that may be achieved if both gas extraction and air injection are performed. Because of the dramatic improvement in gas flow, the project team secured a new blower from matching funds that allowed us to operate the landfill as in Case 4. The IBM-IS was "tested" by 
evaluating the operating conditions of the landfill for Cases 1 and 4 . Our hypothesis was that the operations guided by the simulation results for Case 4 would result in significantly improved gas flow, oxygen distribution, and heat dissipation in the cell.

\section{Field Tests of IBM-IS for Aerobic Operations}

The aerobic cell was operated following Case 1 and 4 operating conditions. While Case 4 showed improved results with less methane generated and more even flow of air into the cell, the system still generated significant amounts of methane. Aerobic operations are intended to suppress methane generation.

A manuscript describing this work was recently published in Environmental Science \& Technology. Portions of that work are given below, which summarize our findings.

A study of an operating aerobic bioreactor landfill cell constructed in 2001 (landfill cell) was undertaken at the Yolo County Central Landfill in Woodland, California for a six month period in 2006 (3/28/06 to 9/12/06). In addition, some data from 2004 were also used. The specific questions to be addressed in this study were (1) Can anaerobic activity be maintained at low levels in an aerated landfill cell as liquids are added and recirculated? (2) How does the incremental addition of liquid affect gas flow and aerobic conditions? (3) At what average waste moisture content is difficulty encountered in maintaining aerobic conditions? And (4) Can in-situ respiration and gas tracer tests be used to determine waste oxygen depletion rates and understand gas flow patterns?

\section{a) Materials and Methods}

(1) Landfill design and instrumentation

The Planning and Public Works Department of Yolo County, Division of Integrated Waste Management, constructed a one hectare landfill cell at the Yolo County Central Landfill 
in Woodland, California. The cell was constructed on a composite liner system that received about 12,800 tonne of compacted municipal solid waste with $300 \mathrm{~mm}$ of soil cover as final cap. Waste was placed and compacted in three $3 \mathrm{~m}$ lifts with 2-to-1 side slope as shown in Figure 12. The use of daily cover soil during waste filling was minimized to aid in the overall permeability of the waste. Whenever possible, greenwaste or removable tarps were used as an alternative daily cover, and in the event that soil was used to construct an access road or tipping pad, the soil was removed prior to placing the next waste lift. 

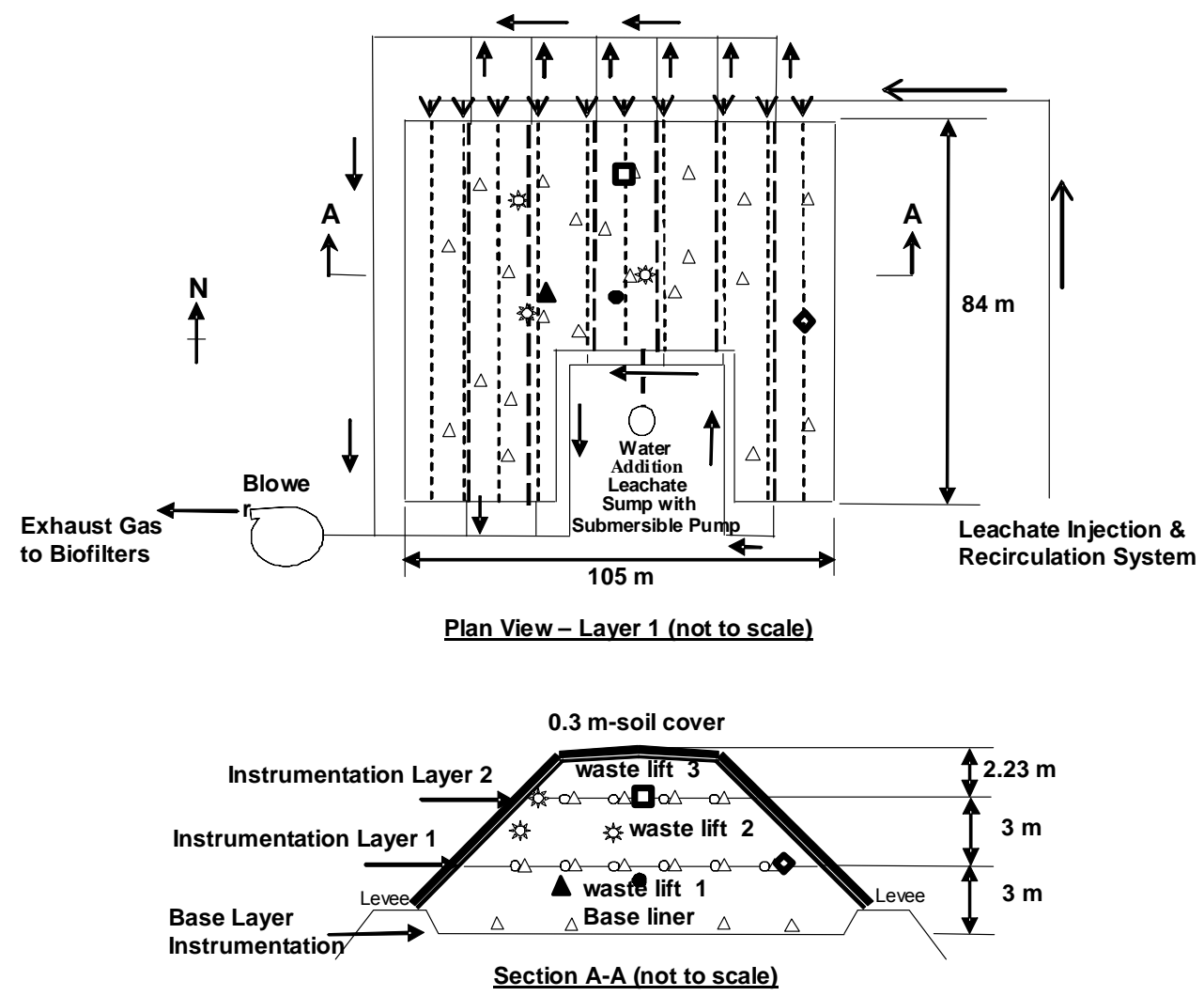

Legends:

- Gas collection pipe

- - Leachate recirculation pipe

Partitioning gas tracer testing

$\triangle \quad$ Sampling tube, thermistor, moisture

$\boldsymbol{D} \Delta \bullet$ In-situ respiration test location

- Gas collection pipe or

Leachate recirculation pipe

Figure 12. Plan and cross sectional view of Yolo County aerobic bioreactor landfill cell illustrating the location of instrumentation, gas collection and leachate recirculation lines, respiration tests locations, and partitioning gas tracer tests.

The horizontal leachate injection and recirculation piping used was $31.8 \mathrm{~mm}$ ID and constructed of either high density polyethylene (HDPE) or polyvinyl chloride (PVC) pipe. Injection pipes were installed at the top of each lift of waste and spaced approximately 4.5 to 7.0 
$\mathrm{m}$ apart. Piping within the waste was perforated with $2.4 \mathrm{~mm}$ diameter holes spaced every $3 \mathrm{~m}$ and connected to pressurized $100 \mathrm{~mm}$ ID HDPE solid header lines. The perforated injection pipes were placed within beds of shredded tires to protect them from waste compaction and biological clogging from leachate recirculation.

The gas collection system was designed to collect gas between each lift of waste and pull air into the cell through the permeable soil cover. The collected gas could then be easily monitored to assess the composition of gas exiting the landfill cell. Gas collection lines consisted of a perforated 10 and $150 \mathrm{~mm}$ ID PVC or HDPE pipe spaced 11.9 to $13.7 \mathrm{~m}$ apart horizontally. Shredded tires (maximum dimension, measured in any direction of $300 \mathrm{~mm}$ ) were used as the permeable medium placed around and over the pipe to facilitate landfill gas collection. Each gas collection line was equipped with a valve to control flow and ports for monitoring gas composition, temperature, pressure, and flow rate where the gas line exited the landfill. Gas collection header pipes, installed on the north and south sides of the cell, were connected to a single blower under suction. The main header lines for gas collection and leachate recirculation system were equipped with volumetric flow meters and pressure gages.

As each lift of waste was placed, sensors were installed to monitor temperature, moisture and fluid pressure of the waste. Each sensor location received a thermistor sensor (QT06005, Quality Thermistor, Inc., Boise, ID), an electrical resistance moisture sensor to monitor the degree of waste wetness, and a linear low-density polyethylene (LLDPE) tubing for pressure and gas composition measurement (6.35 mm ID) [Augenstein and Yazdani, 1997] [Imhoff et al., 2007]. A total of 59 thermistors, 52 electrical resistance moisture sensors, and 42 LLDPE tubes were installed. Horizontal sensor spacing ranged from 6 to $12 \mathrm{~m}$ for each lift of waste. To protect sensor wires and LLDPE tubing from damage, each was encased in a $31.8 \mathrm{~mm}$ ID HDPE 
pipe. The ends of sensors and LLDPE tubing were buried on top of $150 \mathrm{~mm}$ of gravel and overlaid with $0.5 \mathrm{~m}$ of compacted shredded tires.

\section{(2) Landfill cell operation and testing}

The main vacuum line connected to all gas collection piping was turned on from 03/28/06 through 09/12/06, and air was pulled into the landfill cell through the soil cover. It took almost a week to achieve stabilized gas compositions in the main header lines. At certain intervals the blower was turned off for maintenance (see Figure 14). Within a day after blower was turned back on the gas composition reverted to the original stable composition. Gas flow through individual wells varied depending on the local gas permeability, which fluctuated through time because of liquid addition. The average gas flow through the cell from $3 / 27 / 06$ to $5 / 31 / 06$ was 0.48 standard cubic meters per second (SCMS), which occurred prior to significant leachate recirculation or supplemental water addition (see Figure 13). The average gas flow rate was reduced to 0.33 SCMS for the remainder of aerobic operations $(6 / 1 / 06$ to $9 / 12 / 06)$. The gas composition in the main header lines was also measured frequently using a model $\mathrm{GEM}^{\mathrm{TM}} 2000$ landfill gas analyzer (CES Landtec Inc., Colton, CA). The GEM ${ }^{\mathrm{TM}} 2000$ was field-calibrated daily against gas standards $\left(5 \% \mathrm{O}_{2}\right.$ and $95 \% \mathrm{~N}_{2}$; and $50 \% \mathrm{CH}_{4}, 35 \% \mathrm{CO}_{2}$ and $\left.15 \% \mathrm{~N}_{2}\right)$. 


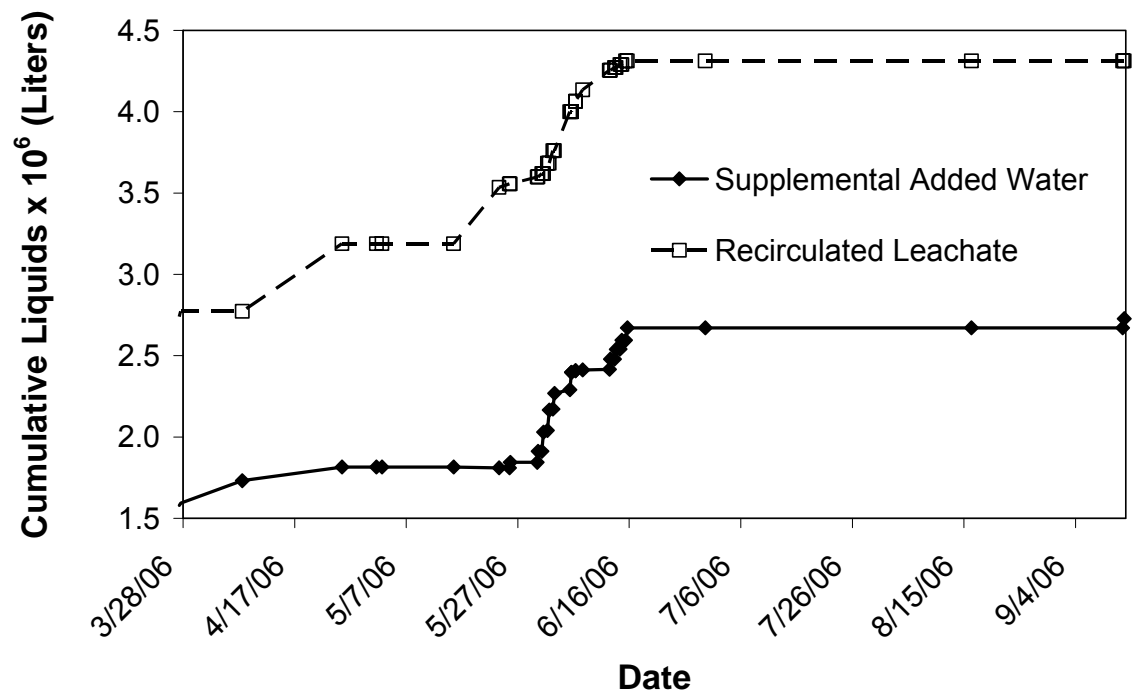

Figure 13. Cumulative supplemental liquid added and leachate recirculated during the operational period.

Liquid was added to the cell either as recirculated leachate or supplemental water through horizontal leachate recirculation lines. The cumulative volume of recirculated leachate and supplemental water during the operational period is shown in Figure 13. Of the total supplemental water added, 80\% was injected between 5/30/06 and 6/15/2006. 


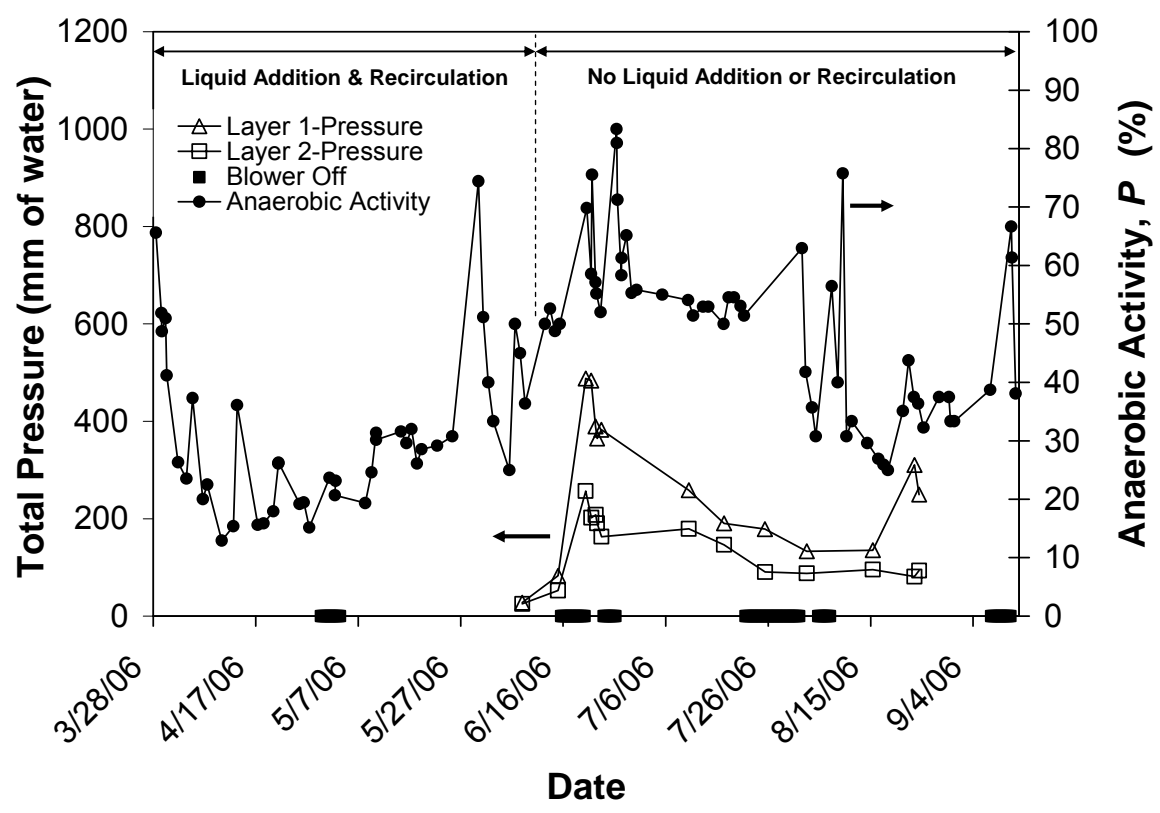

Figure 14. Percent anaerobic activity and total fluid pressure in instrumentation layers 1 and 2. Measurements reported for layer 1 and 2 are averages of all readings in each layer. Periods when the blower was off for longer than 2 days are indicated.

(3) In-situ aerobic respiration tests

An in-situ test method typically used for measuring aerobic biodegradation rates of hydrocarbons in soil [Hinchee and Ong, 1992] was modified for use in this project. First, the aerobic cell blower was operated continuously for several days: ambient air was pulled through the soil cover of the landfill cell and through the waste until the exiting gas reached a steady state composition of $\mathrm{CH}_{4}, \mathrm{CO}_{2}$, and $\mathrm{O}_{2}$. The blower was then turned off, the LLDPE tubing, terminated at the four measurement locations shown in Figure 12, was purged by evacuating twice the volume of each sampling tube, and $\mathrm{CH}_{4}, \mathrm{CO}_{2}$, and $\mathrm{O}_{2}$ concentrations were measured using a GEM ${ }^{\mathrm{TM}} 2000$ landfill gas monitor. Measurements continued at 30 min intervals or less, purging the tubing between sampling, with measurements terminated after 4.5 to $6 \mathrm{hrs}$. 
(4) Partitioning gas tracer tests

Two sets of field-scale partitioning gas tracer tests (PGTT) were performed in May 2004 and January 2006 to determine the water saturation and moisture content of waste and to characterize gas flow patterns [Han et al., 2007]. The estimated water saturation and moisture content values reflect the average values in approximately $20 \mathrm{~m}^{3}$ of waste in the aerobic cell. The locations of these tests are shown in Figure 1. Two tests (PGTT4-1, PGTT6-1) were located in the center of the landfill cell in waste between instrumentation layers 1 and 2 , while the remaining tests (PGTT4-2, PGTT6-2) were located at the north-west side of the landfill cell between the same two instrumentation layers. Detailed procedures for these tests are described elsewhere [Han et al., 2007]. The tracer breakthrough curves from these tests were used to estimate the fraction of immobile gas in the waste and the rate of mass transfer between mobile and immobile gas zones.

\section{b) Results and discussion}

(1) Fluid pressure and gas composition

Over 826,336 liters of supplemental water were added to the landfill cell beginning on 5/30/2006, while 1,539,905 liters of leachate were recirculated beginning on 4/7/06 until 6/15/06. The addition of supplemental water to the landfill cell and recirculation of leachate significantly increased total fluid pressure at the sampling tubes dispersed throughout the waste. The total pressure in the monitoring tubes averaged for instrumentation layers 1 and 2 at several measurement times is shown in Figure 3. Initially, total pressure was a few mm of water, which based on past operational experience, would be consistent with a small amount of liquid buildup at the sampling tubes: total pressures were typically negative or near atmospheric when excess liquid was not present. Layer-averaged pressures rapidly increased to $480 \mathrm{~mm}$ of water in instrumentation layer 1 and $250 \mathrm{~mm}$ of water in layer 2, reflecting the influence of liquid 
addition on total pressures (see Figure 13). After cessation of liquid addition on 6/15/06, total pressures decreased slowly eventually reaching $80-140 \mathrm{~mm}$ of water in August 2006. Electrical resistivity moisture sensor readings were essentially invariant between June and August 2006: the waste and sensors were already wetted, and changes in liquid buildup within already wetted waste cannot be determined easily with this instrument [Imhoff et al., 2007].

The increase in total pressure within the landfill cell is attributed to buildup of liquid, which had a significant impact on the composition of gas extracted from the landfill cell during this period, namely the concentrations of $\mathrm{CH}_{4}$ and $\mathrm{CO}_{2}$. The concentrations of these two gases can be used to estimate the fraction of waste that is degraded anaerobically at any point in time. Landfill gas extracted from traditional anaerobic landfills is usually composed of $45-60 \% \mathrm{CH}_{4}$ and $40-60 \% \mathrm{CO}_{2}$ [Tchobanoglous and Theisen, 1983]. Because the redox state of carbon in $\mathrm{CH}_{4}$ and $\mathrm{CO}_{2}$ is -4 and +4 , respectively, and because these gases occur at approximately 1:1 mole ratio in landfills, biodegradable waste within the landfill should have carbon atoms at an average redox state close to zero. In this case, aerobic and anaerobic degradation equations for carboncontaining compounds are
Anaerobic Degradation
$\mathrm{C}+\mathrm{H}_{2} \mathrm{O} \Rightarrow(1 / 2) \mathrm{CH}_{4}+(1 / 2) \mathrm{CO}_{2}$
Aerobic Degradation
$\mathrm{C}+\mathrm{O}_{2} \Rightarrow \mathrm{CO}_{2}$

Based on the stoichiometry of these two reactions, the percentage of waste degraded anaerobically, $P$, can be estimated

$$
P=\frac{2 C_{C H_{4}}}{2 C_{C_{4}}+\left(C_{C_{2}}-C_{C H_{4}}\right)} \times 100
$$

where $\mathrm{C}_{\mathrm{CH}_{4}}$ and $\mathrm{C}_{\mathrm{CO}_{2}}$ are the measured concentrations (\% v/v) of $\mathrm{CH}_{4}$ and $\mathrm{CO}_{2}$, respectively. 
Note that in Eqs (1) and (2) cell growth is ignored and only "net" organic waste degradation leading to the formation of $\mathrm{CH}_{4}$ and $\mathrm{CO}_{2}$ is considered. Dry cell biomass has an elemental composition that is typically represented by the formula $\mathrm{C}_{5} \mathrm{H}_{7} \mathrm{O}_{2} \mathrm{~N}$ [Rittmann and McCarty, 2000], in which the carbon atoms have an average redox state of zero. Thus, for the purpose of this analysis, the portion of waste converted to biomass is assumed to be indistinguishable from the undegraded waste, as the redox state of carbon had not changed.

The value of $P$ is plotted versus time in Figure 14 and ranges between 13 and almost 83\% (including spikes) over the operational period. Except on 5/30/06 when water addition was restarted, the spikes in $P$ that appear throughout Figure 14 are associated with short rest periods when the blower was turned off. Once the blower was restarted and the pore gas was flushed out of the landfill cell, the value of $P$ returned to background levels. Ignoring the short-term spikes in $P$, there are clear temporal trends. After the onset of gas extraction on $3 / 28 / 06, P$ decreased from 66 to $13 \%$ on $04 / 10 / 06$ and remained relatively constant for the next month. Because leachate was recirculated (see Figure 13), the landfill cell-average moisture content of the waste during this period was $M_{c}=33.0 \%$, hence, most of the waste was degraded aerobically. A water balance method [USEPA, 2003] was used to estimate landfill cell-average moisture content.

Soon after the onset of supplemental water addition on 4/7/06 followed by leachate recirculation, $P$ increased and reached almost $65 \%$ on $06 / 28 / 06$ (ignoring short-term spikes in $P$ ). While liquid addition only increased the cell-average $M_{c}$ to a maximum of $36.0 \%$ on $6 / 30 / 06$, the additional water increased fluid pressures in the landfill (see Figure 13), likely due to water pooling, and increased the degree of undesired anaerobic activity significantly. After cessation of water addition and leachate recirculation on $6 / 15 / 06, P$ gradually decreased, eventually reaching 34-35\% during August/September 2006. The cell-average $M_{c}$ also decreased, reaching 
$34.7 \%$ on $8 / 31 / 06$. The decrease in $P$ after $6 / 30 / 06$ likely resulted from drainage of water from waste near the leachate injection lines and more uniform distribution of liquid in the landfill cell. The landfill cell-average moisture content changed by less than $1 \%$, while layer-average fluid pressures measured with LLDPE tubes decreased from $180-350 \mathrm{~mm}$ to $100-150 \mathrm{~mm}$ of water over this same period (see Figure 14). Many LLDPE tubes are located near leachate injection lines and were impacted by leachate recirculation (see Figure 12).

Equal production of $\mathrm{CH}_{4}$ and $\mathrm{CO}_{2}$ is assumed in Eq. (1). However, the composition of landfill gas in anaerobic landfills is variable. Two extreme cases of gas composition with $60 \%$ $\mathrm{CH}_{4}$ and $40 \% \mathrm{CO}_{2}$, and $40 \% \mathrm{CH}_{4}$ and $60 \% \mathrm{CO}_{2}$ were also examined. While computed $P$ values were affected by the assumed gas composition from anaerobic degradation, observations about the impact of liquid addition (supplemental water or leachate) on the degree of anaerobic activity are the same. The peak value of $P$ (ignoring short-term spikes) was increased to $75 \%$ for an assumed $60 \% / 40 \%$ mix of $\mathrm{CH}_{4} / \mathrm{CO}_{2}$ and decreased to $64 \%$ for an assumed $40 \% / 60 \%$ mixture.

On 08/23/06 gas samples were collected from the 42 LLDPE tubes inserted throughout the landfill. Contours of anaerobic activity, oxygen concentration, and temperature from measurement locations in layer 1 are shown in Figure 15(a), (b), and (c) respectively, where $P$ was calculated assuming $50 \% / 50 \%$ mixture of $\mathrm{CH}_{4} / \mathrm{CO}_{2}$ for anaerobic degradation for aerobic decomposition. The northern region of the landfill cell with $P>50 \%$ is enclosed with dashed lines in Figure 15(a). In most of these regions oxygen concentrations were less than $10 \%$, enclosed in dashed lines in Figure 15(b). Southeast regions with temperatures greater than $70^{\circ} \mathrm{C}$ also corresponded to low anaerobic activity $(P<50 \%)$, as highlighted with dashed lines in Figure 15(c). 
(a)

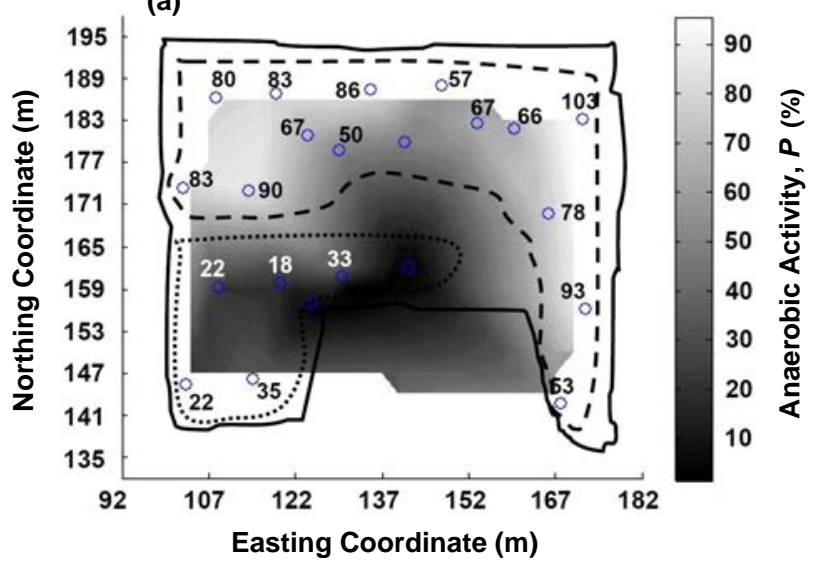

(b)

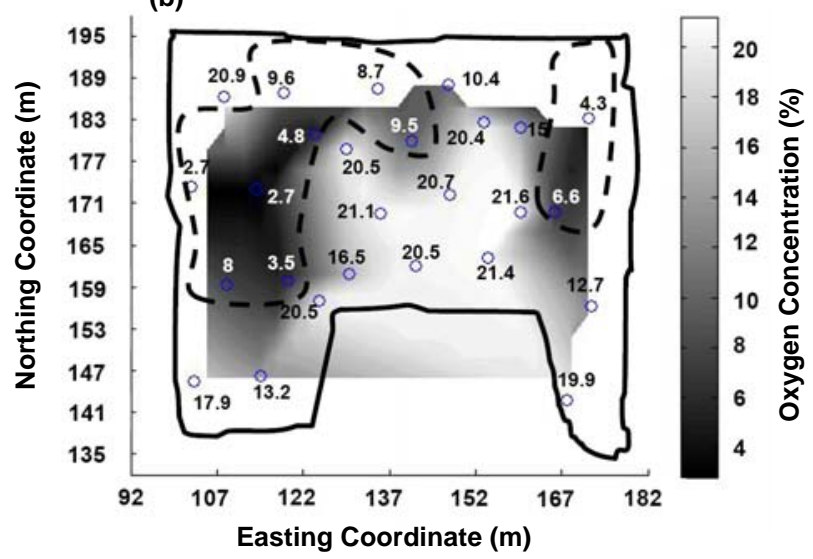

(c)

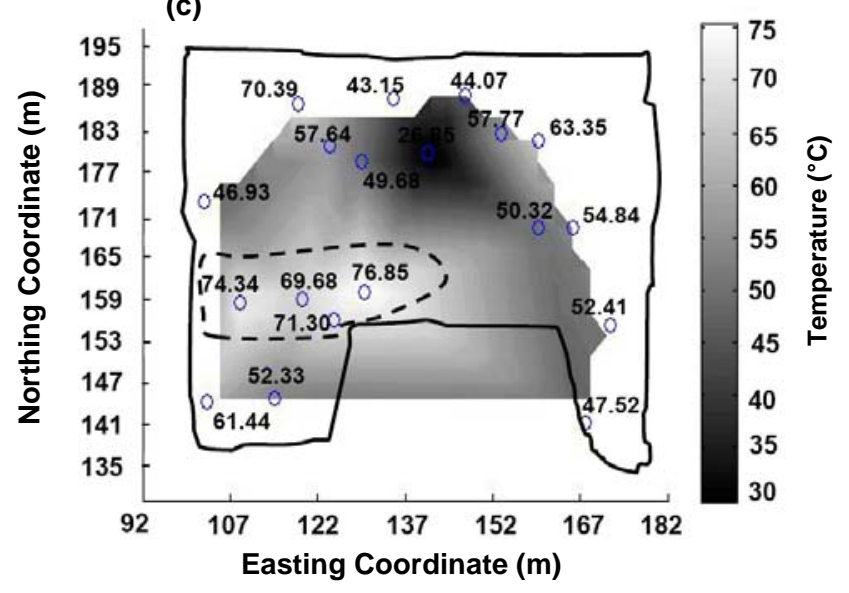

Figure 15. Contours of gas composition in layer 1 on $8 / 23 / 06$. Solid lines correspond to outline of landfill. (a) Percent anaerobic activity. Dashed lines represent regions where $P \geq 50 \%$ and dotted lines where $P<50 \%$. (b). Oxygen concentration. Dashed lines represent regions where 
oxygen concentration $<10 \%$. (c) Waste temperature. Dashed lines represent regions where landfill temperature $>70^{\circ} \mathrm{C}$.

One puzzling observation is the large number of measurement points with oxygen concentrations close to $20 \%$, many in the center of instrumentation layer 1, shown in Figure 15(b). These high concentrations of oxygen are consistent with oxygen levels measured from horizontal gas extraction lines located in the same vicinity as the gas sampling tubes (see Figure 12). It is hypothesized that for some trenches, gas preferentially entered the landfill cell from the south side slope and flowed through the trenches, bypassing much of the waste. While the southern ends of the trenches were covered with several feet of dirt to inhibit air entry, for some trenches, most notably those in the center of the landfill cell, the low permeability soil cover material might have been insufficient to inhibit preferential air entry from the south side slope.

The landfill cell appears to be more anaerobic on the north side based on Figure 15(a), where oxygen concentrations are lower and the percent anaerobic activity higher. This result is consistent with the gas flow measured from the horizontal gas collection lines: while a similar vacuum was imposed on both the north and south sides of each gas collection line, approximately $70 \%$ of the landfill gas was extracted from the southern end of the gas collection wells. The cause of the preferential gas flow through the southern side is unknown, although it appears to be associated with lower waste permeability on the north side due to non-uniformity of water addition and better sealing of the horizontal shredded tire trenches on the north side slopes.

Finally, it is interesting to note that even in aerobic regions where oxygen concentrations are high (greater than $\sim 15 \%$ ), $P$ is seldom below $10 \%$. From this finding it was concluded that even when sufficient oxygen is supplied locally within the landfill cell, anaerobic pockets persist where a portion of the waste degrades anaerobically. The observed measurement for layer 2 was 
similar to layer 1, where $P$ never decreased below 13\% (see Figure 14). Based on these data, the difficulty of achieving a high degree of aerobic activity in this landfill cell is clear. Even with the intentional injection of air, anaerobic activity was never less than $13 \%$ and sometimes exceeded $65 \%$. An analysis of the in-situ aerobic respiration and partitioning gas tracer test data were helpful in understanding mechanisms limiting aeration of the waste.

(2) In-situ aerobic respiration test results

Six respiration tests were conducted between $6 / 30 / 06$ and $9 / 7 / 06$, and the oxygen depletion data are shown in Figure 16. At the cessation of gas pumping, oxygen concentrations at the sampling locations ranged between 5 and $20 \%$ for the six tests and decreased steadily through time. A first-order model provided an excellent fit to the early-time data. Fitted rate coefficients ranged from $K=0.26$ to $1.41 \mathrm{~h}^{-1}$, with a mean rate coefficient of $\bar{K}=0.70 \pm 0.17$ $\mathrm{SE}^{-1}(\mathrm{SE}=$ one standard error). These rates represent the rate of oxygen consumption by bacteria, the rate of mass transfer of oxygen from sampling locations to zones with oxygen utilizing bacteria, or a combination of these processes. These rates are compared, below, to rates of mass transfer between mobile and immobile gas zones to assess factors limiting aerobic degradation. 


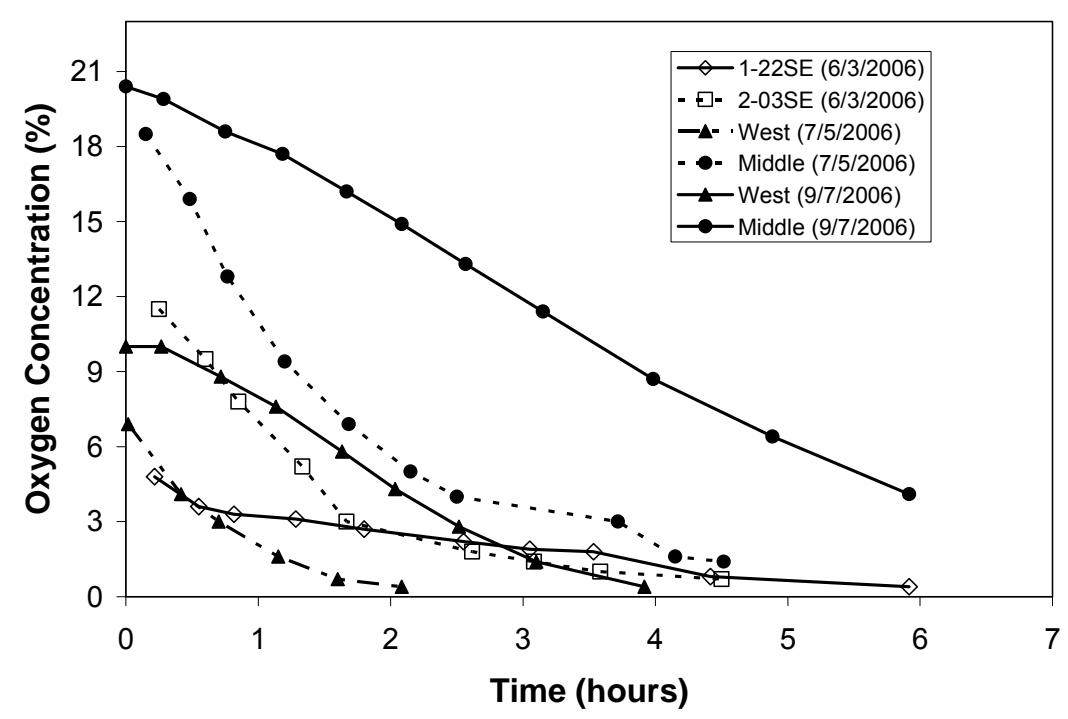

Figure 16. Data from in-situ respiration tests in aerobic bioreactor landfill cell

(3) Partitioning gas tracer tests

Tracer tests are used commonly to gain insight into flow paths and pore structure in geological materials [McKenna et al., 2001][Sanchez-Villa and Xarrera, 1997]. For landfills, based on liquid tracer tests, it has been found that water flow commonly occurs along preferential pathways, likely due to the heterogeneous nature of waste placed in a landfill [Beaven et al., 2003][Bendz et al., 1998]. A similar analysis of gas tracer tests to evaluate gas flow patterns in waste has not been reported in the literature. Four PGTTs were conducted in the landfill cell: two in May 2004, and two in January 2006 using difluoromethane and helium. While data from these tests were used to determine water saturation and moisture contents [Han et al., 2007], these data are re-examined here to assess gas flow in the landfill. Although these PGTTs were not conducted during the period of aerobic operation, the waste moisture contents for some of these tracer tests were similar to conditions during aerobic operations in 2006 and thus shed light on gas flow during this period. 
To evaluate fluid flow patterns in porous media, it is common to fit alternative conceptual models to tracer test data [McKenna et al., 2001][Sanchez-Villa and Xarrera, 1997][Luo et al., 2005]. For example, a multivariate model has been used to describe a distribution of mass exchange rates between mobile and immobile zones commonly found in heterogeneous porous media [Haggerty and Gorelick, 1995]. A simpler two domain model was found to be the best approach to model transport in a contaminated [Beaven et al., 2003]. For the PGTTs conducted in 2004 and 2006 in the landfill cell, the simplest model that provided a good fit to the data was sought. Here, a one-dimensional stream tube model worked well, where the gas-filled pore space consisted of two overlapping continuous regions: a mobile domain, in which advectivedispersive transport occurred, and an immobile domain, where water that retarded the transport of difluoromethane was assumed to exist. Mass transfer between the mobile and immobile gas domains was assumed to be rate-limited and described with a first order model. Mixing in the immobile domain was assumed much faster than mass transfer between the mobile and immobile domains and, thus, was well-mixed.

The classic two domain model was fitted to the tracer test data and provided an excellent fit to three of the four tracer tests. The exception was PGTT4-1 in 2004, where the two domain model provided only a slight improvement over an even simpler single domain model with no immobile gas phase. For the three tracer tests requiring a two domain modeling approach, the immobile gas phase comprised 32,39 , and $92 \%$ of the gas filled pore space. Thus, a large fraction of the gas-filled pore space was in immobile zones where it might be difficult to maintain aerobic conditions. Fitted mobile/immobile mass transfer coefficients for difluoromethane, which has a gas diffusivity within $30 \%$ of the value for oxygen, were $K_{m t}=$ $0.13 \mathrm{~h}^{-1}\left(\right.$ PGTT6- $\left.1, M_{c}=0.31 \pm 0.04 \mathrm{SE}\right), 0.18 \mathrm{~h}^{-1}\left(\right.$ PGTT6-2, $\left.M_{c}=0.22 \pm 0.06 \mathrm{SE}\right)$ and $0.34 \mathrm{~h}^{-1}$ 
(PGTT4-2, $M_{c}=0.10 \pm 0.01 \mathrm{SE}$ ), where the reported moisture contents are those determined for the region sampled by each PGTT. The lower two mass transfer coefficients were measured in January 2006 in the center $\left(M_{c}=0.31 \pm 0.04 \mathrm{SE}\right)$ or on the northwest side $\left(M_{c}=0.22 \pm 0.06 \mathrm{SE}\right)$ of the landfill cell. The landfill cell-average moisture content in January 2006 was $M_{c}=35 \%$, which is similar to the $33-36 \%$ landfill cell-average moisture content determined for MaySeptember 2006. Thus, the results from the January 2006 PGTTs are believed to be representative of conditions during aerobic operations.

It is instructive to compare the mobile/immobile mass transfer rate coefficients for difluoromethane with the first-order rate coefficients measured during in-situ aerobic respiration tests. These two rates were of the same order of magnitude, although the mean respiration rate $\left(\bar{K}=0.70 \pm 0.17 \mathrm{SE} \mathrm{h}^{-1}\right)$ was three times higher than the mean rate of mobile/immobile mass transfer $\left(\bar{K}_{m t}=0.21 \pm 0.06 \mathrm{SE} \mathrm{h}^{-1}\right)$. Based on the similarity of the respiration rates and the mobile/immobile mass transfer rates, it appears that rates of respiration in the waste was influenced significantly by rates of oxygen transfer to immobile gas zones. In this case, the rate of oxygen depletion and, thus, the rate of aerobic waste degradation might have been controlled by how quickly oxygen was transported to degrading waste. Coupling this observation with the relatively large portion of the gas phase that resided in an immobile zone (32 to $92 \%$ ), it is clear that in some portions of the waste oxygen transfer to immobile gas zones likely limited the degree of aerobic waste degradation. This observation can, most likely, be used to explain, the high degree of anaerobic activity observed during the operation of this landfill cell, even when fluid pressures were not elevated due to the addition of liquid. Clearly, during periods of liquid addition it was even more difficult to achieve aerobic waste degradation. Unfortunately, partitioning gas tracer tests were not conducted during periods of liquid addition, when buildup 
of liquids in small pools increased measured fluid pressures (see Figure 2) and likely impacted gas flow patterns. Similar difficulties in maintaining conditions for aerobic degradation may occur in other aerobically operated bioreactor landfills.

\section{c) Findings}

The principal findings derived from the operation of this landfill cell are: (1) even though excess air was injected, the observed anaerobic activity in the landfill was never less than $13 \%$, and sometimes exceeded 65\%. (2) Even when sufficient oxygen was supplied, anaerobic pockets

of waste persisted and increased as the moisture content of the waste was increased. (3) At an average waste moisture content of $33-36 \%$, a large fraction of the gas-filled pore space was in immobile zones where it was difficult to maintain aerobic conditions. (4) Based on the gas tracer and respiration test results the respiration rate in the waste was significantly influenced by the rate of oxygen transfer to immobile gas zones.

\section{Intelligent Control of Anaerobic Bioreactor Operations}

Intelligent control of anaerobic bioreactor operations relies upon optimal addition of liquid and efficient collection of landfill gas. When the landfill is operated as an anaerobic bioreactor, refuse degrades more rapidly than in conventional landfilling. This results in faster stabilization of the waste, but also greater rates of methane generation. Efficient collection of this methane is essential so that greenhouse gas emissions are minimized.

In this project we developed a new landfill design for collecting landfill gas - a nearsurface high permeability layer. In the following section, we report results from a modeling analysis that evaluated the performance of this layer and which was published in the Journal of Environmental Engineering. 
Following this section, we report a new inverse modeling approach that we developed for determining the gas permeability field and the landfill gas generation rate in an anaerobic landfill. This technology will enable better design of landfill gas collection systems. This inverse modeling approach was recently accepted for publication in Transport in Porous Media.

Finally, using information from these two studies we designed an automated system for adjusting gas collection rates in response to barometric pressure changes. This intelligent control system was installed on the anaerobic bioreactor test cell at Yolo County Central Landfill, where the near-surface high permeability layer was also constructed to enhance capture of landfill gas. We report on the performance of the near-surface high permeability layer and the automated system for adjusting gas collection rates.

\section{Performance of a Near-Surface High Permeability Layer}

Methane accounts for 50-60\% of landfill gas (LFG). Collecting and then generating energy from LFG provides an economic benefit to landfill owners, offsets the use of nonrenewable fossil fuels, and reduces greenhouse gas emissions. But the feasibility of using LFG for energy production depends on the quality and volume of the gas collected. Cracks/fissures in the cover, wind impaction on the surface, or diffusion of air through the surface can result in oxygen intrusion and methane leakage, which limit the quality and volume of LFG recovered. Careful design and operation of LFG collection systems are required to achieve maximum LFG recovery and minimum greenhouse gas emissions. This is particularly important for landfills that are actively operated or have intermediate covers. LFG recoveries from such landfills in France have been estimated to be only $35 \%$ for active landfills and $65 \%$ for landfills with intermediate covers [Spokas et al., 2006]. Clearly, there is tremendous room for improvement in LFG recovery systems for such landfills. 
A new gas collection system recently proposed is intended to improve capture of LFG, inhibit air intrusion into the landfill, and reduce fugitive methane emissions [Augenstein et al., 2007]. This gas collection system is shown in Figure 17 and involves a gas-permeable conductive layer near the landfill cover. The system is envisioned for landfills with intermediate covers, which might remain in place for extended periods before additional landfilling. The highpermeability layer serves to equalize gas pressures beneath the landfill cover; gases are not extracted from it, but from deeper wells in the refuse. This system may compensate for factors that diminish the zone of influence of pumping wells. [Augenstein et al., 2007] estimated the LFG capture efficiency for this design with a simplified model. Preliminary results were encouraging, but did not account for factors such as gas diffusion or waste anisotropy. 

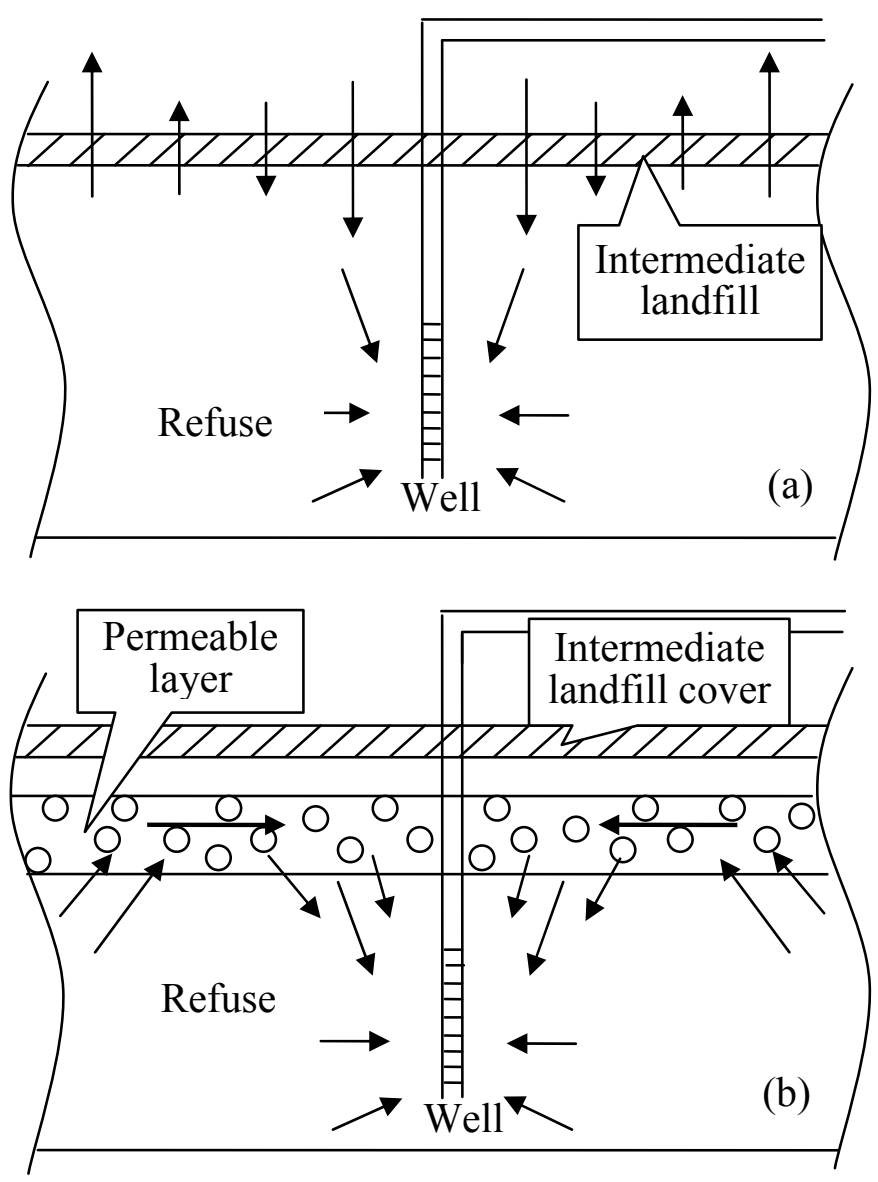

Figure 17. Simplified cross section of gas collection systems. (a) Conventional vertical pumping well. (b) Pumping well with permeable layer.

The objective of this study was to evaluate the utility of the innovative gas collection system suggested by [Augenstein et al., 2007] and to compare this new system with conventional gas collection systems. To model LFG transport, alternative methods were examined with particular attention to multicomponent diffusion. Using an approach developed for our work, we evaluated the influence of a high permeability layer on gas collection efficiency and oxygen intrusion for a variety of landfill conditions including the influence of barometric pressure changes, varying waste permeability with depth, permeability anisotropy of the waste, and the location of the permeable layer within the waste. Simulations indicate that this new gas 
collection system will significantly reduce fugitive methane emissions and result in improved gas quality in collected LFG.

\section{a) Gas Flow in Landfills}

(1) Landfill gas collection systems

Active gas collection systems generally apply a vacuum to pull gas out of the waste in landfills via vertical extraction wells or horizontal extraction trenches. Figure 17a shows a typical gas collection system with a vertical well; the arrows indicate the expected direction and magnitude of gas flows. In conventional vertical gas collection systems, pumping wells may cause unequal methane emissions and air intrusion at the landfill surface. The alternative design proposed by [Augenstein et al., 2007] is shown in Figure 17b. In the new design, a highpermeability layer is installed near the landfill surface and LFG is collected at deep pumping wells. The expectation is better efficiency of gas collection because a high permeability layer equalizes differences in gas pressure near the landfill surface resulting in (1) reduced methane emissions through cover materials, (2) more uniform flow of landfill gas through landfill covers, and (3) reduction in the extent of air intrusion.

Permeable layers have been used before in landfill designs as venting layers, which are part of the final cover system [McBean et al., 1995][Qian et al., 2002]. The purpose of the gas vent layer is to vent LFG generated from the decomposition of underlying wastes. In some cases the surface permeable layers are combined with a vacuum system located at the surface [Zison, 1984], but for the most part flow of LFG through the layers occurs passively under a natural pressure gradient within the closed landfill [USEPA, 1994]. While such permeable layers have been proposed and constructed, to our knowledge there has been no study to quantify the influence of such permeable layers on LFG flow 
(2) Diffusion of multicomponent gas mixtures in porous media One of the most important aspects of gas transport near the landfill surface is gaseous diffusion. Several models have been used to describe diffusion of multicomponent gas mixtures in soils. The Dusty Gas Model (DGM) is the most rigorous and accounts for molecular, nonequimolar, and Knudsen diffusion [Mason et al., 1967]. The DGM can be used to describe both diffusive and advective transport [Thorstenson and Pollock, 1989]. Molecular diffusion only depends on concentration gradients while nonequimolar diffusion results from different thermal velocities of nonequimolar components. Knudsen diffusion describes the phenomenon of gas molecule collision with pore walls, which is important in low permeability media where the mean free path of gas molecules is comparable to pore radii. If Knudsen diffusion is negligible, which is the case for many porous media where the permeability is sufficiently large, the StefanMaxwell equations can be used to describe gas transport [Curtiss and Hirschfelder, 1949][Thorstenson and Pollock, 1989].

By confining the number of gas components to two, the Stefan-Maxwell equations can be further simplified to an advection diffusion model (ADM) with Fick's law describing molecular diffusion. Fick's law is generally not appropriate for multicomponent gaseous systems [Thorstenson and Pollock, 1989], since it was developed for binary mixtures and neglects both Knudsen and nonequimolar diffusion. However, because of the computational advantages of the ADM, many researchers have attempted to develop simplified approaches that might allow the use of Fick's law within an ADM framework to describe transport of multicomponent gas mixtures. The objective has been to define a characteristic diffusion coefficient of each species in the mixture, i.e., an effective diffusivity $D_{i}^{*}$, which results in solutions that approximate those from the Stefan-Maxwell equations. Several formulas estimating $D_{i}^{*}$ have been derived for 
particular limiting cases [Taylor and Krishna, 1993]. Several researchers have selected Wilke's formula to estimate $D_{i}^{*}$ for LFG [Findikakis and Leckie, 1979][Nastev et al., 2001].

$$
D_{i}^{*}=\left(1-x_{i}\right) / \sum_{\substack{j=1 \\ i \neq j}}^{v} \frac{x_{j}}{D_{i j}}
$$

where $x_{i}$ is the mole fraction of gas component $i, D_{i j}$ is the diffusion coefficient of component $i$ in gas $j$ in a binary gas mixture $\left(\mathrm{L}^{2} \mathrm{t}^{-1}\right)$, and $v$ is the total number of gas species.

A recent study by [Molins et al., 2008] provides insight into the error associated with using Fick's law to describe multicomponent gas diffusion in landfill soils. In their work an equimolar form of the Stefan-Maxwell equations and the DGM were used to simulate methane oxidation and multicomponent gas transport in a landfill cover soil with an assumed intrinsic permeability of $2 \times 10^{-13} \mathrm{~m}^{2}$ [De Visscher and Van Cleemput, 2003]. Both models fitted the data well producing nearly identical results, which implied that both Knudsen and nonequimolar diffusion were minor. Simulations using Fick's law in the ADM framework also produced very small errors in this landfill cover soil [Molins and Mayer, 2007b; Molins and Mayer, 2007a]. Together these results suggest that Knudsen and nonequimolar diffusion are small in some landfill cover soils, and that using Fick's law in the ADM framework is adequate for describing multicomponent gas transport in such systems. The error associated with using Fick's law is expected to be more important, though, for soils with lower gas permeabilities [Fen and Abriola, 2004][Oldenburg et al., 2004][Webb and Pruess, 2003]. In a recent simulation study [Molins et al., 2008]found that nonequimolar diffusion, which is not included in Fick's law, accounted for $18 \%$ of the gas diffusion in the upper reaches of a landfill cover soil where the gas permeability was $5 \times 10^{-15} \mathrm{~m}^{2}$. Because errors associated with using Fick's law are believed to be minor for the high permeability refuse and soils used in this study $\left(>10^{-13} \mathrm{~m}^{2}\right)$ and because of the 
significant computational effort in solving the DGM in two dimensional anisotropic systems, Fick's law was used in the simulations reported below.

TMVOC is an extension of the TOUGH2 (transport of unsaturated groundwater and heat) general-purpose simulation program that was developed in the Earth Sciences Division of Lawrence Berkeley National Laboratory [Pruess and Battistelli, 2002][Pruess et al., 1999] and was selected for this work. In TMVOC the diffusive flux of component $i$ in the gaseous phase $\left(J_{i}\right)$ is described using Fick's law and written as

$J_{i}=-n \phi \tau_{0} \tau_{g} D_{i j} \nabla x_{i}$

where $n$ is the total molar concentration $\left(\mathrm{mol} \mathrm{L}^{-3}\right) ; \phi$ is the gas-filled porosity; and $\tau_{0} \tau_{g}$ is the tortuosity and is the product of the medium tortuosity, $\tau_{0}$, and the saturation-dependent tortuosity, $\tau_{g}=\tau_{g}\left(S_{g}\right)$, where $S_{g}$ is the gas saturation. The [Millington and Quirk, 1961] model is used to calculate $\tau_{0} \tau_{g}$ in TMVOC. $D_{i j}$ is re-calculated at each grid block according to temperature and pressure [Pruess and Battistelli, 2002].

One modification was made to TMVOC for calculating diffusive fluxes for this application. Fick's law stated in equation (2) describes the molar flux relative to the molar average velocity, $v^{*}$, not to stationary coordinates [Bird et al., 1960]

$$
\begin{aligned}
J_{i} & =n_{i}\left(v_{i}-v^{*}\right) \\
& =n_{i} v_{i}-\frac{n_{i}}{n} \sum_{j=1}^{v} n_{j} v_{j} \\
& =N_{i}-x_{i} \sum_{j=1}^{v} N_{j}
\end{aligned}
$$

where $n_{i}$ is the molar concentration of the $i$ th species, $v_{i}$ is the velocity of the $i$ th species with respect to stationary coordinates, and $N_{i}$ is the total diffusive flux of gas component $i$ relative to stationary coordinates and includes both molecular and nonequimolar fluxes (mol $\left.\mathrm{L}^{-2} \mathrm{t}^{-1}\right)$. Only 
in the case of equimolar counterdiffusion can equation (5) be used to describe diffusive flux $\left(J_{i}=N_{i}\right)$ with respect to stationary coordinates, which requires that the sum of the total diffusive fluxes of all gas components is zero

$$
N^{N}=\sum_{j=1}^{v} N_{j}=0
$$

where $N^{N}$ is the nonequimolar flux. This requirement is not currently enforced in TMVOC, but was implemented in the code for this work. As noted above, equimolar flux is a reasonable assumption for multicomponent gas transport in high permeability landfill cover soils [Molins and Mayer, 2007b].

In this application gas was assumed composed of three components: methane, carbon dioxide, and air. Diffusion for methane and carbon dioxide were modeled explicitly, while the diffusion of air was determined by enforcing the requirements of equation (7). Binary diffusion coefficients were used for the molecular diffusion coefficients of methane and carbon dioxide because (1) it is the simplest approach, (2) the error associated with using approximations like Wilke's formula [Wilke, 1950] for effective diffusion coefficients is unknown, and (3) differences between the binary diffusion coefficients and effective diffusion coefficients determined from Wilke's formula were minor. For example, differences between the two methods were about $3 \%$ near the landfill surface where the diffusive flux is most important. It is important to note that TMVOC uses a molar-based diffusion equation, which was recently shown to more closely match DGM predictions than mass-based models [Fen and Abriola, 2004].

\section{b) Methodology}

A simplified conceptual model was used to evaluate the influence of a permeable layer on LFG collection and fugitive methane emissions for a hypothetical landfill. Simulations were 
focused on a region where a pumping well was centrally positioned. Considering the characteristics of gas flow, a two-dimensional, axisymmetric, radial domain was selected. Figure 18 shows a schematic of the base model domain, which was $46 \mathrm{~m}$ in radius and $12.4 \mathrm{~m}$ in depth. The domain included three major material types: refuse, shredded tire layers (high permeability layers), and soil cover. One of the tire layers was installed between the soil cover and the pumping well and acted as a permeable layer to distribute the gas pressure evenly near the top of the landfill. The remaining tire layer, referred to as the "pancake" layer or pancake well, served as the pumping well to permit more uniform flow conditions into the extraction well. Both tire layers were $0.6 \mathrm{~m}$ thick and the pancake tire layer had a radius of $3.8 \mathrm{~m}$. The pancake well was used instead of a more standard vertical well design because a similar pumping well was constructed in one of our ongoing test cells in California. As will be shown below, the performance of the permeable layer near the top of the landfill was insensitive to the type of gas collection well. While shredded tires were selected as the permeable material in our study, other waste materials with high porosity and low resistance to gas flow might also be used and may be more desirable in some applications.

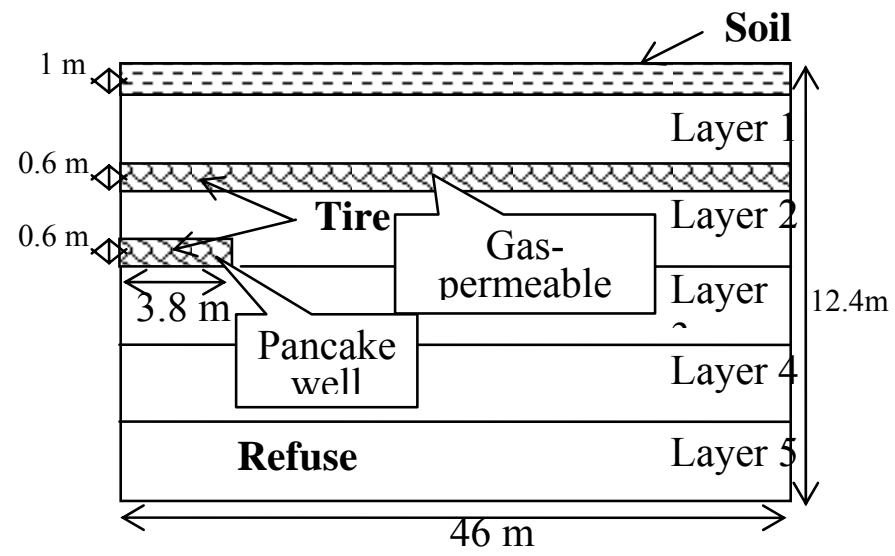

Figure 18. One half of cross section for base-case simulations. The thicknesses of layers 1 to 5 are $2.1,2.4,2.3,2.0$, and $2.0 \mathrm{~m}$, respectively. 
The intrinsic permeability of the tire layers was assumed based on previous measurements [Warith et al., 2004]. Warith and colleagues measured the hydraulic conductivity of shredded tires that were used for leachate collection systems. The permeability calculated from their data ranged from $7.3 \times 10^{-10}$ to $1.9 \times 10^{-8} \mathrm{~m}^{2}$ under vertical stresses in the range of 250 $-440 \mathrm{kPa}$. For the smaller stress conditions near the landfill surface, a permeability of $3 \times 10^{-8}$ $\mathrm{m}^{2}$ was selected for all tire layers in the simulations. Because this permeability was two or more orders of magnitude larger than the average horizontal permeabilities of the refuse in the simulations, a minor error in this estimate had a negligible effect on gas flow. The soil cover was $1.0 \mathrm{~m}$ thick and was representative of intermediate cover materials.

The refuse represented general municipal solid waste in landfills. Waste dumped in landfills is packed over time and compressed by overlying material. Thus, the domain for the refuse was divided into five layers, and the permeability of each layer was specified assuming that the permeability of the waste decreased exponentially with depth. This assumption was based on an empirical relationship between vertical stress and hydraulic conductivity in landfills (Yildiz et al., 2004). Since the vertical stress was approximately proportional to the thickness of the waste above the measuring point, the depth below the landfill surface can replace vertical stress in Yildez et al.'s expression [Yildiz et al., 2004]

$k_{h}=a e^{-b D}$

where $k_{h}$ is the intrinsic permeability in the horizontal direction $\left(\mathrm{m}^{2}\right) ; a$ and $b$ are empirical constants with units of length squared and inverse length, respectively; and $D$ is the depth below the landfill surface (m). Vertical variations of bulk density with depth were not accounted for, since these variations have a minor effect on vertical stress and the resulting estimates of 
permeability. Constants $a$ and $b$ were estimated from a nonlinear regression analysis using recent gas permeability measurements at a landfill site in the state of Florida in the U.S. [Jain et al., 2005], and were $2.5 \times 10^{-11} \mathrm{~m}^{2}$ and $0.12 \mathrm{~m}^{-1}$, respectively. The vertical permeability $k_{v}$ was selected to be 10 times smaller than the horizontal permeability. The anisotropy ratio was varied in the analyses, since we are unaware of any reliable field data for this ratio. The variation of porosity with depth was estimated using the Kozeny-Carmen equation [Bear, 1972]

$$
k_{h}=k_{o} \frac{n^{3}}{(1-n)^{2}}
$$

where $k_{o}=3.48 \times 10^{-11}\left(\mathrm{~m}^{2}\right)$ is the reference permeability and calculated assuming the porosity at $7.2 \mathrm{~m}$ from the top surface is 0.45 , which is slightly lower than the typical porosity of refuse near the surface of landfills [Han et al., 2006]. While the use of the Kozeny-Carmen equation for refuse is untested, we are aware of no better means to estimate the vertical variation of porosity in landfills.

The general properties of each material used in the base case simulations are given in Table 3. To exclude the effect of water movement, the assumed water saturation for each material was specified as the residual water saturation. As a result, the relative permeability for gas-phase transport was equal to one everywhere in the domain. 
Table 3. General properties of model domain for base simulations

\begin{tabular}{|c|c|c|c|c|c|c|c|}
\hline Property & \multicolumn{5}{|c|}{ Refuse } & Tire & Soil \\
\hline \multirow{3}{*}{ Porosity } & \multicolumn{5}{|c|}{ Layer $^{a}$} & \multirow{3}{*}{$0.50^{b}$} & \multirow{3}{*}{$0.35^{b}$} \\
\hline & 1 & 2 & 3 & 4 & 5 & & \\
\hline & 0.51 & 0.48 & 0.45 & 0.425 & 0.4 & & \\
\hline Aqueous phase saturation & \multicolumn{5}{|c|}{$0.21^{b}$} & $0.21^{b}$ & $0.15^{b}$ \\
\hline \multirow{3}{*}{$\begin{array}{l}\text { Intrinsic Horizontal } \\
\text { Permeability }\left(\mathrm{m}^{2}\right)\end{array}$} & \multicolumn{5}{|c|}{ Layer $^{c}$} & \multirow{3}{*}{$3.0 \mathrm{e}-8^{d}$} & \multirow{3}{*}{$1.0 \mathrm{e}-12^{b}$} \\
\hline & 1 & 2 & 3 & 4 & 5 & & \\
\hline & $1.95 \mathrm{e}-11$ & $1.39 \mathrm{e}-11$ & $1.05 \mathrm{e}-11$ & $8.1 \mathrm{e}-12$ & $6.4 \mathrm{e}-12$ & & \\
\hline \multirow{3}{*}{$\begin{array}{l}\text { Intrinsic Vertical } \\
\text { Permeability }\left(\mathrm{m}^{2}\right)\end{array}$} & \multicolumn{5}{|c|}{ Layer $^{c}$} & \multirow{3}{*}{$3.0 \mathrm{e}-9^{d}$} & \multirow{3}{*}{$1.0 \mathrm{e}-13^{b}$} \\
\hline & 1 & 2 & 3 & 4 & 5 & & \\
\hline & $1.95 \mathrm{e}-12$ & $1.39 \mathrm{e}-12$ & $1.05 \mathrm{e}-12$ & $8.1 \mathrm{e}-13$ & $6.4 \mathrm{e}-13$ & & \\
\hline
\end{tabular}

${ }^{\mathrm{a}}$ See methodology section.

${ }^{\mathrm{b}}$ Assumed

${ }^{\mathrm{c}}$ Computed using the data of [Jain et al., 2005]

${ }^{\mathrm{d}}$ Computed using the data of [Warith et al., 2004]

The grid used in the simulations consists of 20 and 82 grid elements in the radial and vertical directions, respectively. Discretization was finer at material interfaces where significant gradients in concentrations or pressures were expected. The top surface boundary for gas flow was a Dirichlet boundary condition of constant pressure $(101.3 \mathrm{kPa})$ and zero methane and carbon dioxide concentrations to represent atmospheric conditions. No flux boundaries were assumed for the lateral and bottom borders of the simulation domain. The lateral condition represents the imaginary boundary between neighboring extraction wells, which are equidistant from each other. The bottom of the model represents the bottom layer to the landfill that is impermeable to both gas and liquid flow. The pumping rate in the system was set equal to the LFG generation rate $\left(25 \mathrm{~m}^{3}\right.$ ton $\left.^{-1} \mathrm{yr}^{-1}\right)$, which was assumed to be $55 \%$ methane and $45 \%$ carbon dioxide. The resulting vacuum in the pumping well varied between simulations and ranged from $2-8 \mathrm{kPa}$, depending on the assumed permeability of the refuse. The binary diffusion 
coefficients of methane and carbon dioxide were estimated to be $2.096 \times 10^{-5}$ and $1.573 \times 10^{-5}$ $\mathrm{m}^{2} \mathrm{~s}^{-1}$, respectively, using a formula from [Fuller et al., 1966] at $101.3 \mathrm{kPa}$ and $25^{\circ} \mathrm{C}$.

Several assumptions were made to simplify the simulations. First, isothermal conditions within the landfill were assumed with a fixed temperature of $25{ }^{\circ} \mathrm{C}$. Second, the LFG generation rate was steady since the simulation period was too short to account for the decrease in the LFG generation rate associated with waste stabilization. Third, chemical and biological degradation processes were not explicitly considered in the refuse or soil cover; instead, a constant LFG generation rate was specified for each grid block in the refuse. While biological activity is important and will affect fugitive methane emissions, it was neglected in this study since the focus was on the influence of a high permeability layer on LFG collection. This approach is reasonable because biological activity will vary depending on temperature and moisture conditions and would confound our interpretation of the influence of various gas collection schemes. We wanted to examine the worst case scenario, where oxygen would intrude the farthest and methane emissions would be the greatest.

All model simulations were for steady-state conditions. Various cases were simulated to explore different setup conditions and the sensitivity of important model parameters, and these cases are summarized in Table 4. Unless otherwise stated, simulation parameters given in Table 3 or described above were base-case parameters and used for all simulations.

To incorporate the transient change of atmospheric pressure, the TMVOC code was modified and time-dependent Dirichlet conditions were implemented for gas pressures. Two different sets of transient atmospheric boundary conditions were selected to represent cases of moderate and strong atmospheric pressure changes. For the moderate variation, barometric pressure data at Sacramento, California in the U.S. were obtained from the National Climatic 
Data Center of the National Oceanic and Atmospheric Administration. The 24-hour pressure data were averaged for a one-month period. For the strong variation, a range of atmospheric pressures was selected from the most severe variations in atmospheric pressures measured at the Skellingsted Landfill, Denmark [Poulsen et al., 2003].

Table 4. Summary of various cases analyzed

\begin{tabular}{|c|c|c|}
\hline Case & $\begin{array}{c}\text { Description or range of } \\
\text { parameter variations }\end{array}$ & $\begin{array}{l}\text { Domain } \\
\text { regeneration }\end{array}$ \\
\hline Base case & - Described in text & No \\
\hline $\begin{array}{l}\text { Effect of vertical location of } \\
\text { permeable layer }\end{array}$ & - 0 (right under landfill cover) $-2.9 \mathrm{~m}$ & Yes \\
\hline $\begin{array}{l}\text { Effect of gas collection well } \\
\text { design }\end{array}$ & - point source, vertically screened well, and pancake well & Yes \\
\hline $\begin{array}{l}\text { Effect of width of } \\
\text { permeable layer }\end{array}$ & $50-100 \%$ of the domain radius & Yes \\
\hline $\begin{array}{l}\text { Effect of permeability } \\
\text { and anisotropy of refuse }\end{array}$ & $\begin{array}{l}\text { - Permeability: } 0.2 k-10 k \text {, where } k \text { is the permeability of the base case } \\
\text { - Anisotropy: } k_{h} / k_{v}=3-10\end{array}$ & No \\
\hline $\begin{array}{l}\text { Effect of atmospheric } \\
\text { pressure change }\end{array}$ & $\begin{array}{l}\text { - Two different magnitudes of barometric pressure variations assessed. } \\
\text { Moderate: } 101.1-101.4(\mathrm{kPa}) \\
\text { Strong: } 100.2-102.2(\mathrm{kPa}) \\
\text { - A time-dependent Dirichlet condition was applied at the top boundary. }\end{array}$ & No \\
\hline
\end{tabular}

\section{c) Results}

(1) Effect of permeable layer - Base case simulation

(a) Flow distribution

Figure 19 shows the computed gas fluxes at the landfill surface for the base-case simulation conditions with and without the permeable layer, where the magnitude of each flux 
was normalized by the largest flux for comparison. Because air diffusion was modeled as a single gas, the oxygen flux was determined based on the air composition.
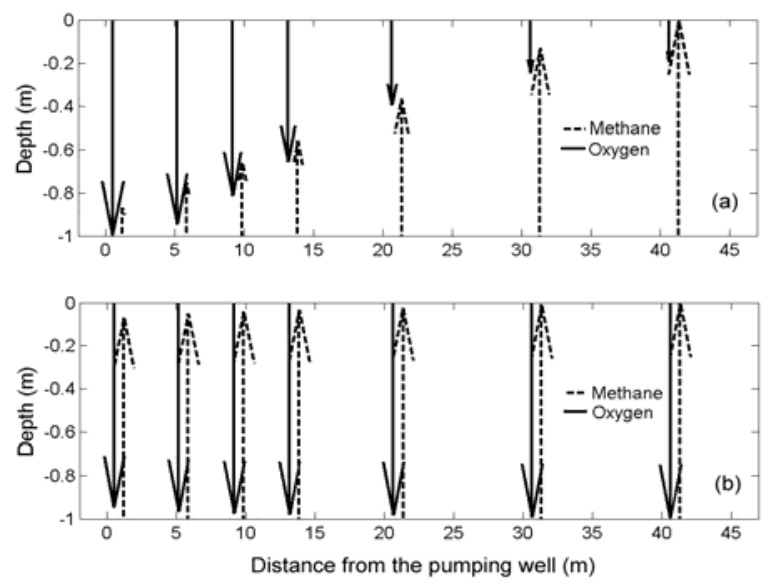

Figure 19. Methane and oxygen gas molar flux vectors for one half of the cover soil. The length and direction of the arrows indicate the magnitude and direction of gas flows. (a) With upper horizontal permeable layer installed. (b) Without upper horizontal permeable layer installed.

For the situation with a permeable layer installed, both methane and oxygen fluxes are uniformly distributed throughout the cover soil (Figure 19a). In this case the gas pressure in the region above the permeable layer becomes laterally uniform, since the suction pressure at the pumping well propagates horizontally through the permeable layer [Augenstein et al., 2007]. The high-permeability layer may increase the methane oxidation capacity in landfill covers by evenly distributing the two counter fluxes of methane and oxygen in the soil cover. Without the permeable layer, the methane flux increased with distance from the pumping well while the oxygen flux was maximum near the well (Figure 19b). Thus, assuming no preferential gas flow associated with cracks or fissures in the soil cover, the majority of fugitive methane fluxes will occur at distances far from extraction wells. 
It is interesting to note that for the simulated gas extraction rate diffusion is the dominant mechanism of methane transport through the soil cover, accounting for $98 \%$ of the total methane flux. Thus, it is important to model diffusive fluxes accurately.

\section{(b) Oxygen profiles}

The effect of the permeable tire layer on oxygen intrusion is shown in Figure 20. When a permeable layer is included, oxygen intrusion occurs uniformly and does not vary with radial distance from the well (Figure 20a). But with removal of the permeable layer from the system, significantly higher concentrations of oxygen are observed at greater depths near the well (Figure 20b). The more even distribution of oxygen shown in Figure 20a mirrors the uniform oxygen fluxes at the landfill surface shown in Figure 19a. Actual gradients in oxygen profiles are expected to be much sharper near the landfill surface in actual landfills, because of consumption by methanotrophic bacteria in landfill covers. The redistribution of oxygen by the permeable layer may be even more advantageous if cracks or fissures form in the cover material.
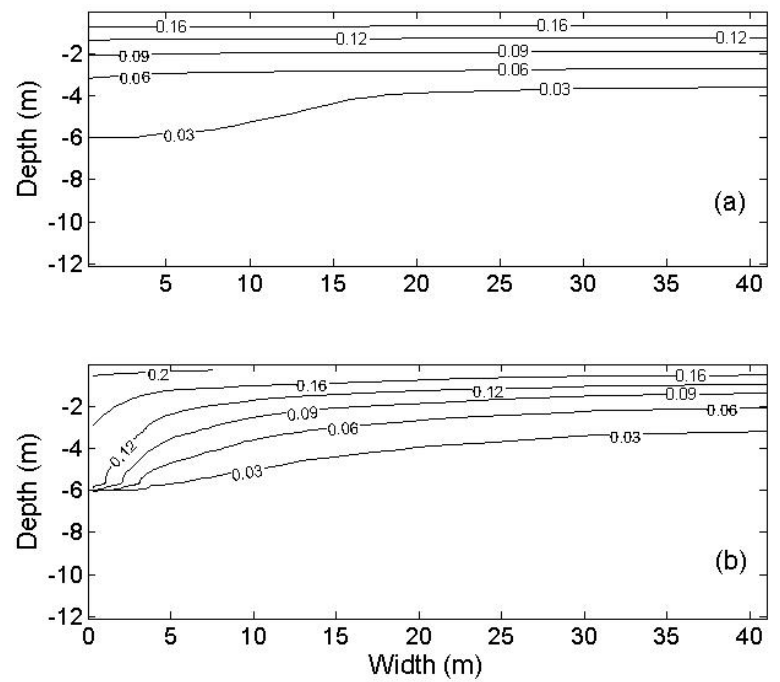

Figure 20. Oxygen (percent by mass) throughout one half of the problem domain. (a) With upper horizontal permeable layer installed. (b) Without upper horizontal permeable layer installed. 
(c) Methane emission and collection

For the base-case simulation with the permeable layer installed, the methane emissions at the surface of the landfill were $32.4 \mathrm{~g} \mathrm{~m}^{-2} \mathrm{~d}^{-1}$, which are close to field measurements $(37.8-43.2$ $\mathrm{g} \mathrm{m}^{-2} \mathrm{~d}^{-1}$ ) obtained from landfills with active gas extraction systems that were temporarily covered with clay or sandy soil [Schuetz et al., 2003][Spokas et al., 2006]. Thus, the parameters used in the simulations were in ranges representative of actual field conditions.

System performance for the base case was quantified by methane emissions, methane or LFG collection efficiencies, and percent ratio of oxygen to methane concentration at the pancake well. Here and elsewhere, methane (or LFG) emission rate is reported as percent of total methane (or LFG) generation rate, while methane (or LFG) collection efficiency is equal to one minus the methane (or LFG) emission rate.

For the situation without a permeable layer, the methane collection efficiency and emission rate was 82 and $18 \%$, respectively, and the mass ratio of oxygen to methane in the pumping well was $11 \%$. The effect of the permeable layer on system performance was minor for the base case: the permeable layer decreased fugitive methane emissions by $3 \%$ and increased the methane concentration in the pumping well by $2 \%$. Even without the permeable layer, the pumping well was able to collect LFG easily owing to the sufficiently high permeability of refuse. However, the influence of the permeable layer on gas flow is increases as the refuse permeability decreases, which is discussed in detail below.

(d) Effect of vertical location of permeable layer

The influence of the vertical location of the permeable layer on methane emissions and oxygen intrusion was evaluated and the results are shown in Figure 21. As the depth increased from 0 (top of permeable layer immediately below the soil cover) to $2.9 \mathrm{~m}$, methane emissions 
decreased while oxygen intrusion increased. The extent of oxygen intrusion was quantified by determining the percent of waste volume above the pumping well with oxygen concentrations over $3 \%$. While methane emissions decreased by $7 \%$ as the permeable layer depth increased from 0 to $2.9 \mathrm{~m}$, the volume of refuse with oxygen concentrations over $3 \%$ increased by $23 \%$. While this analysis neglects oxygen utilization in the soil and refuse, it clearly illustrates the competing benefits of enhanced methane capture (deep permeable layer) and reduced oxygen intrusion (shallow permeable layer) that are influenced by the vertical location of the permeable layer.

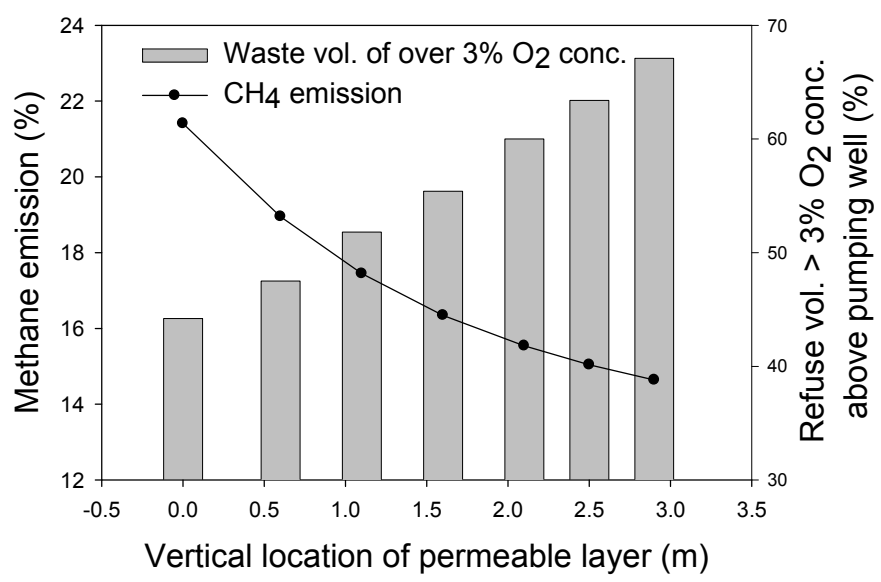

Figure 21. Variation of methane emissions and refuse volume with $>3 \%$ oxygen concentration above the pumping well.

\section{(e) Effect of width of permeable layer}

The influence of the radius of the permeable layer was also evaluated by varying the radius from $50 \%$ to $100 \%$ of the domain radius. When the coverage of the permeable layer decreased from the entire domain to only half, fugitive methane emissions increased by only $1 \%$ and oxygen intrusion decreased by $5 \%$. Compared to the simulations where the vertical location of the permeable layer was varied, the influence of the spatial extent of the permeable layer on gas flow was much smaller. That is, it is not necessary to completely cover refuse with the 
permeable layer to extend the zone of influence of pumping wells and enhance methane collection. This is a desirable result because unless a permeable layer is made of waste materials it results in a loss of landfill capacity.

\section{(f) Effect of gas collection well design}

Three different pumping well designs were tested using the base case conditions with the permeable layer installed: the pancake well, a point sink at the center of the pancake well, and three vertical wells screened at different depths (between 1-3,1-4, and 1-5.7 $\mathrm{m}$ below the permeable layer). In all cases the geometry of the extraction well had a minor effect on methane emissions, with methane emission rates differing by less than $1 \%$ between the three well types. Thus, the permeable layer equalizes gas pressures and mitigates the influence of well construction on gas collection.

\section{(g) Effect of permeability and anisotropy}

Landfills are heterogeneous systems with properties, particularly waste permeabilities, varying from site to site and dependent upon refuse composition, initial compaction densities, and subsequent biodegradation rates. Gas permeability will also change with season due to variations in rainfall rates, which alter the local gas saturations in waste. The influence of refuse permeability and the ratio of horizontal to vertical permeability on system performance were examined. Refuse permeabilities in each layer were adjusted by a similar multiplicative factor to modify the domain-average horizontal and vertical permeabilities. The methane emissions are presented in Figure 22 for a range of permeabilities and anisotropy ratios. When the permeable layer was present, no matter how large the gas permeability or the anisotropy ratio, the methane emission rate was essentially constant; differences caused by variations in the anisotropy ratio 
and/or permeabilities were within $1 \%$. Thus, the averaged data were used in Figure 22 to represent the results for the simulations where the permeable layer was installed.

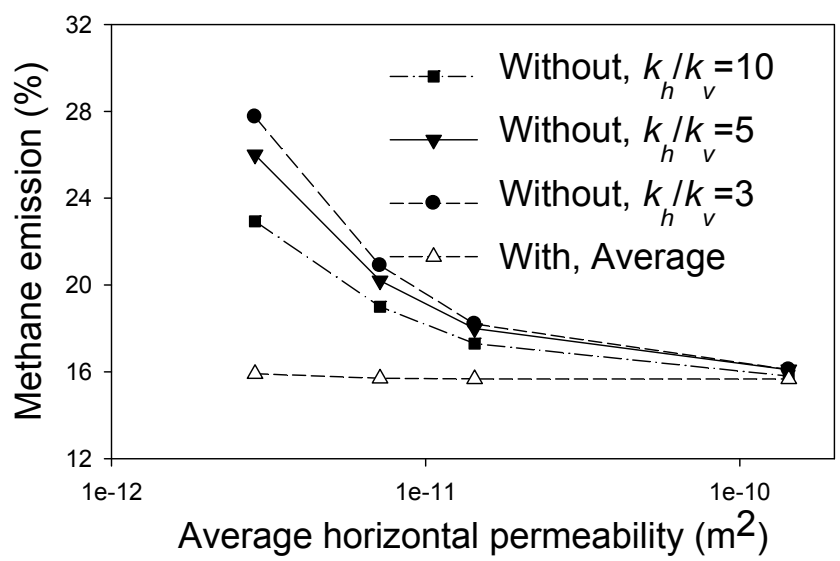

Figure 22. Variations of methane emissions as a function of the gas permeability and waste anisotropy ratio. Results are shown for cases with or without the horizontal permeable layer.

However, when the permeable layer was not included, the effect of the anisotropy ratio was substantial. Only when the horizontal permeability was over $10^{-10} \mathrm{~m}^{2}$, the influence was minor $(<1 \%)$. Methane emissions increased significantly when permeability decreased. The increase was more dramatic at the lower anisotropy ratio $\left(k_{h} / k_{v}=3\right)$, where the methane emission rate increased from 16 to $28 \%$ as the permeability of refuse decreased by two orders of magnitude. These results imply that the radius of influence of pumping wells is dependent on properties of refuse in conventional landfills, which unfortunately will change with time due to compaction and variations in moisture content that affect gas permeabilities. The installation of a permeable layer minimizes the influence of waste conditions on LFG emissions and reduces methane emissions, especially when refuse permeabilities are small.

The composition of LFG at the pumping well also revealed the significant influence of the permeable layer as the permeability of refuse decreased. For the case of $k_{h} / k_{v}=3$, the percent 
ratio of oxygen to methane was almost identical when the domain-average $k_{h}$ for the refuse varied from $3 \times 10^{-12}$ to $1.4 \times 10^{-10}$, if the permeable layer was present. However, the ratio doubled from 12 to $24 \%$ when the permeable layer was not included over this same range of permeability variations. This means that much more of the air from the atmosphere directly flows into the well when the permeable layer is absent, which deteriorates the value of the collected LFG as an energy source.

The benefits of the near-surface permeable layer may be more significant when landfills are operated as bioreactors, since during bioreactor operations moisture content varies with time and will affect gas permeability. When liquid is added the moisture content is increased, pores that gas would otherwise flow through are blocked, and gas permeabilities drop [Jain et al., 2005]. With enhanced biodegradation during bioreactor operations, refuse settles more quickly, waste porosity is reduced, and gas permeabilities decrease. Both changes reduce the refuse gas permeability and the efficiency of methane collection. Thus, the addition of a near-surface permeable layer is expected to enhance the efficiency of LFG collection during bioreactor operations.

\section{(h) Effect of atmospheric pressure change}

Methane emissions were examined in response to the atmospheric pressure changes shown in Figure 23a. In the base case, the permeable layer reduced methane emissions by about $2 \%$ for both moderate and strong variations in barometric pressure (data not shown). The fugitive methane emissions were dramatically reduced as waste permeability decreased. Figure $23 \mathrm{~b}$ shows the results for waste permeabilities five times smaller than base case conditions. Here, the permeable layer results in an $11 \%$ reduction in averaged methane emissions over the 24 hour period for both moderate and strong atmospheric pressure changes. The data also illustrate 
significant variations in methane emissions over a 24-hour period, which suggests that it may be beneficial to alter LFG extraction rates in response to barometric pressure changes.

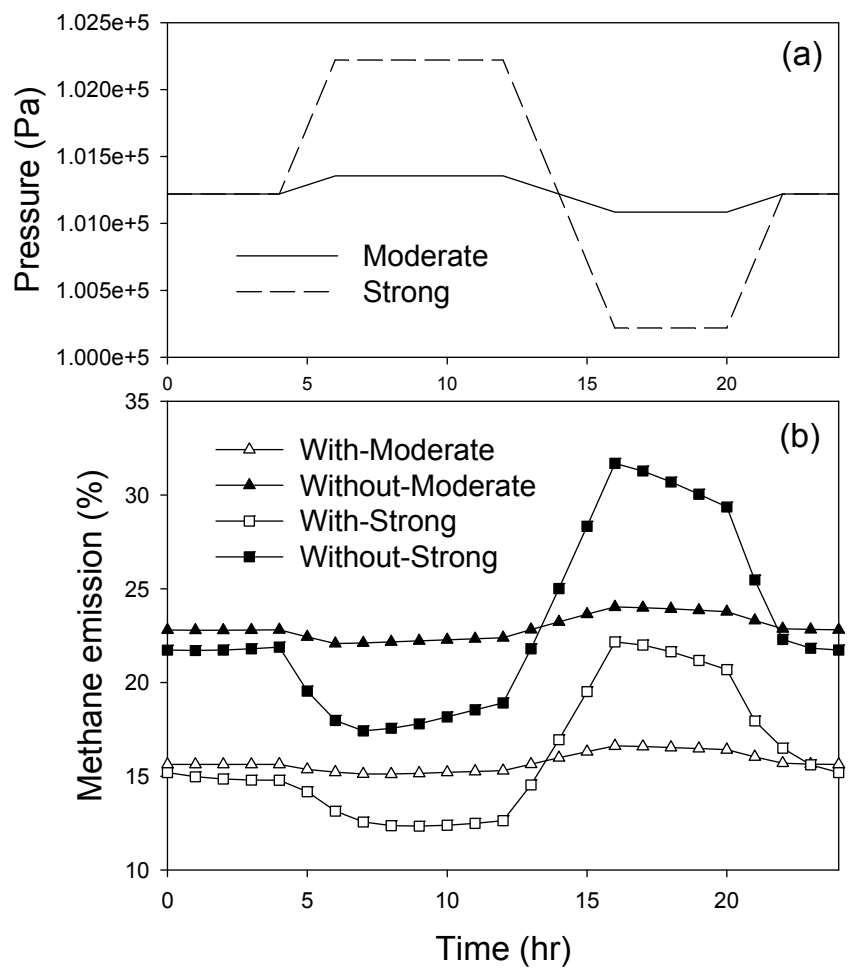

Figure 23Variations in methane emissions associated with atmospheric pressure changes over a 24-hour period. Results are shown for a landfill with and without a horizontal permeable layer installed at the top of the landfill. (a) Variations in atmospheric pressure. (b) Methane emissions.

The increase of methane emissions at low barometric pressures resulted from the temporary increase in upward advective flux of LFG. Under high atmospheric pressure conditions the diffusive flux at the surface accounted for $99 \%$ of the total flux. Under low pressures, the advective flux accounted for up to $25 \%$ of the total flux. Thus, advective fluxes are the main factor causing the fluctuations of methane emissions even though molecular diffusion was the dominant transport mechanism in the cover soil in all simulations.

In previous studies more significant variations of methane emissions resulted from changes in atmospheric pressure [Czepiel et al., 2003][Poulsen et al., 2003]. At the Nashua 
municipal landfill located in New Hampshire in the US the unit surface methane emission rate increased from $2.92 \times 10^{-5}$ to $1.06 \times 10^{-4} \mathrm{~m} \mathrm{~min}^{-1}$ when the atmospheric pressure dropped from 102.3 to $100.7 \mathrm{kPa}$ [Czepiel et al., 2003], while the emission rate in this modeling work increased from $2.69 \times 10^{-5}$ to $5.76 \times 10^{-5} \mathrm{~m} \mathrm{~min}^{-1}$ for similar changes in atmospheric pressure. The greater impact of atmospheric pressure changes on fugitive methane emissions at the Nashua landfill than in our simulations may be due to cracks/fissures in the soil cover at this site, which were not accounted for in our model. Further study is needed to substantiate this hypothesis.

\section{d) Discussion}

Methane oxidation in soils covering landfills depends on a number of environmental conditions including moisture content, temperature, and soil nutrient content [Hilger and Humer, 2003]. In addition, methane oxidation requires a balance between the upward flux of methane and the downward flux of oxygen. If the upward methane flux is large and the downward flux of oxygen small, methane oxidation may not be sufficiently fast to prevent unwanted methane emissions. Conversely, if the downward oxygen flux is too large and the upward methane flux too small, minimal methane oxidation will occur in the soil cover. In this case oxygen concentrations may rise to undesired levels in the refuse, resulting in poorer gas quality in gas collection systems and increased fire risk. When a permeable layer is installed near the landfill surface, though, the imbalance between methane and oxygen fluxes is significantly reduced over systems without this layer (see Figure 19 and 20). The more even distribution of gas fluxes across the landfill surface should promote more uniform levels of methane oxidation in soil covers.

The installation of a permeable layer under the landfill cover is quite similar to a venting layer installed in some composite landfill cover systems. The latter is used to vent gases 
generated from underlying wastes into the atmosphere or collect gases in connection with a vacuum pump connected to this permeable layer [Qian et al., 2002][Zison, 1984]. In the present case, the permeable layer only works as a distributor of gases so that vertical gas flux above the permeable layer is uniform horizontally. Because LFG is not directly collected from the permeable layer in our design, the quality of extracted LFG is better (less oxygen) and is less affected by barometric pressure changes than systems where the permeable layer immediately beneath the landfill cover is used for gas capture. For example, when atmospheric pressure variations are strong over a 24-hour period as shown in Figure 23a, the ratio of oxygen to methane flux in the collected LFG was nearly constant when the permeable layer was used only as a conductive layer. However, this ratio varied by $50 \%$ over the 24 -hour period when LFG was collected from the permeable layer, and more oxygen was extracted in the LFG. It is important to note that because a permeable layer equalizes gas pressure near the landfill surface it effectively increases the zone of the influence of a gas collection well. The gas collection efficiencies reported above for low permeability refuse demonstrates this improvement. Thus, a permeable layer might reduce the number of gas collection wells needed to achieve a prescribed LFG collection efficiency. It is also conceivable that a permeable layer might be incorporated in the design of a final landfill cover system: future analyses are planned to examine this.

If a permeable layer is installed beneath the intermediate cover of a landfill, the airspace available for landfilling will be reduced. To mitigate this, instead of shredded tires pre-screened waste materials having high porosity and permeability might be used for the permeable layer. While the high-permeability of such a layer could decrease over time because of compaction or decomposition of degradable material, its permeability might be retained until the next lift of 
refuse is added. In addition, the spatial extent of the permeable layer could be reduced to encompass only regions around gas collection wells. When the permeable layer covered half versus the entire simulation domain, the LFG collection efficiency decreased by only $4 \%$ for the case with permeability five times lower than the base case.

Another potential limitation of the permeable layer is that the layer could impede the movement of water vertically through the landfill, with leachate accumulating at the bottom of the permeable layer. To prevent this situation, minimal leachate should be injected above the permeable layer, or means provided to allow drainage of leachate from this layer.

\section{e) Conclusions}

Based on this simulation study, a high-permeability layer installed near the top surface of landfills presents several advantages for intermediate landfill covers. For a wide range of conditions, including variations in refuse permeability and atmospheric pressure, methane emissions are reduced and oxygen intrusion is decreased. More importantly, the presence of a permeable layer results in near constant collection rates of biogas regardless of variations in the permeability anisotropy ratio of waste or in the waste permeability (see Figure 22).

The simulation results showed that diffusion was the primary mechanism determining the extent of methane emissions from the landfill surface, which highlights the importance of modeling gaseous diffusion correctly. This result was a bit surprising and may be due to the fact that cracks and fissures often occur in landfill cover soils, but such fissures were not modeled in this study. The influence of such preferential gas flow paths may be exacerbated under wet conditions, when water saturations in the cover soil are higher than the $15 \%$ assumed in this study. Another possible explanation for the important role of gas diffusion is that the LFG extraction rate was set equal to the LFG generation rate in all simulations. If the LFG extraction 
rate was lower than the generation rate, gas pressures would be higher in the landfill and advective fluxes would increase.

While vertical variability of refuse properties was captured in the simulations reported here, the random nature of both permeability and LFG generation rates was not accounted for. Such variations may result in LFG collection efficiencies that are poorer than what were achieved in this study. Finally, we note that biological activity was not accounted for in cover materials. While this will result in conservative (high) estimates for methane emissions and oxygen intrusion, the inclusion of such processes would lend further confidence in our understanding of the influence of various gas collection systems on LFG recovery and methane emissions.

\section{Inverse Modeling to Estimate Gas Permeability Field and Landfill Gas Generation Rate}

Despite the widespread use of LFG collection systems for over three decades, little information on their capture efficiency is available: although LFG collection rates are readily and accurately measured, LFG (or $\mathrm{CH}_{4}$ ) generation rates, the second measurement needed for determining efficiency, are usually unknown. Several methods have been proposed to estimate the LFG generation rate at a landfill: combining pneumatic well test data with assumptions about well recovery to estimate LFG generation [EMCON, 1980][El-Fadel et al., 1996], employing biokinetic models describing stages of waste decomposition $\{\{48$ El-Fadel,M. 1996 $\}$, and using simple first-order kinetic gas generation models such as the Landfill Gas Emission Model (LandGEM) [USEPA, 2005][Pierce et al., 2004]. However, these methods suffer significant limitations. Estimates based on pneumatic well tests rely on precise pressure measurements $\{\{165$ Pierce,J. 2004\} $\}$ [Walter, 2003]. Biokinetic modeling requires biokinetic parameters and 
detailed data about the refuse, such as mass fractions for each waste category that are often unavailable or estimated with limited data [El-Fadel et al., 1997]. Kinetic models also require parameters that must be estimated. For example, when the LandGEM model is used to predict $\mathrm{CH}_{4}$ production [USEPA, 2005][USEPA, 1998], the default $\mathrm{CH}_{4}$ generation potential, $L_{0}$, and first-order waste decay rate, $k$, recommended under the Clean Air Act or AP-42, Compilation of Air Pollutant Emission Factors $\{\{28619$ USEPA 1998\}\} are often used without considering unique conditions at each landfill site [Scharff and Jacobs, 2006]. When parameters are estimated using site-specific data, uncertainties in parameters may still be significant: errors in measured $L_{0}$ can significantly affect estimates of $k$ [Tolaymat et al., 2010], and estimates require assumptions about the landfill gas collection efficiency, which is also unknown [Tolaymat et al., 2010]. Furthermore, these methods provide little information or quantitative understanding of LFG flow within landfills. Such an understanding would result in more rationally designed LFG collection system that might improve $\mathrm{CH}_{4}$ capture efficiency and minimize air intrusion during LFG collection.

The baro-pneumatic method is a recently proposed technique for quantifying LFG generation rates and estimating the gas permeability field within landfills [Bentley et al., 2003]. This method involves the simultaneous measurement of gas pressures at the landfill surface and with depth during a baro-pneumatic test and one or more pneumatic pump tests. The technique is based on mathematical analyses of pressure changes in the refuse in response to variations in atmospheric pressure, LFG generation, and pumpage at a LFG a. A one- or three-dimensional gas flow model is calibrated by hand to provide a match to field data by varying gas permeabilities, gas-filled porosity, and LFG generation rate. The calibrated model can be used to improve the design of LFG collection systems and LFG capture efficiency. In contrast to the well 
testing method used in earlier approaches [EMCON, 1980], the baro-pneumatic method does not assume that the LFG generation rate is equal to the flow rate of a gas extraction well within its zone of influence, an assumption shown to be technically flawed [Walter, 2003]. In addition, the method uses site-specific data that may reduce uncertainties in estimates of LFG generation rates.

While a limited number of field applications have employed the baro-pneumatic method to estimate LFG generation rates [Bentley et al., 2005], the efficacy of the method in heterogeneous landfills has not been rigorously evaluated. Gas permeability, gas-filled porosity, and LFG generation rate are all expected to vary spatially in landfills. For example, where it has been measured the gas permeability of refuse varied several orders of magnitude within a given landfill [Bentley et al., 2005][Jain et al., 2005]. Spatial variability in the gas permeability likely affects LFG collection efficiency and $\mathrm{CH}_{4}$ emissions and can make it difficult to operate landfills as bioreactors [Reinhart, 1996; Reinhart et al., 2002]. While we are unaware of data evaluating the spatial variability of gas-filled porosity and LFG generation rate in refuse, the heterogeneous nature of landfill materials suggests these properties vary as well. A second limitation of the baro-pneumatic method is that manual calibration of the gas flow models is typically employed. Inverse modeling has not been attempted and could achieve improved results, particularly in heterogeneous refuse.

The primary objective of this study was to modify the baro-pneumatic method by incorporating an inverse modeling approach, the pilot point method [de Marsily, 1994; RamaRao et al., 1995], to calibrate the LFG flow model to site-specific gas pressure data. The modified baro-pneumatic method was evaluated using synthetic data sets to examine the efficacy of the method in landfills with heterogeneous gas permeabilities. Synthetic data are particularly useful 
for this exercise, since the gas flow field and LFG generation rate are known precisely and thus errors associated with the method can be readily quantified. For the synthetic data used here, gasfilled porosity and LFG generation rate were assumed to be uniform within the region "sampled" by the baro-pneumatic method. Future work will examine the impact of spatial variations of these parameters.

\section{a) Background}

(1) Baro-pneumatic method

In a porous medium with no in situ gas generation, gas pressures in the subsurface change in response to variation of barometric pressure at the surface. As the surface pressure signal propagates into the subsurface, responses are delayed and attenuated as a function of depth and pneumatic diffusivity, which is defined as

$$
D_{g}=\frac{k_{z} P_{g}}{\phi_{g} \mu_{g}}
$$

where $D_{g}$ is pneumatic diffusivity $\left[\mathrm{L}^{2} \mathrm{~T}^{-1}\right], k_{z}$ is the vertical gas permeability $\left[\mathrm{L}^{2}\right], P_{g}$ is the mean gas pressure $\left[\mathrm{M} \mathrm{L}^{-1} \mathrm{~T}^{-2}\right], \phi_{g}$ is the gas-filled porosity $\left[\mathrm{L}^{3} \mathrm{~L}^{-3}\right]$, and $\mu_{g}$ is the dynamic viscosity of the gas $\left[\mathrm{M} \mathrm{L}^{-1} \mathrm{~T}^{-1}\right]$. Time-varying pneumatic pressure data collected in situ can be used to estimate the pneumatic diffusivity, which when combined with estimates of $\phi_{g}$ have been used to determine vertical gas permeability of unsaturated soils [Shan, 1995; Weeks, 1978] and fractured rocks [Ahlers et al., 1999].

A similar approach has been applied to landfills to estimate gas permeability of refuse and LFG generation rate [Bentley et al., 2005]. With this approach, gas pressures within a landfill and at the landfill surface are monitored simultaneously. The LFG generation rate is estimated by attributing the difference between the mean absolute gas pressure in the landfill and 
the barometric pressure to LFG generation, while the lag in gas pressures measured in situ with those measured at the landfill surface is used to infer the pneumatic diffusivity. To support the baro-pneumatic test data, pneumatic pump tests are conducted, which provide an independent measurement of horizontal gas permeability of the refuse. If pressure data are available at a monitoring well near the gas extraction well, the gas-filled porosity can also be estimated from pneumatic pump tests.

\section{(a) Pilot point method}

The pilot point method was originally devised by [de Marsily, 1994]. It combines geostatistical techniques and optimization algorithms to estimate parameters that best fit measured and simulated data. The method uses geostatistical semivariogram models to describe spatial variability in parameters while honoring available property measurements. The method involves three steps. First, a spatially correlated parameter field given an assumed geostatistical model is generated. The parameter field is conditioned to measured values at points where actual data are available, but also at points distributed throughout the model domain where adjustable parameter values are estimated during the inversion process; these points are referred to as pilot points. Second, a forward model simulates observations corresponding to measured data using the parameter field generated in the previous step. Finally, the parameters at the pilot points are perturbed to reduce the mismatch between measured and simulated data. The pilot point method is a way to estimate site-specific property fields that honor the known or assumed spatial correlation and measured property values (if available), as well as the observed system state (e.g., pressures measured during a pneumatic pump test). It is the matching of the system state that makes the property field site-specific rather than just a geostatistical realization. The pilot point method has been applied to assess heterogeneity in hydrological parameters. For instance, 
transmissivity in the saturated zone was determined using piezometric head measurements and tracer data [RamaRao et al., 1995; Certes and de Marsily, 1991; Gómez-Hernández et al., 1997; Wen et al., 2002], and the intrinsic permeability and water saturation in the unsaturated zone were determined using ground-penetrating radar and water saturation measurements [Kowalsky et al., 2004; Kowalsky et al., 2005].

The application of the pilot point method to analyze pneumatic data appears promising to characterize gas flow through highly heterogeneous refuse in a landfill. Note that the pilot point method requires additional information, particularly a geostatistical model describing the refuse. We are not aware of any study that characterized the spatial variation of gas permeability in waste with geostatistical models. In the absence of such a description, it may be possible to concurrently estimate geostatistical parameters along with the pilot point values and other hydrological parameters of interest. Such an approach was demonstrated by [Finsterle and Kowalsky, 2008], but was not investigated here as our focus is on evaluating the ability of the pilot point method to approximate spatial variation in gas permeability rather than to estimate the geostatistical structure of the gas permeability field.

\section{b) Methods}

(1) Overview

We modified the baro-pneumatic method by employing inverse modeling, i.e., the pilot point method, to estimate the heterogeneous gas permeability field and LFG generation rate in a landfill. The analysis was based on synthetic data and assumed that the geostatistical parameters of the permeability field were known. Transient gas pressure data from a pneumatic pump test were used to determine the gas permeability field, while baro-pneumatic pump test data were used to estimate the LFG generation rate. 
To model LFG generation and transport of multiple gas constituents $\left(\mathrm{CH}_{4}, \mathrm{CO}_{2}, \mathrm{O}_{2}\right.$, and $\mathrm{N}_{2}$ ), the integral finite difference simulator TMVOC [Pruess and Battistelli, 2002] was used. TMVOC is an extended version of the multiphase flow simulator TOUGH2 [Pruess et al., 1999] and can simulate transport of multiple gaseous constituents. iTOUGH2 [Finsterle, 2004], which is an inversion program based on the TOUGH2 simulator, was coupled with TMVOC for this study and used for inverse simulations. The pilot point method and geostatistical simulation routines from the widely-used Geostatistical Software Library GSLIB [Deutsch, 1992] are integrated into iTOUGH2 [Finsterle and Kowalsky, 2007].

\section{(2) Baro-pneumatic Method Evaluation}

(a) Synthetic Data

The modified baro-pneumatic method was evaluated using synthetic data, which involved a pneumatic pump test and a baro-pneumatic test in a two-dimensional vertical domain with a single gas extraction well at the center of the landfill cell (Figure 24a). The landfill cell was patterned after an anaerobic bioreactor cell at Yolo County Central Landfill, Woodland, California. The model domain was discretized into gridblocks of size $\Delta \mathrm{X} \times \Delta \mathrm{Z}=1.0 \times 0.48 \mathrm{~m}$.

For this simulated example that served as the "true field", mean horizontal $\left(\bar{k}_{x}\right)$ and vertical $\left(\bar{k}_{z}\right)$ gas permeabilities of $2 \times 10^{-11}$ and $2 \times 10^{-12} \mathrm{~m}^{2}$ were specified, which are on the higher end of the estimated range reported at the New River Landfill, Florida USA [Jain et al., 2005]. The spatially varying component of the gas permeability field was introduced by a permeability modification coefficient that scaled the mean gas permeability

$$
\begin{aligned}
& k_{x}(\boldsymbol{x})=\bar{k}_{x} \times \zeta(\boldsymbol{x}) \\
& k_{z}(\boldsymbol{x})=\bar{k}_{z} \times \zeta(\boldsymbol{x})
\end{aligned}
$$


where $\zeta(\mathbf{x})$ is the permeability modification coefficient. The gas permeability in the refuse was assumed to be lognormally distributed because of the wide range of materials in landfills. The spatial correlation of the log gas permeability field was assumed to follow an anisotropic spherical semivariogram, with nugget $c_{0}=0.1$, variance $\sigma^{2}(\log k)=1.0$, and horizontal and vertical correlation lengths of $r_{x}=15.0$ and $r_{z}=1.5 \mathrm{~m}$, respectively. Because of the presence of isolated pores and water, the gas-filled porosity was $\phi_{g}=0.24$, which is smaller than the commonly reported total porosity ranging between 0.4 and 0.5 [Oweis et al., 1990]. One realization of the resulting log gas permeability field was presumed the true gas permeability field and is shown in Figure 24b. This realization was assumed to represent reality, and subsequent testing of the modified baro-pneumatic method was conducted in this domain.
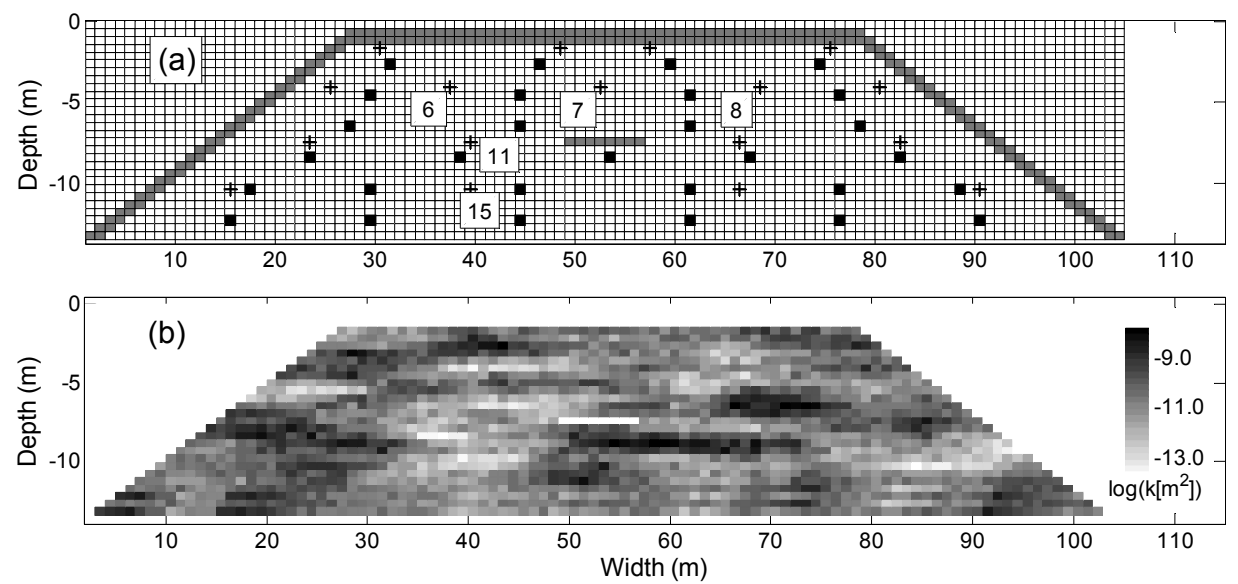

Figure 24. Schematic of the model domain for synthetic example. (a) Geometry of observation $(+)$ and pilot points $(-)$ and (b) the true horizontal gas permeability distribution in a logarithmic scale. The numbers in the box indicate observation points (e.g., OBS6).

The soil layer covering the surface of the domain represented an intermediate landfill cover that was in place for an extended period. Based on field measurements [Barlaz et al., 2004] and estimated values of the intrinsic permeability of intermediate covers [Spokas et al., 
2006; Schuetz et al., 2003; Barlaz et al., 2004; Abichou et al., 2006], the gas permeability of intermediate covers may range between $1.1 \times 10^{-15}$ and $1.1 \times 10^{-12} \mathrm{~m}^{2}$. In this study, an isotropic gas permeability of $k_{c}=5.0 \times 10^{-13} \mathrm{~m}^{2}$ and a gas-filled porosity of 0.3 were selected for the $0.96-$ $\mathrm{m}$ thick soil cover at the top boundary of the domain. A gas extraction well of dimensions $8.0 \times$ $0.48 \mathrm{~m}$ at the center of the landfill represented the pumping well constructed in the bioreactor landfill cell in California [Yazdani, 2008]. Water was assumed at residual saturation for each material type, which precluded water movement during the simulations; the residual water saturations for the refuse and the soil cover were assumed to be 0.2 and 0.15 , respectively.

The surface boundary condition for the pneumatic pump test was a constant atmospheric pressure of $1.013 \times 10^{5} \mathrm{~Pa}$. A no-flow boundary condition was assumed for the bottom boundary, representing a landfill liner. A homogeneous LFG generation rate of $25 \mathrm{~m}^{3} \operatorname{ton}^{-1} \mathrm{yr}^{-1}$ was assumed in the domain, which corresponds to relatively fresh waste $(<\sim 5 \mathrm{yr})$ with readily degradable refuse materials [Hoeks, 1983]. LFG was assumed to be $55 \% \mathrm{CH}_{4}$ and $45 \% \mathrm{CO}_{2}$ by mole fraction. The LFG extraction rate at the gas collection well was specified as $80 \%$ of the total LFG generation and was a specified mass flux boundary condition. While actual conditions at landfill pumping wells are more complicated and likely result in transient changes in vacuum and mass flux, these conditions were deemed representative and employed here. These boundary conditions were used to establish the steady-state gas field that served as the initial condition for the pneumatic pump test and baro-pneumatic test. Once steady-state initial conditions were established, the pneumatic pump test was simulated. A 6-hour period of barometric pressure changes were initiated at the landfill surface, and between hours 1 and 2 the pumping rate at the gas extraction well was increased by a factor of three over the rate used to collect LFG to generate short-term transient pressure changes. Figure 25 shows the barometric pressure 
changes, the status of the change in the pumping rate at the gas extraction well, and gas pressure data at two observation points. Barometric pressure variations matched data collected at the bioreactor landfill cell at the Yolo County Central Landfill. Synthetic gas pressure data were collected at 10 min intervals at the extraction well and at monitoring points $\left(N_{m}=17\right)$ distributed throughout the domain as shown in Figure 24a.

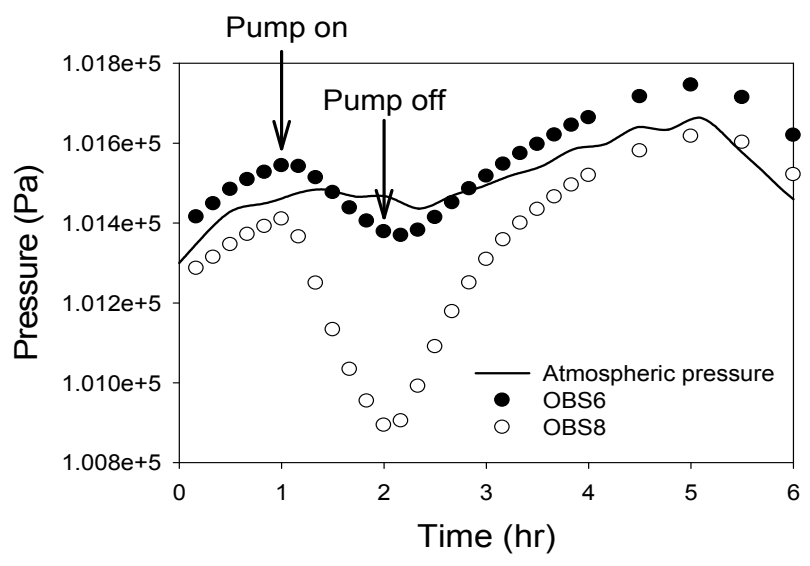

Figure 25. Variation of atmospheric pressure and the corresponding pressure responses at observation points OBS6 and OBS8 during the pneumatic pump test. The pumping schedule is also shown, where "Pump on" is when the gas extraction rate was increased by a factor of three and "Pump off" is when the gas extraction rate returned to $80 \%$ of the LFG generation rate of the landfill.

A four-day baro-pneumatic test followed the pumping test. Initial conditions were established following the same procedures for the pneumatic pump test, after which barometric pressures at the landfill surface were varied to match data collected over a four-day period at the Yolo County Central Landfill. The LFG extraction rate at the pumping well was kept constant, and gas pressures were recorded every $30 \mathrm{~min}$ at the observation points. Synthetic data from the pneumatic pump test and baro-pneumatic test represented the "true" response of the landfill.

(b) Heterogeneous permeability fields 
The pilot point method was employed to estimate landfill parameters using the pneumatic pump test data obtained from the simulated example. Four different cases were examined, each differing in the assumed gas-filled porosity and/or geostatistical model of the gas permeability field. For Case 1, only the mean values of the log gas permeabilities and the log gas permeability modifiers at the pilot points were fitted; the gas-filled porosity and the geostatistical model parameters were known. However, the correlation lengths were chosen to be three times larger than the actual values, i.e., $r_{x}=45$ and $r_{z}=4.5 \mathrm{~m}$. These larger correlation lengths were needed to reduce the number of pilot points (29), since 2 to 3 pilot points per correlation length are typically needed and the computational time for inversion increases proportional to the number of pilot points. Since no point measurements of gas permeability were available in this synthetic example, as is the case in most landfills, all pilot points were initially assumed to have log gas permeabilities equal to the initial estimates of the mean values.

With these specified conditions, the pilot point method was applied for Case 1 using the pneumatic pump test data. The LFG generation rate was fixed and not subjected to the inversion procedure. For all cases, the LFG generation rate was assumed equal to the flow rate at the gas extraction well, which was $80 \%$ of the true LFG generation rate specified in the synthetic example. The LFG generation rate was intentionally incorrectly specified to reflect the uncertainty in a priori estimates. Using this generation rate, the gas pressure at a given location would not be accurately reproduced by the model. This systematic error may lead to biased estimates of the gas permeability field because the inversion scheme attempts to minimize differences in the mean pressure rather than match the time lag and attenuation of pressure fluctuations. To resolve this issue and improve the fit, the pressure offsets for the synthetic data and Case 1 simulation at each observation point were matched, rather than the actual gas 
pressures. Here, the pressure offset at a particular observation point and measurement time is the difference between the pressure at this location and time and the initial pressure measured at this location. Case 1 pressure data were shifted by their respective offsets to match the synthetic pressure measurement data.

After estimating the gas permeability field with pneumatic pump test data, the baropneumatic test data were fitted. Here, the gas permeability field determined from the pilot point method was considered known, and the LFG generation rate was the only parameter estimated. The LFG generation rate was assumed spatially constant. Least-squares regression was used to provide the best match to transient pressure data at the observation points. This sequential fitting procedure using first the pneumatic pump test data followed by the baro-pneumatic test data was repeated until 20 realizations of the gas permeability field and matching LFG generation rate were estimated. For each realization, the random seed number was changed, whereas the same geostatistical model parameters and initial estimates for the mean values of the log gas permeabilities and the log gas permeability modifiers at the pilot points were used.

Cases 2-4 were similar to Case 1 except that less information was assumed known about the gas-filled porosity and inaccurate information was sometimes assumed for the gas permeabilities. In Case 2, only the gas-filled porosity was unknown. In Case 3, the gas-filled porosity was unknown, while the nugget and variance of the lognormal gas permeabilities were incorrectly specified. Case 4 was similar to Case 3, except that in addition the ratio of the correlation lengths was in error. The parameters specified for these cases are summarized in Table 5 . 
Table 5. Assumed parameters for various cases tested ${ }^{\mathrm{a}}$

\begin{tabular}{c|c|c|c|c|c|c|c}
\hline & $\log \overline{k_{x}}\left(\mathrm{~m}^{2}\right)$ & $\begin{array}{c}\log \overline{k_{z}} \\
\left(\mathrm{~m}^{2}\right)\end{array}$ & $\phi_{g}$ & $c_{0}$ & $\sigma^{2}(\log k)$ & $r_{x}$ & $r_{x} / r_{z}$ \\
\hline $\begin{array}{c}\text { True } \\
\text { model }\end{array}$ & -10.699 & -11.699 & 0.24 & 0.1 & 1.0 & 15.0 & 10.0 \\
\hline Case 1 & & & {$[-]$} & {$[-]$} & {$[-]$} & $\{45.0\}$ & {$[-]$} \\
Case 2 & $(-11.0)$ & $(-12.0)$ & $(0.32)$ & {$[-]$} & {$[-]$} & $\{45.0\}$ & {$[-]$} \\
Case 3 & & $(0.32)$ & $\{0.01\}$ & $\{0.9\}$ & $\{45.0\}$ & {$[-]$} \\
Case 4 & & & $(0.32)$ & $\{0.01\}$ & $\{1.2\}$ & $\{45.0\}$ & $\{8.3\}$ \\
\hline
\end{tabular}

a (-) are the initial value used for inversion; $\{-\}$ are the incorrect parameters assumed (fixed) in inverse simulation; [-] means that the true model value is assumed.

\section{(c) Layered permeability fields}

While landfills are known to be heterogeneous with spatially varying gas permeabilities [Jain et al., 2005], many modelers make the simplifying assumption that the landfill consists of multiple homogeneous zones [Jung et al., 2009], thus neglecting small-scale heterogeneity within a given layer. To evaluate the impact of this assumption on gas flow modeling and estimates of LFG generation rate, the baro-pneumatic method was applied assuming the test landfill was composed of layers containing one or two zones of homogeneous materials. Here, rather than employing the pilot point method, we estimated the gas permeabilities for each layer and the LFG generation rate in the domain using least squares regression.

To evaluate the significance of the assumed layering, three homogeneous layering conditions were examined: HO1, a single homogeneous layer for the entire domain; $\mathrm{HO}$, five homogeneous layers of equal thickness; and $\mathrm{HO} 3$, ten homogeneous layered zones of equal thickness, five on either side of the centerline of the model. The log horizontal and vertical gas permeabilities were determined for each layer by matching the pressure offsets between the synthetic data and each layered simulation at each observation point $\left(N_{m}=17\right)$ for the pneumatic pump test data. The gas-filled porosity was assumed known as in Case 1, and the LFG generation 
rate was then estimated following the procedures employed for the heterogeneous permeability fields.

\section{c) Results}

(1) Parameter Estimation

(a) Heterogeneous permeability fields

The mean $\log$ horizontal and vertical gas permeabilities and the log gas permeability modifiers at the pilot points were estimated for 20 realizations in Case 1 with results shown in Table 6. The mean values of the estimated horizontal and vertical gas permeabilities were 37 and $38 \%$ smaller, respectively, than the true values; the variance of the log gas permeability field was also $33 \%$ smaller than in the true model. These errors might result from the model domain, which was not large enough to accurately represent the intended variogram model. Despite differences between the true and estimated means and variance of the gas permeabilities, the match between observation data and simulation results at each observation point was excellent for all tested cases. 
Table 6. Comparison of model performance with heterogeneous gas permeability field ${ }^{\mathrm{a}}$

\begin{tabular}{c|c|c|c|c|c}
\hline & $\log \overline{k_{x}}\left(\mathrm{~m}^{2}\right)$ & $\log \overline{k_{z}}\left(\mathrm{~m}^{2}\right)$ & $\sigma^{2}(\log k)$ & $\begin{array}{c}\text { Objective } \\
\text { function } \\
\left(\times 10^{3}\right)\end{array}$ & $\begin{array}{c}\text { Gas } \\
\text { generation } \\
\text { rate }(\%)\end{array}$ \\
\hline $\begin{array}{c}\text { True } \\
\text { model }\end{array}$ & -10.767 & -11.767 & 1.156 & & 100 \\
\hline Case 1 & $\begin{array}{c}-10.966 \\
( \pm 0.256)\end{array}$ & $\begin{array}{c}-11.975 \\
( \pm 0.285)\end{array}$ & $\begin{array}{c}0.780 \\
( \pm 0.263)\end{array}$ & $2.4( \pm 1.7)$ & $97.9( \pm 3.6)$ \\
\hline Case 2 & $\begin{array}{c}-10.820 \\
( \pm 0.166)\end{array}$ & $\begin{array}{c}-12.081 \\
( \pm 0.186)\end{array}$ & $\begin{array}{c}0.744 \\
( \pm 0.207)\end{array}$ & $1.7( \pm 0.8)$ & $99.1( \pm 4.1)$ \\
\hline Case 3 & $\begin{array}{c}-10.849 \\
( \pm 0.184)\end{array}$ & $\begin{array}{c}-12.065 \\
( \pm 0.208)\end{array}$ & $\begin{array}{c}0.732 \\
( \pm 0.281)\end{array}$ & $1.3( \pm 0.7)$ & $98.2( \pm 4.9)$ \\
\hline Case 4 & $\begin{array}{c}-10.872 \\
( \pm 0.215)\end{array}$ & $\begin{array}{c}-12.063 \\
( \pm 0.258)\end{array}$ & $\begin{array}{c}0.741 \\
( \pm 0.180)\end{array}$ & $1.5( \pm 0.8)$ & $99.0( \pm 3.9)$ \\
\hline
\end{tabular}

\footnotetext{
${ }^{a}$ Values reported for Cases $1-4$ are averages of 20 different realizations; values in parentheses are the standard deviations.
}

Figure 26a presents a single realization of the estimated permeability field for Case 1 simulations. The estimated permeability field does not reproduce all features of the actual permeability field shown in Figure 24b: local heterogeneity was smoothed out, which was expected since correlation lengths were assumed to be three times larger than those in the true model. However, the overall spatial structure of the gas permeability field was captured well. For instance, the relatively low gas permeability zone on the west side of the pumping well in Figure 1b was also observed in Figure 26a. Thus, the pilot point method captured the major heterogeneities in the gas permeability field that influenced gas flow patterns. The average and standard deviations of the 20 estimated permeability fields are shown in Figure 26b and 26c, respectively. 

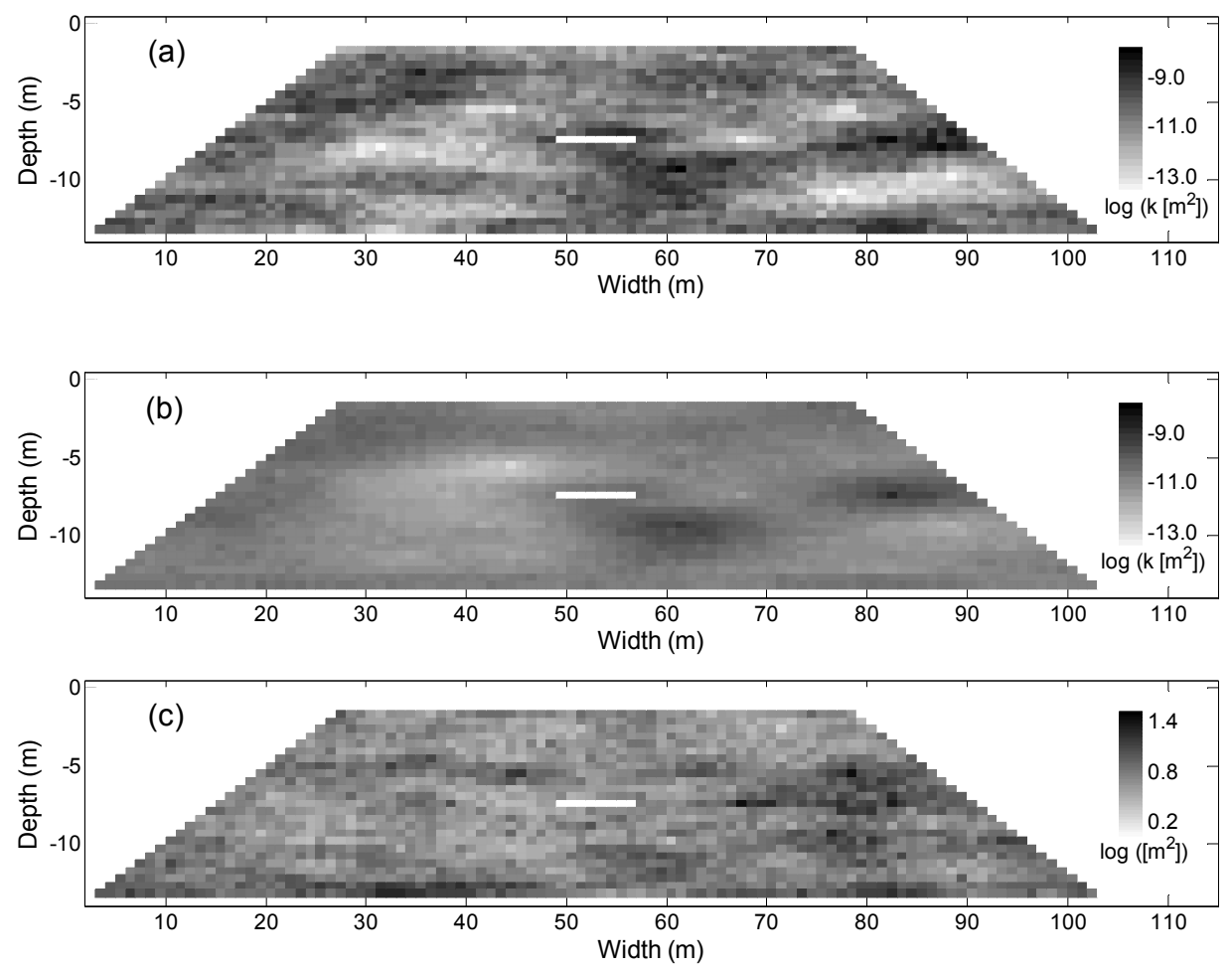

Figure 26. Estimated horizontal gas permeability field when the log gas permeability was the only unknown parameter: (a) one realization among the 20 estimated gas permeability fields, (b) the mean of the predicted distributions, and (c) the standard deviation of the predicted distributions. The results are shown in a logarithmic scale.

Assuming the gas permeability field estimated from the pneumatic pump test is fixed, the LFG generation rate was estimated from the baro-pneumatic test. The fit between the observed and the simulated gas pressures was excellent at every observation point. Data are shown in Figure 27 for observation points OBS6, OBS11, and OBS15. Note that the average pressure at the deeper observation point (OBS11) was lower than that at the shallow observation point (OBS6) due to constant pumping at the extraction well during the test. The pressure fluctuations at all observation points follow variations in the barometric pressure. The average estimated LFG generation rate for 20 realizations for Case 1 was $98 \pm 4 \%$ of the true value, demonstrating the capability of the estimated gas permeability fields to capture gas flow patterns and pressure distribution. Here and elsewhere, \pm values represent the standard deviation of the 20 realizations. 


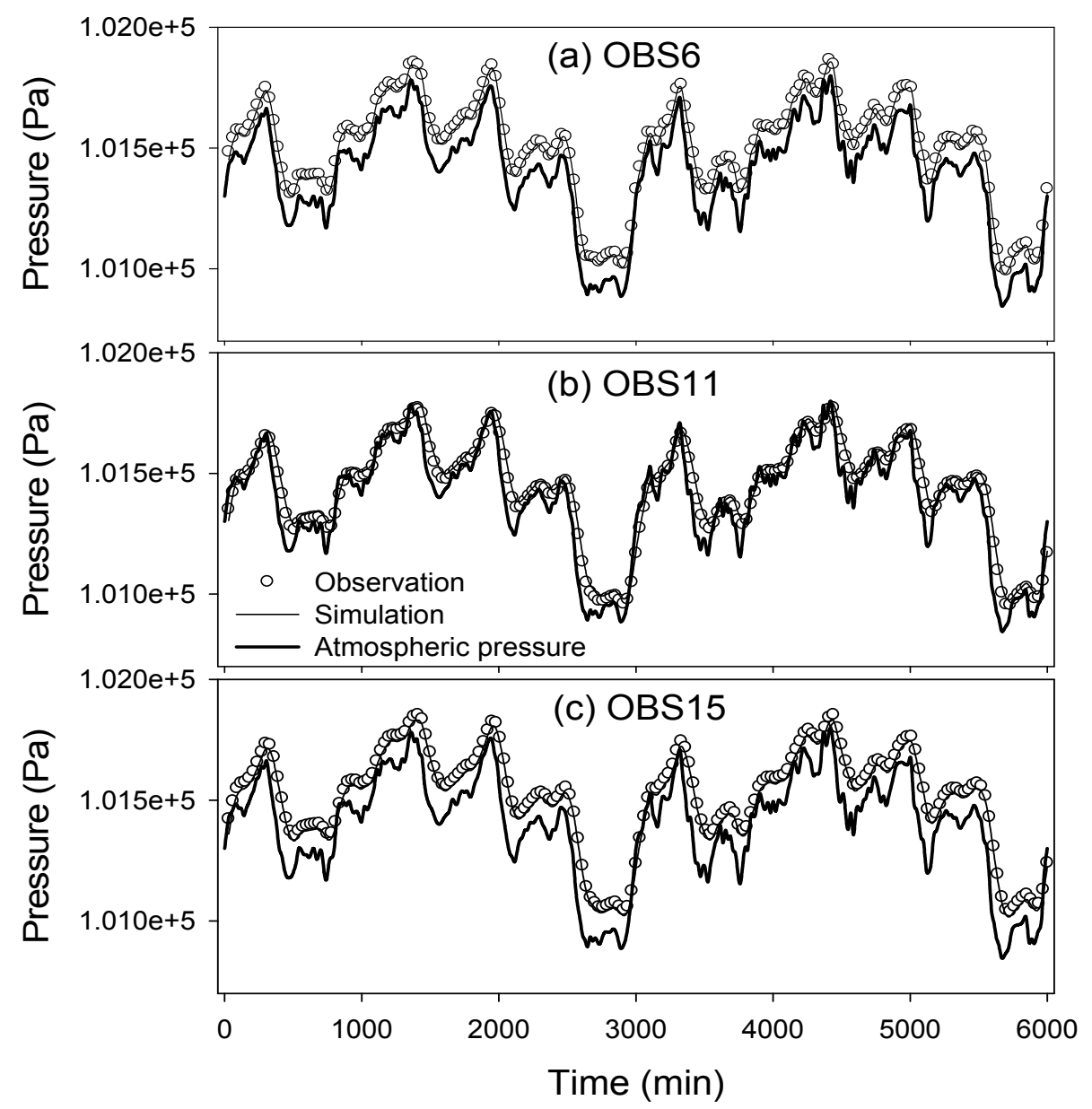

Figure 27. Match of pneumatic pressures during the baro-pneumatic test at different locations in Case 1 for one example realization: (a) OBS6, (b) OBS11, and (c) OBS15.

For Cases $2-4$, the gas-filled porosity was now unknown in addition to the mean log gas permeabilities and the log gas permeability modifiers at the pilot points. In addition, incorrect information was sometimes assumed for the semi-variogram describing spatial variation of the gas permeabilities (see Table 5). The results of these cases are shown in Table 6. The difference of the estimated mean horizontal and vertical gas permeabilities between Case 1 and the other cases (Cases 2-4) was not statistically significant $(p<0.05)$, with the exception of the mean horizontal gas permeability in Case 2. The difference in the objective functions between the 
cases was also not significant (see Table 6), and the match between observed and simulated data at each observation point was excellent for all realizations for each case.

The vertical profiles of the estimated horizontal gas permeability fields for Cases $2-4$ at two locations $(X=35$ and $70 \mathrm{~m})$ were compared with those for Case 1 and are shown in Figure 28 along with the true gas permeability field. The results for Cases $1-4$ were obtained through inversion with the same seed numbers. As also observed in Figure 26a, the accuracy of the estimated gas permeabilities varied depending on location and depth. The difference between the estimated and true values ranged from $<1$ to $23 \%$ at $\mathrm{X}=35 \mathrm{~m}$ (Figure 28a), and from $<1$ to $34 \%$ at $\mathrm{X}=70 \mathrm{~m}$ (Figure 28b). However, the differences between Case 1 and the other cases (Cases $2-4)$ were minor. The estimated gas-filled porosities were also very similar between the cases: $0.254( \pm 0.016)$ for Case 2, $0.251( \pm 0.018)$ for Case 3, and $0.254( \pm 0.015)$ for Case 4, which are only $5-6 \%$ higher than the true gas-filled porosity. The estimated LFG generation rates for Cases $2-4$ were almost identical to the true value $(98-99 \%)$ and thus of similar accuracy as the estimate for Case 1 (see Table 6). Thus, while the assumed errors in the semivariogram model for gas permeabilities for Cases 3 and 4 certainly affected the estimated gas permeability field, the impact of these errors on the estimated LFG generation rate was minor. 


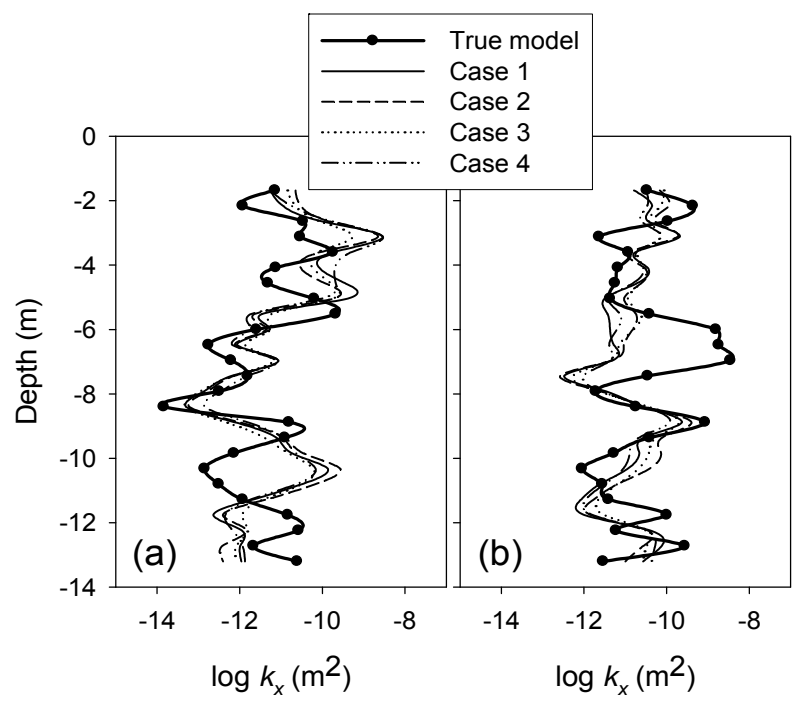

Figure 28. Vertical profiles of the estimated horizontal gas permeability fields at (a) $X=35 \mathrm{~m}$ and (b) $\mathrm{X}=70 \mathrm{~m}$ for one realization for each case using the same seed number.

\section{(b) Layered permeability fields}

In previous applications of the baro-pneumatic method, the horizontal and vertical gas permeability of the refuse was often assumed uniform, unless data from pneumatic pump tests indicated decreases (or sometimes increases) of gas permeability with depth, in which case layered systems were assumed [Bentley et al., 2003]. The impact of these simplifying assumptions for spatially random conditions was analyzed with the assumption that the model domain for the synthetic example was composed of homogeneous layers: HO1 (one layer), HO2 (five layers), and HO3 (10 layered zones).

When the domains were assumed to be composed of layers containing one or two zones of homogeneous materials, the goodness of fit depended on the number of homogeneous zones. As the number of homogeneous zones increased the match between the observation data and the simulation results improved; the minimum value of the objective function decreased by more than a factor of 3 between $\mathrm{HO} 1$ and HO3, as shown in Table 7. Only for HO3 was the model able to match the observation data reasonably well at the monitoring points. To achieve 
satisfactory agreement between measured and simulated data, the domain had to become rather heterogeneous with 10 zones each with different gas permeabilities, indicating the importance of appropriate estimation of the heterogeneous gas permeabilities in this domain.

Table 7. Comparison of model performance with homogeneous gas permeability approximation

\begin{tabular}{c|c|c|c|c}
\hline & $\log \overline{k_{x}}\left(\mathrm{~m}^{2}\right)$ & $\log \overline{k_{z}}\left(\mathrm{~m}^{2}\right)$ & $\begin{array}{c}\text { Objective } \\
\text { function }\left(\times 10^{3}\right)\end{array}$ & $\begin{array}{c}\text { Gas generation } \\
\text { rate }(\%)\end{array}$ \\
\hline $\begin{array}{c}\text { True } \\
\text { model }\end{array}$ & -10.767 & -11.767 & & 100 \\
\hline HO1 & -10.895 & -12.168 & 29.9 & 109.3 \\
\hline HO2 & -10.288 & -11.840 & 23.2 & 110.3 \\
\hline HO3 & -10.990 & -11.938 & 9.0 & 93.3 \\
\hline
\end{tabular}

While the match of the gas pressure field was clearly much better for the pilot point method than simulations $\mathrm{HO} 1-\mathrm{HO}$, the fit of the LFG generation rate was within $10 \%$ of the true value when layered heterogeneity was assumed. Thus, while the simplified approach assuming layered heterogeneity may result in poor fits to gas pressure data, estimates of the LFG generation rate might be acceptable. The assumption of layered heterogeneity may be required in field cases where few observation points are available.

\section{(2) Performance of Calibrated Models}

To evaluate the utility of the modified baro-pneumatic method with the pilot point inversion technique, the quality of gas flow model predictions should also be examined [RamaRao et al., 1995; Keidser and Rosbjerg, 1991]. Performance of the calibrated models was assessed by evaluating their ability to predict variations of gas pressures during the pneumatic pump tests and tracer gas breakthrough curves at the gas extraction well. The 20 estimated 
models for Case 1 were used as representative examples that utilized the pilot point method and were compared with predictions from the three layered heterogeneity models (HO1 - HO3).

\section{(a) Pressure distributions}

Results from the pneumatic pump test are compared with the true pressure distributions from the synthetic example at two different times, the beginning and the end of the pumping period, in Figure 29. The pressure distributions for the synthetic example are shown in Figure 29a, while Case 1 realizations with the minimum and maximum objective functions are shown in Figure $29 \mathrm{~b}$ and $29 \mathrm{c}$, respectively. The predicted pressure distributions agreed reasonably well with the true pressure fields.

When layered heterogeneity was assumed, the model-predicted gas pressure fields deviated more significantly from true conditions than Case 1 simulations, as shown in Figure 30 for $\mathrm{HO} 1$ and $\mathrm{HO} 3$. This was particularly true for $\mathrm{HO} 1$, where a single homogeneous layer was assumed for the entire domain. While estimates of the LFG generation rate for HO1-HO3 differed from the true value by at most $10 \%$, matches to gas pressure distributions were poorer. 

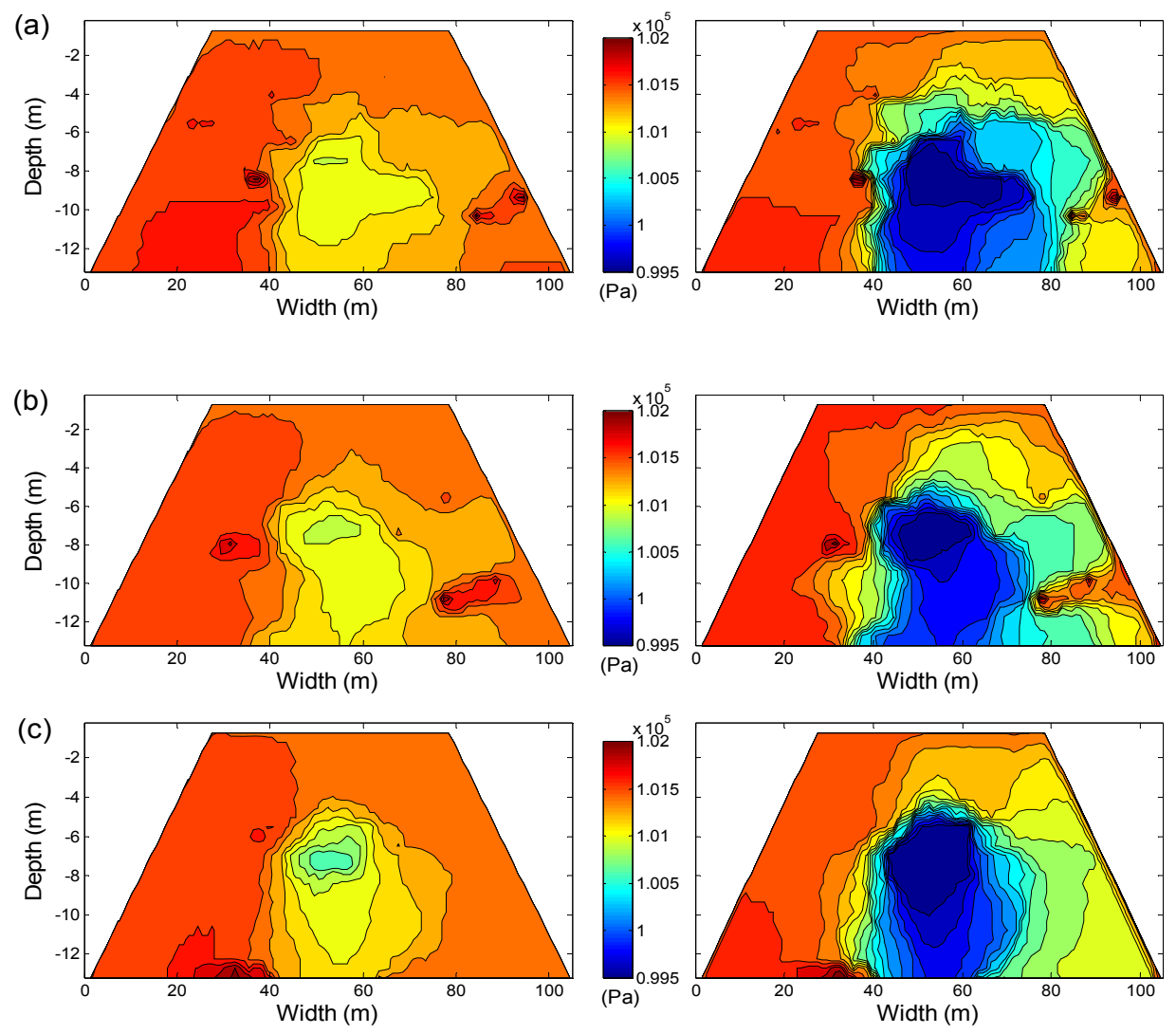

Figure 29. Pressure distributions at the beginning (left column) and the end (right column) of the pumping period in which the flow rate was tripled in the true model (a), and predicted pressure distributions for the heterogeneous case with the (b) minimum and (c) maximum objective function among 20 different inversions for Case 1. Contour lines delineate changes in pressure of $125 \mathrm{~Pa}$.

\section{(b) Tracer breakthrough curves}

Two gas tracer tests were conducted in the domain to evaluate the utility of the modified baro-pneumatic method to capture gas flow patterns. In each tracer test, a 10-minute slug of a conservative tracer was injected into a single location within the refuse, OBS6 for Test 1 and OBS8 for Test 2, and then tracer gas concentrations were measured at the gas extraction well. Figure 31 presents the true and the predicted breakthrough curves (BTCs) at the gas extraction well for Case 1 and the layered heterogeneity simulations. The accuracy and precision of the predictions varied depending on the location of tracer injection. For Case 1, the predicted BTCs were in better agreement with the true BTCs for Test 1; the uncertainty bounds were wider for 
Test 2, indicating the difficulty of predicting the entire heterogeneous structure of the refuse with the baro-pneumatic method. However, the predicted BTCs for Case 1 did envelope the true BTC within the uncertainty bounds for both tracer tests. The situation for the layered heterogeneity simulations was in general poorer than for Case 1, with predictions poorer than the mean BTCs for Case 1.
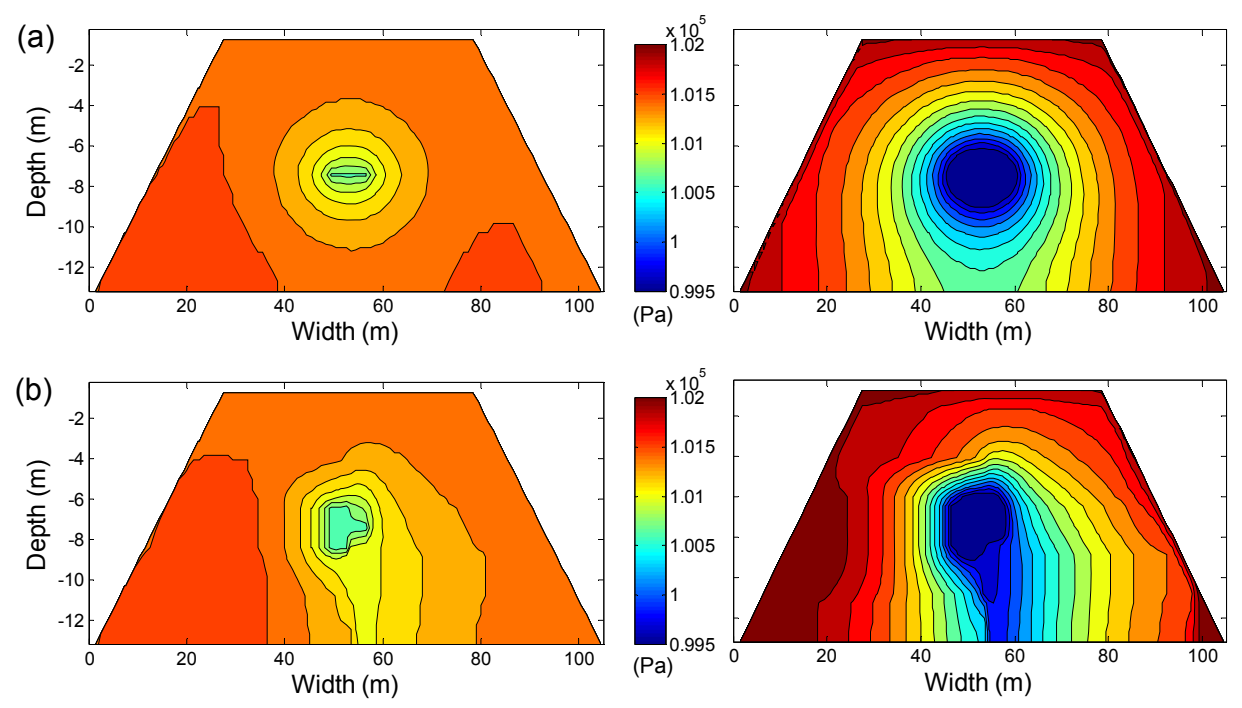

Figure 30. Pressure distributions at the beginning (left column) and the end (right column) of the pumping period in which the flow rate was tripled: (a) HO1 and (b) HO3. . Contour lines delineate changes in pressure of $125 \mathrm{~Pa}$. 

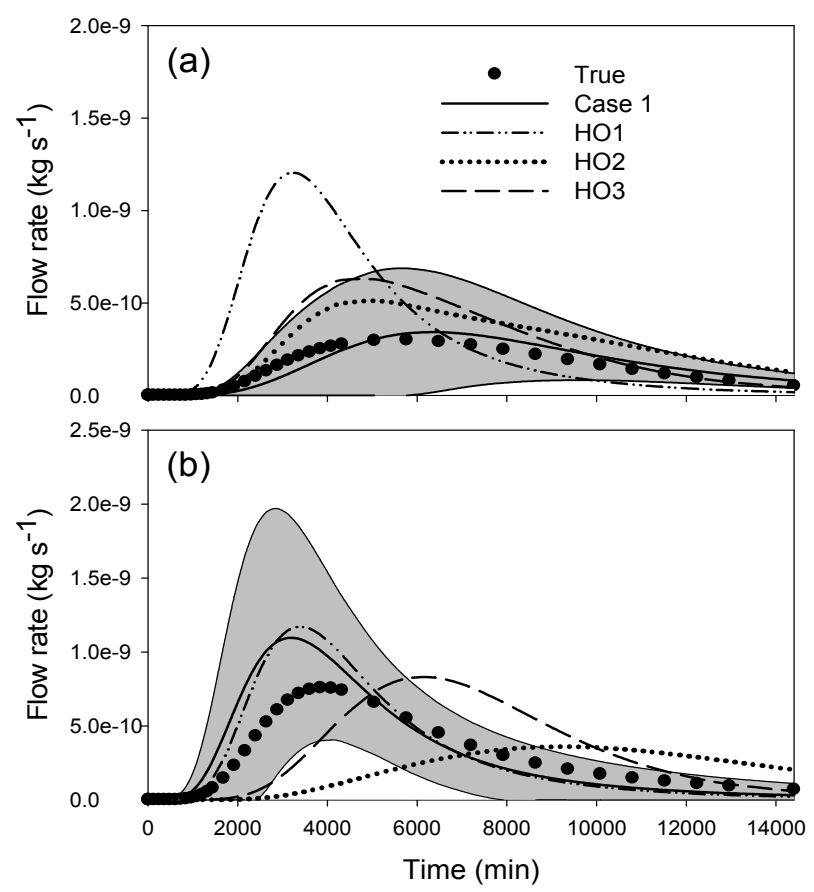

Figure 31. Predicted BTCs for (a) Test 1 and (b) Test 2. True BTCs are shown with solid circles. The mean predicted BTCs in Case 1 are shown with thick solid lines, and the prediction bounds (the mean surface $+/-2$ times the standard deviations) are shown with shade.

\section{d) Conclusions}

LFG collection systems have been used to reduce $\mathrm{CH}_{4}$ emissions and provide a renewable energy source. However, the efficiency of LFG collection systems is largely unknown, because these systems have been designed and operated without careful assessment of LFG generation rates. In addition, a poor understanding of gas flow patterns in the refuse hinders optimal LFG collection practices.

The baro-pneumatic method is a promising technique for estimating LFG generation rates. It involves pneumatic pump tests and baro-pneumatic tests. The method can be used to create a gas flow model for individual landfills, which may be used to design or improve existing LFG collection systems. While the method holds much promise, there is considerable uncertainty about its utility in heterogeneous refuse, where the gas permeability field varies significantly in space. An additional limitation is that the method provides only a snapshot of LFG generation 
rate and gas flow patterns. Actual generation rate and flow patterns will vary with time as refuse degrades and refuse moisture contents change in response to climatic conditions. Thus, it may be necessary to combine results from the baro-pneumatic method with other models (e.g., LandGEM [USEPA, 2005] to predict temporal variability of LFG generation rate, or multiple applications of the baro-pneumatic method might be needed through time. Based on prior experience applying the baro-pneumatic method at several landfills, the collection of the necessary field data appears feasible for most sites [Bentley et al., 2003].

Based on the simple example in this study, if the gas permeability field heterogeneity is layered, the baro-pneumatic method cannot accurately reproduce the gas pressure field. Thus, the simplifying assumption of layered heterogeneity may be at odds with this method of estimating gas flow patterns in some heterogeneous landfills. However, estimates of the LFG generation rate with such "inaccurate" gas permeability fields are surprisingly good - less than $10 \%$ error in this study.

To apply the baro-pneumatic method to heterogeneous refuse, an inversion approach using the pilot point method was evaluated. In this modified baro-pneumatic method, the heterogeneous structure of the gas permeabilities was captured well using the pilot point method and the pneumatic pump test data: the fit to simulated data was excellent. The LFG generation rate was also well matched, with errors less than $2 \%$.

Despite the promising results from this work, the efficacy of the baro-pneumatic method with the pilot point technique might be sensitive to the spatial variability of the gas permeability field, the availability of observation data, and the location of monitoring points, factors not varied in this work. This study also only examined two-dimensional domains, while the modified 
baro-pneumatic method will be employed in three-dimensional systems. Future work should focus on the utility of the baro-pneumatic method with the pilot point technique in such settings.

\section{Performance of Near-Surface High Permeability Layer and Automated System for Landfill Gas Collection}

\section{a) Performance of Near-Surface High Permeability Layer}

The near-surface permeable layer was constructed on a new anaerobic test cell at the Yolo County Central Landfill. Sketches of this permeable layer are shown below in Figures 31 and 32. Initial tests of the near-surface high permeability layer indicated that air entered the layer and then propagated quickly to the gas collection well. This layer was intended to distribute gas suction evenly across the landfill surface, providing a uniform gas composition. Thus, measurements of air in the gas collection well indicated that the near-surface high permeability layer was not performing as designed. Subsequent surface scans of the landfill cell indicated a couple of local "hot spots" on the side slopes to this cell in the region where the permeable layer was terminated. We believe these hot spots formed because the intermediate cover soil was too thin along the side slopes.

To address this situation, in fall 2009 additional dirt was placed on the side slopes in the region where the hot spots were located. Photographs of this construction activity are shown in Figure 33 below. 


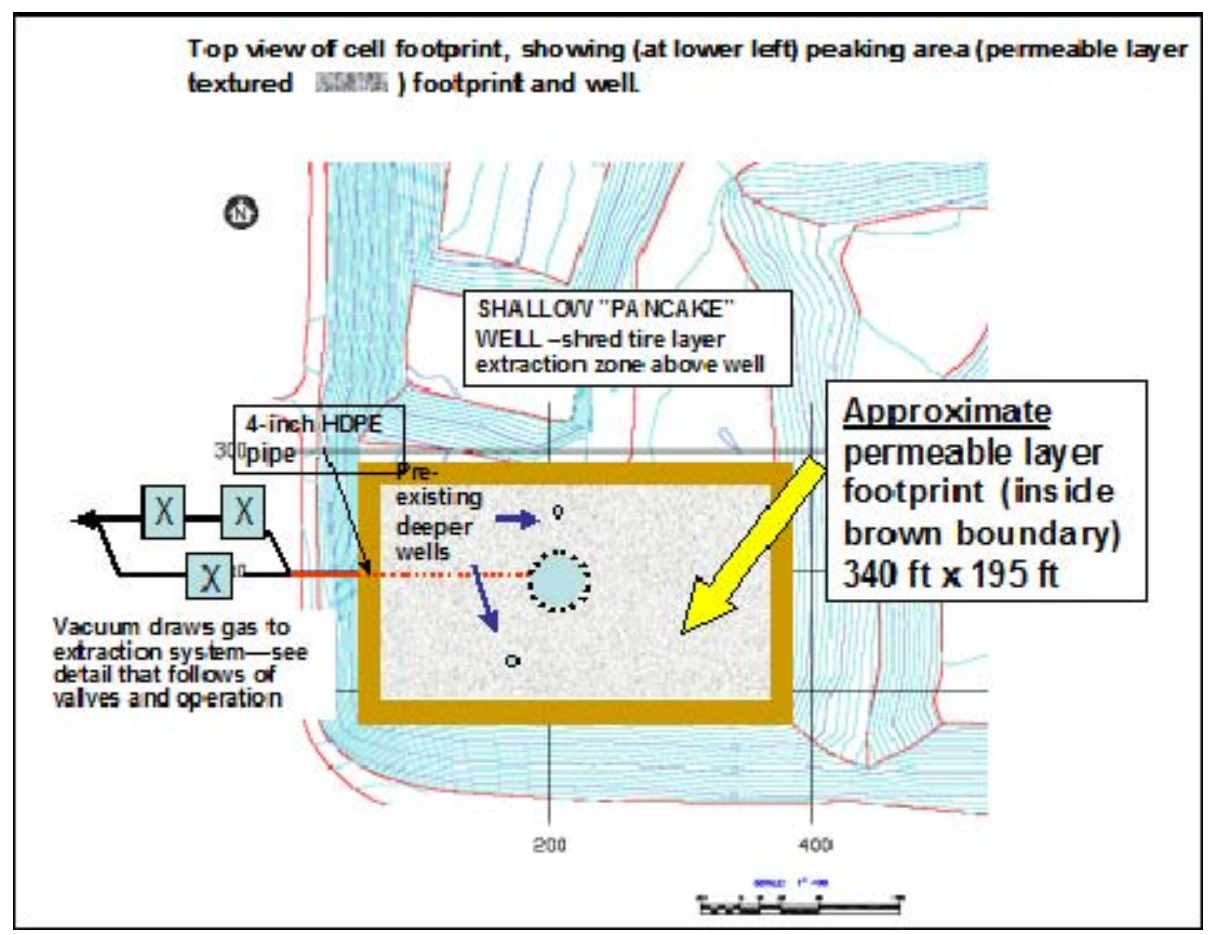

Figure 32. Top view of well design and permeable layer components.

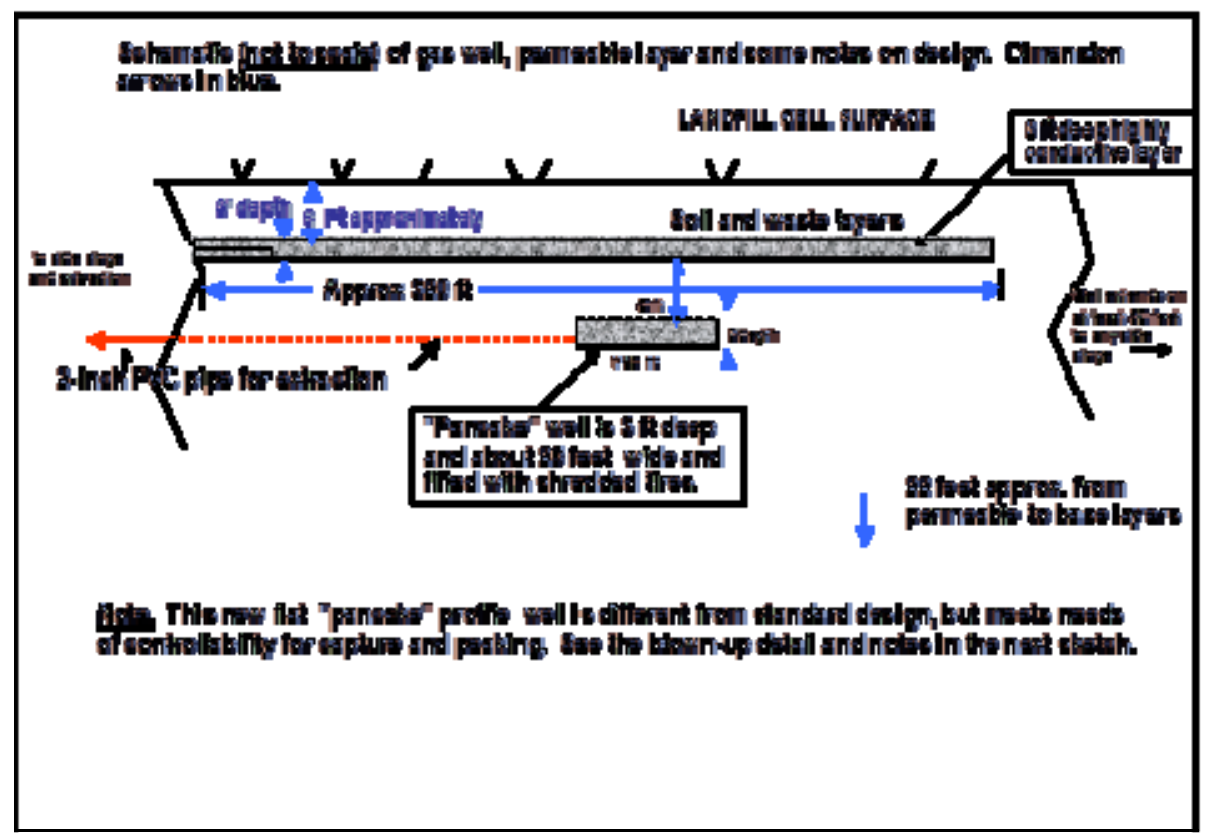

Figure 33. Well design and permeable layer components in profile view. 


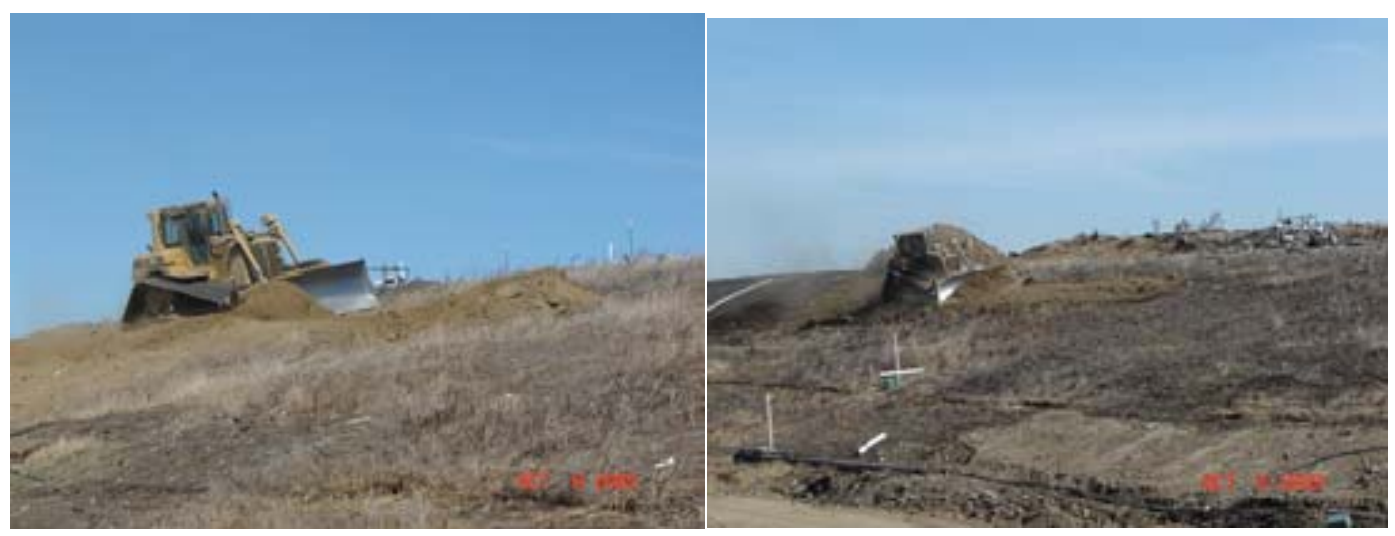

Figure 34. Placement of additional cover soil on side slope of anaerobic test cell with near-surface high permeability layer.

Tests of the "fixed" landfill and the IBM-IS control of gas collection wells were then conducted. These tests involved evaluating the utility of the near-surface high permeability layer, which was installed in this landfill cell during construction, for distributing the gas suction provided by a landfill gas collection well. For this test, we installed probes at 15 locations along the landfill surface. Each probe extended through the intermediate landfill soil cover into the underlying waste. Probe locations are shown in Figure 35 with an "X". 


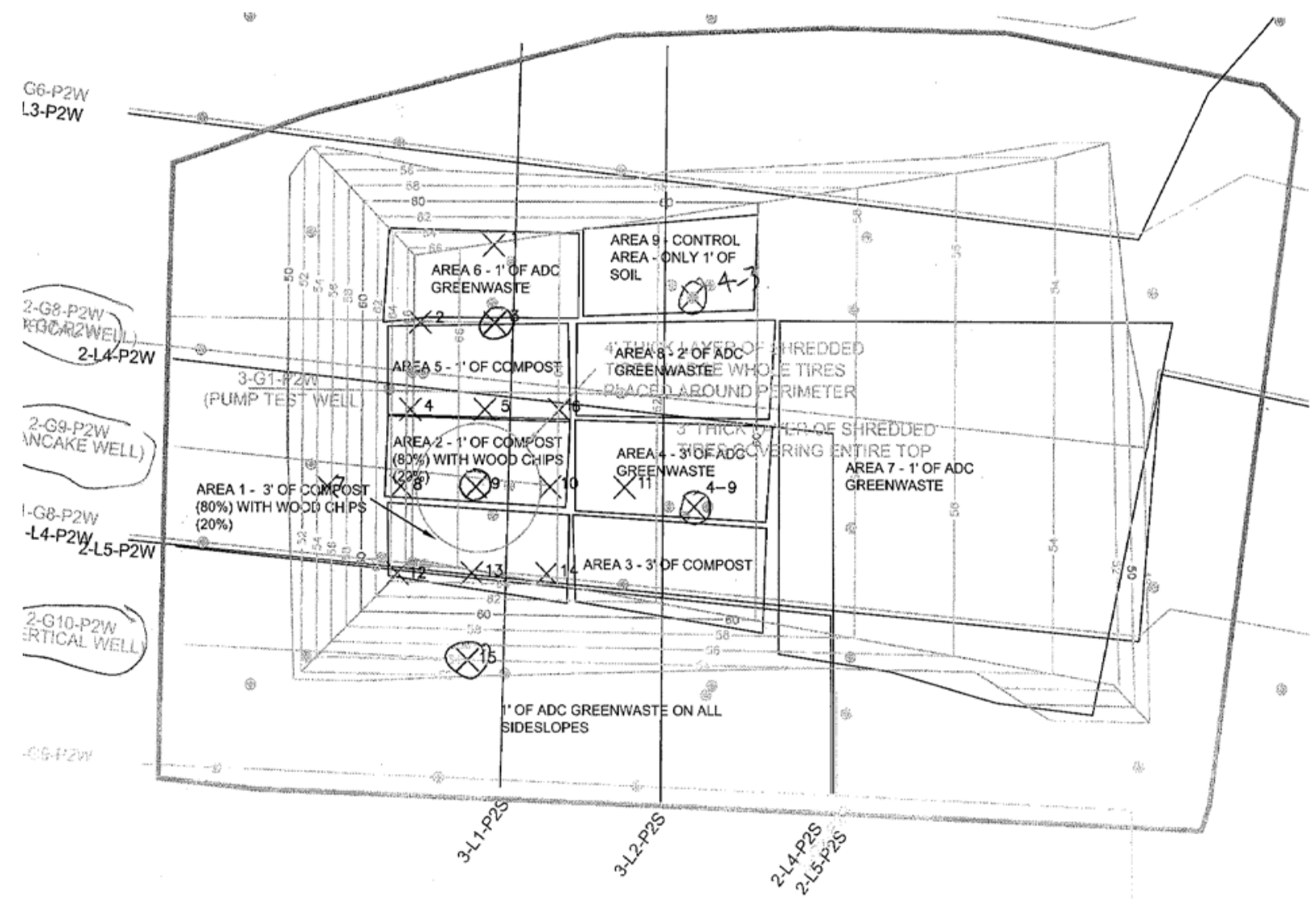

Figure 35. Locations of surface probes for measuring gas pressure at the top surface of the landfill beneath the cover soil. Probe locations are indicated by " $\mathrm{X}$ " and are numbered 1-15.

A series of pump tests were conducted from a well (2G9) located vertically beneath probe location "9" in the center of the landfill cell. The outline of this well is indicated by the circle drawn around probe location "9" in Figure 35. The gas extraction rate from this well was varied systematically, set at either 0 SCFM or 87 SCFM, and then gas pressures beneath the landfill cover soil at the " $\mathrm{X}$ " locations were measured. Results from this test are presented in Table 8 below. 
Table 8. Performance of near-surface high permeability layer for distributing gas suction.

\begin{tabular}{|c|c|c|c|c|}
\hline Probe & $\begin{array}{c}\text { Probe Depth } \\
\text { (inches) }\end{array}$ & $\begin{array}{c}\text { Gas Pressure with } \\
\text { 2G9 Well “On” } \\
\text { (inches of water) }\end{array}$ & $\begin{array}{c}\text { Gas Pressure } \\
\text { with 2G9 Well } \\
\text { “Off” } \\
\text { (inches of water) }\end{array}$ & $\begin{array}{c}\text { Change in Gas } \\
\text { Pressure from 2G9 } \\
\text { Pumpage } \\
\text { (inches of water) }\end{array}$ \\
\hline 1 & 18 & 0.001 & 0.345 & -0.344 \\
\hline 2 & 29 & -0.6 & 0.071 & -0.671 \\
\hline 3 & 29 & 0.01 & 0.224 & -0.214 \\
\hline 4 & 43 & 0.01 & 0.258 & -0.248 \\
\hline 5 & 27 & 0.01 & 0.245 & -0.235 \\
\hline 6 & 53 & -0.007 & 0.129 & -0.136 \\
\hline 7 & 74 & -0.008 & 0.167 & -0.175 \\
\hline 8 & 44 & 0 & 0.12 & -0.12 \\
\hline 9 & 31 & 0.012 & 0.295 & -0.283 \\
\hline 10 & 51 & 0.011 & 0.034 & -0.023 \\
\hline 11 & 42 & -0.333 & -0.313 & -0.02 \\
\hline 12 & 67 & -0.26 & -0.278 & -0.018 \\
\hline 13 & 62 & 0.002 & 0.015 & -0.027 \\
\hline 14 & 50 & 0.02 & 0.047 & -0.593 \\
\hline 15 & 55 & -0.838 & -0.245 & \\
\hline
\end{tabular}

There are several important points to be made from these data. First, with the well "off" the gas pressures should be larger than atmospheric and thus positive numbers. This was true for all probes, with the exception of probes 11,12 , and 15 . These probes showed negative pressures even with the well 2G9 well off. We speculate that methane oxidation in the cover soil and upper regions of the waste was significant and caused a small amount of suction. At these locations, gas pressures were affected both by the gas collection well and methane oxidation. Because the impact of methane oxidation was so significant, we postulate that using gas pressures at these locations to infer the behavior of the near-surface high permeability layer is problematic.

If the data from probes 11,12 , and 15 , are neglected, the average change in gas pressure at the 13 probes caused by $2 \mathrm{G} 9$ pumpage was -0.20 inches of water with a standard deviation of 0.18 inches of water. More importantly, there was no noticeable increase in gas suction right 
above $2 \mathrm{G} 9$ at probes $5,8,9$, and 10 . The average gas pressure at these locations was -0.16 inches of water. Thus, the near-surface high permeability layer distributed the gas suction from 2G9 across the landfill surface. There is one noticeable outlier to this trend, though, and this is probe 2 , where pumpage from $2 \mathrm{G} 9$ caused gas a change in gas pressure of -0.67 inches of water. This data suggests that $2 \mathrm{G} 9$ has a strong connection to this region of the cover, although probe 2 is located far from 2G9 (see Figure 35). This is an unusual result and requires further investigation.

The results from these field tests indicate that for the most part the near-surface high permeability layer is performing as designed. Suction from a gas collection well beneath this layer is distributed fairly evenly across the landfill surface. There was not a measureable increase in suction above the gas collection well, which is expected for standard landfill covers (see Figure 17).

\section{b) Performance of Automated System for Gas Collection}

Methane emission data from landfills have shown that emissions are significantly related to changes in atmospheric pressure. Here, gas collection wells are often "set" with fixed valve openings. As barometric pressures change, the flow rates through each gas collection well also change in response to the difference in suction pressure at the gas collection well and the background atmospheric pressure. Thus, the gas collection from any individual well will change with atmospheric conditions. Because the landfill gas generation rate is much less variable in time, this results in landfill gases that are not collected and instead are emitted to the atmosphere during periods of rapid drop in barometric pressure.

To overcome this situation, we constructed and tested an automatic system for intelligently controlling the landfill gas collection. We postulated that with standard operations 
landfill gas collection would vary significantly with time at any well, due to both changes in barometric pressure and suction in the main header gas collection line due to operational issues at landfill gas-to-energy plants. The automatic control system was installed on well 2G9 in the new anaerobic test cell that was constructed in part with funds from this project. The well and landfill cell are shown in Figure 35.

Tests were conducted in Spring/Summer 2010 using the new automated well control system. This system has three operational settings: setting 1 with the valve at a fixed setting, which is standard landfill practice; setting 2 with the valve controlled by a flow controller set to keep the gas flux through the well at a fixed rate; and setting 3 with the valve controlled to fix the difference in atmospheric pressure and suction pressure at the well constant. Gas collection well $2 \mathrm{G} 9$ was operated with all three configurations for approximately a one-week period for each well.

The results from this operation are shown in Figures 36 and 37 for settings 1 and 2, respectively. From top to bottom, the atmospheric pressure, total gas flow rate collected in the main header line in this region of the landfill, flow rate from $2 \mathrm{G} 9$, and gas suction in well $2 \mathrm{G} 9$ are shown. Note first the large temporal variation in gas flow rate in the main header. This flow rate is changing because of barometric pressure changes and operational changes at the landfill gas-to-energy facility. When a fixed setting of the valve is used to control gas flow from $2 \mathrm{G} 9$, the landfill gas collection rate varies significantly with time. See yellow data in Figure 36 . The dips in gas collection recorded in the main header line correspond to dips in gas collection at 2G9.

When the well is operated with an system to maintain a fixed gas flow rate, the situation is very different. The yellow gas flow data shown in Figure 37 are nearly constant, despite the 
wide variation in gas flow in the main header line. Thus, the automatic control of this well using setting 2 was able to maintain a near constant rate of landfill gas collection.

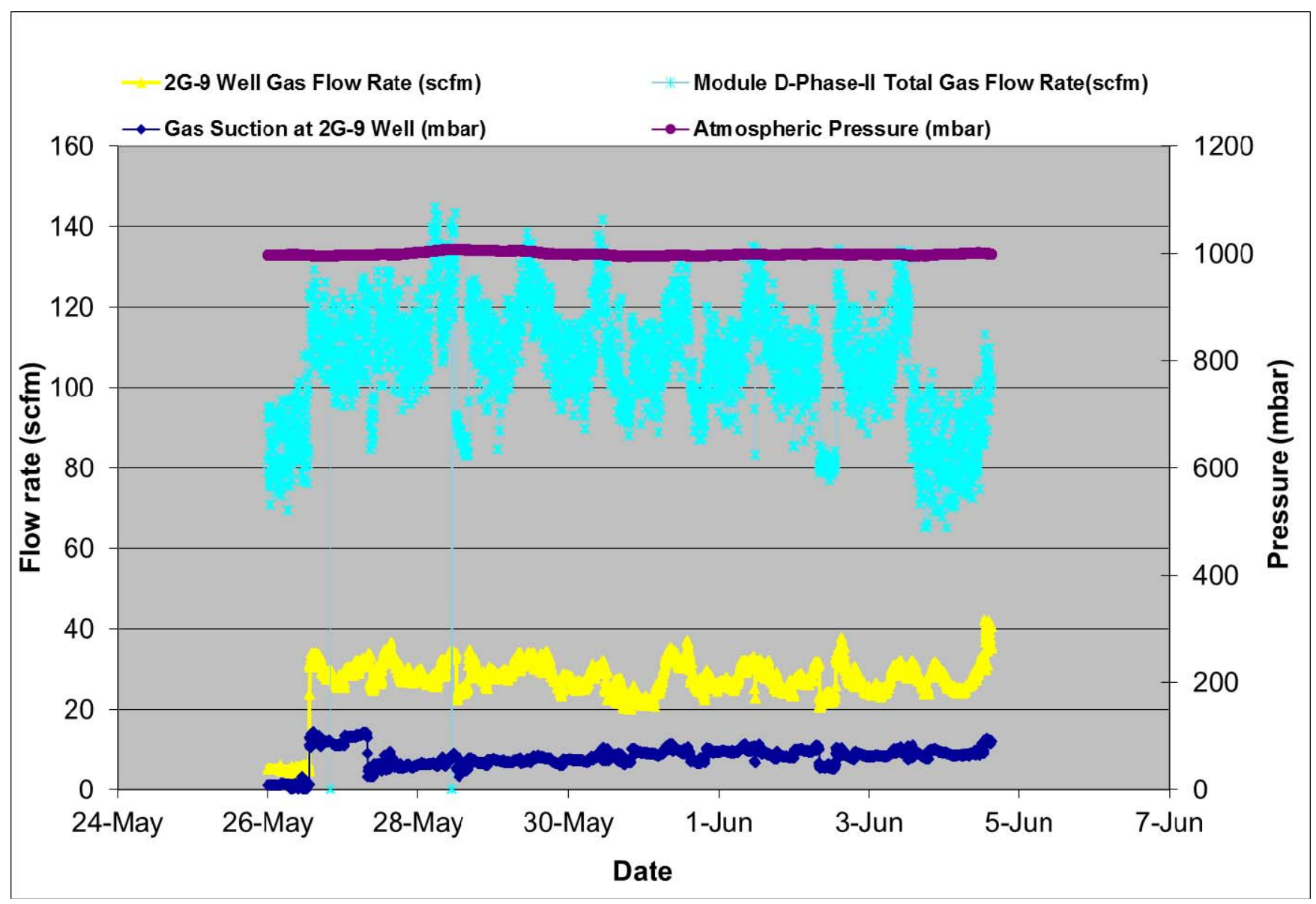

Figure 36. Data from setting 1 for control of gas collection well 2G9: fixed valve position. 


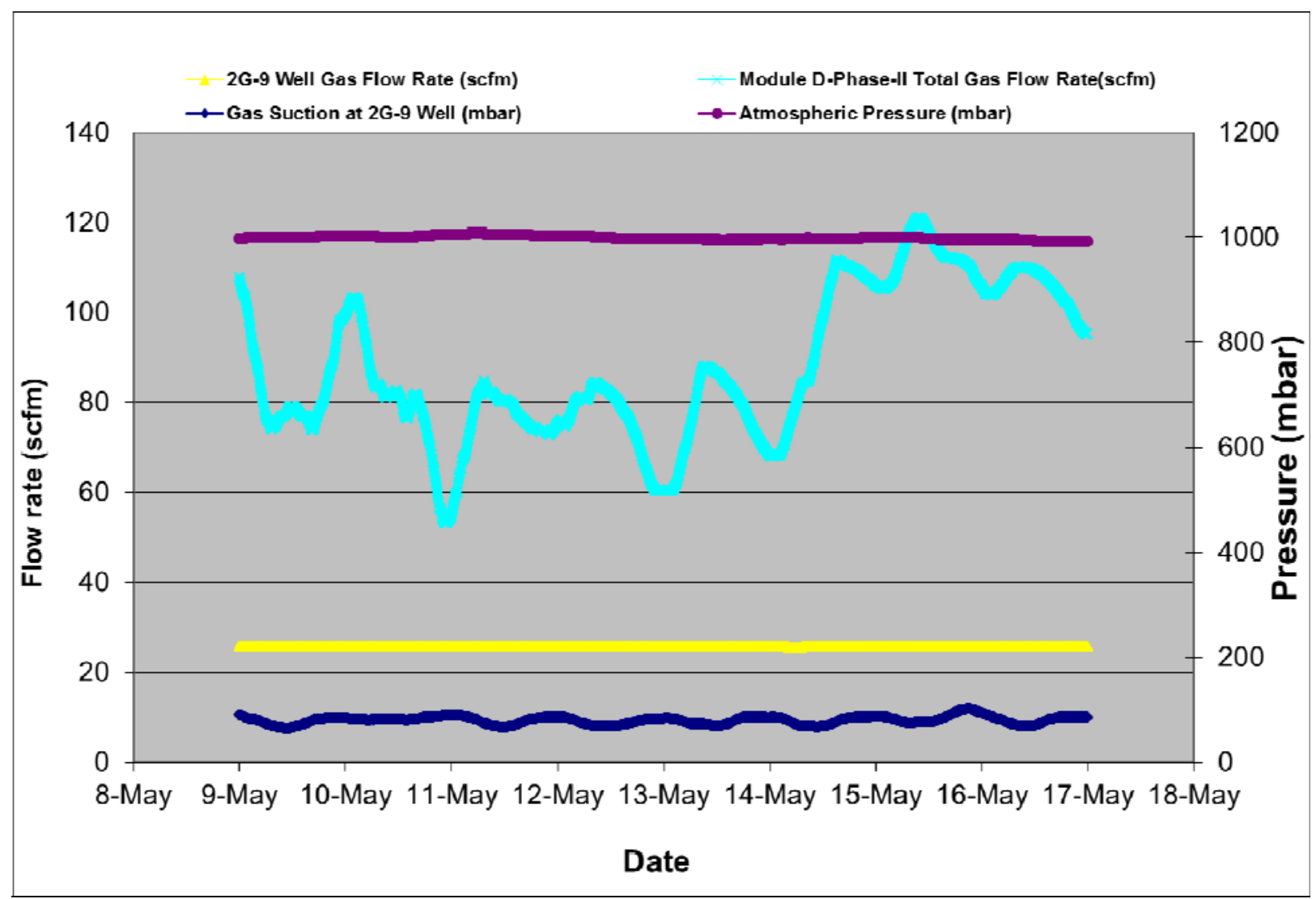

Figure 37. Data from setting 2 for control of gas collection well 2G9: fixed gas flow rate.

Results from setting 3 (not shown) are intermediate to that of settings 1 and 2. Fixing the difference in gas pressure in the well and the atmospheric pressure resulted in less variability in gas flow rate in 2G9 than that observed for setting 1 and shown in Figure 36. However, there was slightly more variability than what was observed for setting 3 shown in Figure 37 . The reason for this is while setting 3 accounts for variations in atmospheric pressure, it does not account for variations in the landfill gas-to-energy plant operations. Setting 2, on the other hand, accounts for variations in gas conditions arising from both sources. Thus, the results for setting 2 were clearly superior to both standard practice with fixed value settings (setting 1) and controlling the difference between atmospheric pressure and the pressure at the gas collection well. For this reason, we recommend that gas wells be controlled using operating conditions identical to that of setting 2 . 


\section{Conclusions}

In this project we developed and demonstrated a new approach to landfill operations that may significantly reduce fugitive greenhouse gas emissions: the Intelligent Bioreactor Management and Information System (IBM-IS). A manual IBM-IS was developed to control injection of air and liquids for suppression of methane generation in aerobic bioreactors. This system involves pneumatic pump tests, the development of a gas flow model for the landfill, and then the controlled extraction or injection of air to achieve aerobic conditions. This approach was developed and then tested in this project using an aerobic bioreactor test cell at Yolo County Central Landfill. The results from these field tests indicated that while air was injected throughout the landfill cell, pockets of anaerobic activity remained and resulted in appreciable methane generation. We quantified this effect and provided a mechanistic explanation of the cause - rate-limited mass transfer to immobile gas pockets in the refuse, which limited aerobic activity. While our intelligent operation of the aerobic bioreactor improved its performance, significant methane was still generated. We suggest that operations of aerobic bioreactors must account for undesired methane generation. In many cases, this may require collection of the landfill gas and subsequent treatment in some type of biological reactor to oxidize the methane.

An automated IBM-IS was developed to reduce methane emissions from anaerobic bioreactors. Here, there were two principle components of this system. The first was a nearsurface high permeability gas collection layer for more efficient collection of landfill gas and more uniform oxidation of fugitive methane in landfill cover soil. The second component was automation of the gas collection wells so that constant gas collection could be maintained during periods of rapid barometric pressure change. Initially, the near-surface high permeability layer allowed air to reach the gas collection well, likely because this high permeability layer was 
terminated too close to the intermediate soil cover on the side landfill side slopes. After adding new cover soil to the side slopes, the permeable layer was tested and showed very good distribution of gas suction across the landfill surface. This result points to the need for careful construction of this new landfill feature.

Testing of the second component demonstrated that standard landfill well operations with fixed valve settings results in significant variability in landfill gas collection: landfill gas was impacted by both barometric pressure changes and changes in operation at the landfill gas-toenergy facility over a one-week period. Because landfill gas generation is not expected to vary significantly over such short time periods, this variation in landfill gas collection causes increased landfill gas emission that has been documented in prior research. However, automating the gas collection well with a flow controller to maintain constant gas flow worked extremely well in mitigating these effects in our anaerobic bioreactor test cell. Over a similar one-week testing period, landfill gas collection was essentially invariant.

While this project has made significant contributions to intelligent control of bioreactor landfills through the advancements summarized above, there are other contributions that are components to the IBM-IS. These contributions include new instrumentation for conducting gas tracer tests landfills, new laboratory techniques and measurements to quantify the appropriate models for liquid and gas flow in refuse, and new techniques for estimating the landfill gas generation in landfills. While some of these were discussed in this report, many were not in order to keep this report to a manageable length. These contributions from this project are listed in Table 9 along with either the peer-reviewed journal paper or conference paper/presentation where these contributions are discussed. Each of the contributions in Table 9 relates to a 
technology, management process, or assessment tool that was developed or advanced in this project.

Table 9. List of important contributions from project and journal publications and conference papers/presentations where these contributions were disseminated.

\begin{tabular}{|c|c|c|}
\hline Contribution & Description & References \\
\hline $\begin{array}{c}\text { Photoacoustic detector for } \\
\text { landfill measurements }\end{array}$ & $\begin{array}{c}\text { Detector allows real-time } \\
\text { measurements of gas tracers to } \\
\text { quantify water content and gas } \\
\text { flow patterns }\end{array}$ & $\begin{array}{c}\text { [Han et al., 2007; Jung } \text { et al., } \\
\text { in review] }\end{array}$ \\
\hline $\begin{array}{c}\text { Inverse modeling for landfill } \\
\text { gas generation }\end{array}$ & $\begin{array}{c}\text { Procedure for measuring } \\
\text { landfill gas generation in } \\
\text { heterogeneous landfills }\end{array}$ & [Jung et al., in press] \\
\hline $\begin{array}{c}\text { Inverse modeling for gas } \\
\text { permeability field in landfills }\end{array}$ & $\begin{array}{c}\text { Procedure for measuring gas } \\
\text { permeability field in } \\
\text { heterogeneous landfills }\end{array}$ & Jung,Y. in press\}\} \\
\hline $\begin{array}{c}\text { Near-surface permeable layer } \\
\text { for capturing methane }\end{array}$ & $\begin{array}{c}\text { New landfill design feature for } \\
\text { increasing gas collection } \\
\text { efficiency }\end{array}$ & [Jung et al., 2009; Jung et al., \\
in press]
\end{tabular}

\section{Future Work}

This five-year project advanced many aspects of intelligent control of bioreactor landfills.

Our results, when combined with recent advancements of others in the landfill-research community, will lead to better operation of bioreactor landfills and reduced methane emissions 
from landfills in general. However, in the course of this project there are several aspects of bioreactor landfilling that while we made advances in require further work. In addition, our work focused on intelligent control of greenhouse gas emissions from bioreactor landfills. There are many landfills that are closed and will emit low levels of greenhouse gas emissions for long periods. Because converting these landfills to bioreactors may be impossible because of their design, alternative means of managing them to reduce greenhouse gas emissions are needed. Below are a number of future tasks that we believe are important for reducing greenhouse gas emissions from landfills. Several tasks related to quantification of greenhouse gas emissions will likely benefit other aspects of greenhouse gas emission control, including reducing unwanted emissions from carbon dioxide sequestration facilities.

- Our work focused on the control of air injection and gas collection in bioreactor landfills. While we made several advancements in understanding and modeling liquid flow, these advances were not critically tested in the field but only in the laboratory. Because liquid addition is an essential element of bioreactor landfilling and because controlling it has been problematic, future work is needed to test and modify our laboratory-developed models for liquid flow in the field.

- A particular challenge we faced in assessing anaerobic bioreactor performance was quantifying the effect of our management and design changes on greenhouse gas emissions. Measurements of gas pressure, gas composition, and above-ground concentrations of VOC's were used, but none provide a quantitative measure of the actual greenhouse gas emission. Future research is needed to develop new methods to quantify landfill gas emissions over entire landfills and smaller 
landfill test regions. Such techniques might be suitable for detecting leaks and quantifying emissions from $\mathrm{CO} 2$ sequestration sites.

- Most closed landfills are not good candidates for bioreactor landfilling. Instead, organic wastes degrade too slowly in such landfills, and methane generation is often too low to warrant standard landfill gas collection systems. Here, we believe engineered landfill cover soils that can oxidize fugitive methane are needed. While considerable research has been conducted on such cover soils in the laboratory, what is needed are field systems that can effectively control the landfill gas and direct it evenly through the biologically active cover soils where the methane is oxidized. Research and testing of such field systems is needed.

- One of the exciting results from our work was the development of a new inverse modeling technique for measuring the gas permeability field in a landfill and the landfill gas generation rate. This advancement could revolutionize how landfill gas collection systems are sized and designed. These techniques should also provide a better assessment of the carbon credits that might be assigned to new landfill controls in the US and in third world countries. However, our approach was only tested on one small landfill cell over a short operational period. It is not clear how our approach would be used over the life of a landfill. Future research should develop and test this approach over larger landfills and over the entire life of the landfill. 


\section{Products Produced and Technology Transfer Activities}

Eleven manuscripts have been produced thus far from this work that are either published or in review. All are in peer-reviewed journals or conference proceedings. In addition to those listed here, we have several other manuscripts in preparation that we anticipate submitting in late 2010 and early 2011.

1. Imhoff, P.T., Reinhart, D.R., Englund, M., Gurin, R., Gawande, N., Han, B., Jonnalagadda, S., Townsend, T., and R. Yazdani (2007), Methods for Measuring Liquid in Bioreactor Landfills - A Critical Review, Waste Management, vol. 27, pp. 729-745.

2. Han, B., Imhoff, P.T., and R. Yazdani (2007), Field Application of Partitioning Gas Tracer Test for Measuring Water in a Bioreactor Landfill, Environmental Science \& Technology, vol. 41, no. 1, pp. 277-283.

3. Mostafid, M.E., Imhoff, P.T., Yazdani, R., Chiu, P., Augenstein, D., Bentley, H.W., and B.J. Travis, (2008) The Influence of Leachate Recirculation and Air Flow on Aerobic Bioreactor Performance, in Geotechnics of Waste Management and Remediation, GeoCongress, pp. 128-135.

4. Jung, Y., Imhoff, P.T., Augenstein, D.C., and R. Yazdani, (2009) Influence of High-Permeability Layers for Enhancing Landfill Gas Capture and Reducing Fugitive Methane Emissions from Landfills, Journal of Environmental Engineering, vol. 135, No. 3, pp. 138-146.

5. Yazdani, R., Mostafid, M.E., Han, B., Imhoff, P.T., Chiu, P., Augenstein, D., Kayhanian, M., and G. Tchobanoglous, (2010) “Quantifying Factors Limiting 
Aerobic Degradation During Aerobic Bioreactor Landfilling," Environmental

Science and Technology, vol. 44, no. 16, pp. 6215-6220.

6. Jung, Y., Imhoff, P.T., and S. Finsterle, "Estimation of Landfill Gas Generation Rate and Gas Permeability Field of Refuse Using Inverse Modeling," Transport in Porous Media, in press.

7. Han, B., Scicchitano, V., and P.T. Imhoff, "Measuring Fluid Flow Properties of Waste and Assessing Alternative Conceptual Models of Pore Structure," Waste Management, in press.

8. Jung, Y., Imhoff, P.T., Augenstein, D., and R. Yazdani, "Mitigating methane emissions and air intrusion in heterogeneous landfills with a high permeability layer," Waste Management, in press.

9. Jung, Y., Han, B., Mostafid, M. E., Imhoff, P. T., Chiu, P., and Yazdani, R. "Use of a Photoacoustic Infrared Spectroscope for Conducting Gas Tracer Tests and Measuring Water Saturation." Waste Management, in review.

In addition, sixteen conference presentations were made: three in Spring/Summer 2006, two in Spring/Summer 2007, five in Summer/Fall 2008, one in Fall 2009, and five in Summer/Fall 2010. These are listed below.

1. "Development of an Intelligent Bioreactor Management Information System for Mitigation of Greenhouse Gas Emissions from Landfills,” by P.T. Imhoff, R. Yazdani, H. Bentley, S. Smith, D. Augenstein, B. Han, and E. Mostafid, presented at the Fifth Annual Conference on Carbon Capture and Sequestration in Washington, DC May, 2006. 
2. "Influence of High Permeability Layers on Collection and Emission of Landfill Methane - Computer Simulations,” by Y.J. Jung, L. Li, P.T. Imhoff, H.W.

Bentley, S.J. Smith, and D. Augenstein, presented at the Fourth Intercontinental Landfill Research Symposium in Gällivare (Lapland) Sweden June, 2006.

3. "Developing Dual Domain Models for Fluid Flow in Refuse: Laboratory Measurement of Capillary Pressure/Saturation Relationships,” by B. Han, E. Mostafid, and P.T. Imhoff, presented at the Fourth Intercontinental Landfill Research Symposium in Gällivare (Lapland) Sweden June, 2006.

4. "The Influence of Leachate Recirculation and Air Flow on Aerobic Bioreactor Performance”, by P. T. Imhoff, R. Yazdani, M.E. Mostafid, P. Chi, D.

Augenstein, H. Bentley, S. Smith, and B. Travis, presented at the Second HydroPhysico-Mechanical Properties of Waste Workshop in Southampton, England, April 2007.

5. "Reducing Greenhouse Gas Emissions through Aerobic Bioreactor Landfilling: Observations from Yolo County Central Landfill,” by M.E. Mostafid, P. Imhoff, R. Yazdani, D. Augenstein, and P. Chiu, presented at the 2007 Association of Environmental Engineering and Science Professors Conference, Blacksburg, VA, USA, July 2007.

6. "Use of a Photoacoustic Infrared Spectroscope for Conducting Gas Tracer Tests in Landfills:, by Yoojin Jung, Byunghyun Han, M. Erfan Mostafid, Paul T. Imhoff, Pei Chiu, and Ramin Yazdani, presented at the Fifth Intercontinental Landfill Research Symposium, Copper Mountain, Colorado, September 2008. 
7. "Quantifying Flow and Transport Properties of Various Biocovers Over Time," by M. Erfan Mostafid, Paul T. Imhoff, and RaminYazdani, presented at the Fifth Intercontinental Landfill Research Symposium, Copper Mountain, Colorado, September 2008.

8. "Use of a Photacoustic Infrared Spectroscope for Conducting Gas Tracer Tests in Landfills," by Yoojin Jung, Byunghyun Han, Erfan Mostafid, Paul Imhoff, Pei Chiu, and Ramin Yazdani, presented at the Global Waste Management Symposium, Copper Mountain, Colorado, September 2008.

9. "Innovative use of a High Permeability Layer for Mitigating Methane Emissions and Enhancing Landfill Gas Capture," by Yoojin Jung, Paul T. Imhoff, and Don C. Augenstein, presented at the Global Waste Management Symposium, Copper Mountain, Colorado, September 2008.

10. "Estimation of Gas Permeability Field in Landfills Using Inversion Modeling," by Yoojin Jung, Paul Imhoff, Stefan Finsterle, Ramin Yazdani, and Don Augenstein, presented at the Computational Methods in Water Resources XVII International Conference, San Francisco, California, July 2008.

11. "Estimation of Landfill Gas Generation Rates and Gas Permeability Field of Refuse Using Inverse Modeling,” by Yoojin Jung, Paul Imhoff, and Stefan Finsterle, presented at the TOUGH Symposium 2009 in Berkeley, California, September 2009.

12. "Biocover Soils for Carbon Sequestration and Oxidation of Fugitive Greenhouse Gas Emissions," by Paul T. Imhoff, Ramin Yazdani, Byunghyun Han, Yoojin 
Jung, M. Erfan Mostafid, and Edwin Wong, presented at the Ninth Annual Conference on Carbon Capture and Sequestration in Pittsburgh, PA May, 2010

13. "Developing Conceptual Models for Fluid Flow in Waste," by Byunghyun Han, Vincent Scicchitano, and Paul T. Imhoff, presented at the Sixth Intercontinental Landfill Research Symposium, Hokkaido, Japan, June 2010.

14. "Airborne Measurements for Quantifying $\mathrm{CH}_{4}$ Emissions from Landfills," Byunghyun Han, Michael A. O’Neal, Jack A. Puleo, Steven K. Dentel, Christopher L. Meehan, and Paul T. Imhoff, presented at the Sixth Intercontinental Landfill Research Symposium, Hokkaido, Japan, June 2010. 15. "Airborne Measurements for Quantifying Methane Emissions from Landfills," Byunghyun Han, Paul T. Imhoff, Vincent Scicchitano, Michael A. O’Neal, Jack A. Puleo, Steven K. Dentel, Christopher L. Meehan, and Daniel A. Fluman, presented at the Second Global Waste Management Symposium, San Antonio, Texas, October 2010.

16. "Developing Conceptual Models for Fluid Flow in Solid Waste," by Byunghyun Han, Vincent Scicchitano, and Paul T. Imhoff, presented at the Second Global Waste Management Symposium, San Antonio, Texas, October 2010.

A very important development that is directly related to this project is the awarding of an NSF grant to host a workshop on Modeling Sustainable Landfills. This NSF grant was awarded to the project PI (P.T. Imhoff) and Dr. S. Bartelt-Hunt of the University of Nebraska - Lincoln. This workshop was held at the University of Delaware in March 2008. This was a unique opportunity for the project team to disseminate the important results learned from the NETL 
project to a national and international audience of landfill researchers and practitioners. Details about this workshop can be found at http://research.ce.udel.edu/ imhoff/nsf_workshop.html.

\section{Project Milestones}

The milestones for this project are listed below along with actual completion dates.

Table 10. Project Milestones

\begin{tabular}{|c|c|c|}
\hline $\begin{array}{l}\text { Anticipated } \\
\text { Completion } \\
\text { Date }\end{array}$ & $\begin{array}{c}\text { Actual } \\
\text { Completion } \\
\text { Date }\end{array}$ & Milestone \\
\hline Dec 05 & Dec 05 & $\begin{array}{l}\text { Initiate installation of automatic gas pressure measurement } \\
\text { system for anaerobic bioreactor. }\end{array}$ \\
\hline Mar 06 & Jan 06 & Initiate in situ permeability tests for aerobic bioreactor. \\
\hline Jan 06 & Jan 06 & $\begin{array}{l}\text { Submit abstract to May Carbon Sequestration Conference in } \\
\text { Virginia }\end{array}$ \\
\hline Sept. 06 & Sept. 06 & Initiate in situ permeability tests for anaerobic bioreactor. \\
\hline Dec. 06 & Dec. 06 & $\begin{array}{l}\text { Initiate tests for gas and liquid flow properties in solid waste } \\
\text { samples in the laboratory. }\end{array}$ \\
\hline Mar 07 & March 07 & $\begin{array}{l}\text { Synthesize and evaluate data from the operation of aerobic } \\
\text { bioreactor landfill cell using the IBM-IS approach (Stage 1) }\end{array}$ \\
\hline Sept. 07 & Sept 07 & $\begin{array}{l}\text { Initiate development of a computational model for flow of } \\
\text { landfill gas in anaerobic test cell. }\end{array}$ \\
\hline Mar 08 & Mar 08 & $\begin{array}{l}\text { Testing of intelligent system for minimizing the influence of } \\
\text { barometric pressure changes on methane emissions from } \\
\text { landfills. }\end{array}$ \\
\hline Sept 08 & Sept 08 & $\begin{array}{l}\text { Completion of experiments to develop constitutive models for } \\
\text { liquid flow in landfills. }\end{array}$ \\
\hline Mar 09** & May $09 * *$ & $\begin{array}{l}\text { Completion of field tests using gas tracers and pneumatic pump } \\
\text { tests to quantify the efficiency of the new landfill cover design } \\
\text { for the anaerobic cell }\end{array}$ \\
\hline Sept 09 & Sept 09 & $\begin{array}{l}\text { Completion of simulations to test advanced data inversion } \\
\text { techniques for bioreactor landfill cells }\end{array}$ \\
\hline Mar 10 & Mar 10 & $\begin{array}{l}\text { Completion of field tests for evaluating surface cracks on the } \\
\text { efficiency of new landfill cover design }\end{array}$ \\
\hline
\end{tabular}

** Note that the field tests for characterizing the efficiency of the new landfill cover design in the anaerobic cell were planned for early Spring 2009. However, because of a delay in allocation of funds from NETL to the University of Delaware, these field tests were postponed until June 2009. Without the assurance of payment, the subcontractor (Yolo County, CA) was unable to 
proceed with the work until funds were allocated from NETL to the University of Delaware. Despite this delay, the project was not negatively impacted. We re-arranged work tasks and project goals and milestones were met. 


\section{XI.References}

Abichou, T., J. Chanton, D. Powelson, J. Fleiger, S. Escoriaza, Y. Lei, and J. Stern (2006), Methane flux and oxidation at two types of intermediate landfill covers, Waste Management, 26, $1305-1312$.

Ahlers, C. F., S. Finsterle, and G. S. Bodvarsson (1999), Characterization of subsurface pneumatic response at Yucca Mountain, Journal of Contaminant Hydrology, 38, 47-68.

Augenstein, D. and R. Yazdani (1997), Yolo County Controlled Landfill Demonstration Project, Yolo County Controlled Landfill Demonstration Project. Solid Waste Association of North America, Landfill Symposium, Sacramento, CA.

Augenstein, D. C., J. R. Benemann, and R. Yazdani (2007), Landfill design and method for improved landfill gas capture.

Barlaz, M. A., R. B. Green, J. Chanton, C. D. Goldsmith, and G. R. Hater (2004), Evaluation of a biologically active cover for mitigation of landfill gas emissions, Environmental Science \& Technology, 38, 4891-4899.

Bear, J. (1972), Dynamics of Fluids in Porous Media, Dover Publ., Inc., New York.

Beaven, R. P., J. A. Barker, and A. Hudson (2003), Description of a Tracer Test through Waste and Applcation of Double Porosity Model, Description of a Tracer Test through Waste and Application of Double Porosity Model. Ninth International Waste Management and Landfill Symposium, Sardinina, Italy.

Bendz, D., V. P. Singh, H. Rosqvist, and L. Bengtsson (1998), Kinematic wave model for water movement in municipal solid waste, Water Resources Research, 34, 2963-2970.

Bentley, H. W., S. J. Smith, and T. Schrauf (2005), Baro-pneumatic estimation of landfill gas generation rates at four operating landfills, Proceedings of SWANA's 28th Annual Landfill Gas Symposium, San Diego, CA, March 7-10.

Bentley, H. W., S. J. Smith, J. Tang, and G. R. Walter (2003), A method for estimating the rate of landfill gas generation by measurement and analysis of barometric pressure waves, Proceedings of the 18th International Conference on Solid Waste Technology and Management, Philadelphia, PA, March 23-26.

Bird, R., W. E. Stewart, and E. N. Lightfoot (1960), Transport Phenomena, John Wiley \& Sons, New York. 
Certes, C. and G. de Marsily (1991), Application of the pilot point method to the identification of aquifer transmissivities, Advances in Water Resources, 14, 284-300.

Curtiss, C. F. and J. O. Hirschfelder (1949), Transport Properties of Multicomponent Gas Mixtures, Journal of Chemical Physics, 17, 550-555.

Czepiel, P. M., J. H. Shorter, B. Mosher, E. Allwine, J. B. McManus, R. C. Harris, C. E. Kolb, and B. K. Lamb (2003), The influence of atmospheric pressure on landfill methane emissions, Waste Management, 23, 593--598.

de Marsily, G. (1994), Spatial variability of properties in porous media: A stochastic approach, in Fundamentals of Transport in Porous Media, edited by J. Bear and M. Y. Corapcioglu, pp. 719769, Martinus Nijhoff, Boston.

De Visscher, A. and O. Van Cleemput (2003), Simulation model for gas diffusion and methane oxidation in landfill cover soils, Waste Management, 23, 581-591.

Deutsch, C. V. J. A. G. (1992), GSLIB: Geostatistical Software Library and User's Guide, Oxford University Press, New York.

El-Fadel, M., A. N. Findikakis, and J. O. Leckie (1997), Numerical modelling of generation and transport of gas and heat in sanitary landfills III. Sensitivity analysis, Waste Management Research, 15, 87--102.

El-Fadel, M., A. N. Findikakis, and J. O. Leckie (1996), Numerical modeling of generation and transport of gas and heat in landfills I. Model formulation, Waste Management \& Research, 14, 483-504.

EMCON (1980), Methane Generation and Recovery from Landfills, Ann Arbor Science Publishers, Ann Arbor, MI.

Fen, C. S. and L. M. Abriola (2004), A comparison of mathematical model formulations for organic vapor transport in porous media, Advances in Water Resources, 27, 1005-1016.

Findikakis, A. N. and J. O. Leckie (1979), Numerical simulation of gas flow in sanitary landfills, Journal of Environmental Engineering Division, ASCE, 105, 927-945.

Finsterle, S. (2004), Multiphase inverse modeling: Review and iTOUGH2 applications, Vadose Zone Journal, 3, 747-762.

Finsterle, S. and M. B. Kowalsky (2007), iTOUGH2-GSLIB User's Guide, Report LBNL/PUB3191.

Finsterle, S. and M. B. Kowalsky (2008), Joint hydrological-geophysical inversion for soil structure identification, Vadose Zone Journal, 7, 287-293. 
Fuller, E. N., P. D. Schettler, and J. C. Giddings (1966), A new method for prediction of binary gas-phase diffusion coefficients, Industrial and Engineering Chemistry, 58, 18-27.

Gómez-Hernández, J. J., A. Sahuquillo, and J. E. Capilla (1997), Stochastic simulation of transmissivity fields conditional to both transmissivity and piezometric data - I. Theory, Journal of Hydrology, 203, 162-174.

Haggerty, R. and S. M. Gorelick (1995), Multiple-rate mass transfer for modeling diffusion and surface reactions in media with pore-scale heterogeneity, Water Resources Research, 31, 2383-2400 .

Han, B., V. Scicchitano, and P. T. Imhoff (in press), Measuring fluid flow properties of waste and assessing alternative conceptual models of pore structure, Waste Management.

Han, B., P. T. Imhoff, and R. Yazdani (2007), Field application of partitioning gas tracer test for measuring water in a bioreactor landfill, Environmental Science \& Technology, 41, 277-283.

Han, B., B. Jafarpour, V. N. Gallagher, P. T. Imhoff, P. C. Chiu, and D. A. Fluman (2006), Measuring seasonal variations of moisture in a landfill with the partitioning gas tracer test, Waste Management, 26, 344-355.

Hilger, H. A. and M. Humer (2003), Biotic landfill cover treatments for mitigating methane emissions, Environmental Monitoring and Assessment, 84, 71-84.

Hinchee, R. E. and S. K. Ong (1992), A rapid in situ respiration test for measuring aerobic biodgeradation rates of hydrocarbons in soil, J. Air \& Waste Management Assoc., 42, 1305-1312.

Hoeks, J. (1983), Significance of biogas production in waste tips, Waste Management \& Research, 1, 323-335.

Imhoff, P. T., R. Yazdani, H. Bentley, S. Smith, D. Augenstein, B. Han, and E. Mostafid (2006), Development of an Intelligent Bioreactor Management Information System for Mitigation of Greenhouse Gas Emissions from Landfills, Washington, DC, May.

Imhoff, P. T., D. R. Reinhart, M. Englund, R. Gurin, N. Gawande, B. Han, S. Jonnalagadda, T. G. Townsend, and R. Yazdani (2007), Review of state of the art methods for measuring water in landfills, Waste Management, 27, 729-745.

IPCC (2001), Intergovernmental Panel on Climate Change, Climate Change 2001: The Scientific Basis, Cambridge University Press, United Kingdom.

Jain, P., J. Powell, T. G. Townsend, and D. R. Reinhart (2005), Air permeability of waste in a municipal solid waste landfill, Journal of Environmental Engineering-Asce, 131, 1565-1573. 
Jung, Y., B. Han, M. E. Mostafid, P. T. Imhoff, P. Chiu, and R. Yazdani (in review), Photoacoustic infrared spectroscopy for conducting gas tracer tests and measuring water saturations in landfills, Waste Management.

Jung, Y., P. T. Imhoff, D. Augenstein, and R. Yazdani (in press), Mitigating methane emissions and air intrusion in heterogeneous landfills with a high permeability layer, Waste Management.

Jung, Y., P. T. Imhoff, D. C. Augenstein, and R. Yazdani (2009), Influence of high-permeability layers for enhancing landfill gas capture and reducing fugitive methane emissions from landfills, Journal of Environmental Engineering, 135, 138-146.

Jung, Y., P. T. Imhoff, and S. Finsterle (in press), Estimation of landfill gas generation rate and gas permeability field of refuse using inverse modeling, Transport in Porous Media.

Keidser, A. and D. Rosbjerg (1991), A comparison of four inverse approaches to groundwater flow and transport parameter identification, Water Resources Research, 27, 2219-2232.

Kowalsky, M. B., S. Finsterle, J. Peterson, S. Hubbard, Y. Rubin, E. Majer, A. Ward, and G. Gee (2005), Estimation of field-scale soil hydraulic and dielectric parameters through joint inversion of GPR and hydrological data, Water Resources Research, 41, W11425, doi:10.1029/2005WR004237.

Kowalsky, M. B., S. Finsterle, and Y. Rubin (2004), Estimating flow parameter distributions using gound-penetrating radar and hydrological measurements during transient flow in the vadose zone, Advances in Water Resources, 27, 583-599.

Luo, J., O. A. Cirpka, W. M. Wu, M. N. Fienen, P. M. Jardine, T. L. Mehlhorn, D. B. Watson, C. S. Criddle, and P. K. Kitanidis (2005), Mass-transfer limitations for nitrate removal in a uranium-contaminated aquifer, Environmental Science \& Technology, 39, 8453-8459.

Mason, E. A., Malinaus.A., and R. B. Evans (1967), Flow and Diffusion of Gases in Porous Media, Journal of Chemical Physics, 46, 3199-3216.

McBean, E. A., F. A. Rovers, and G. J. Farquhar (1995), Solid Waste Landfill Engineering and Design, Prentice Hall, Upper Saddle River, NJ.

McKenna, S. A., L. C. Meigs, and R. Haggerty (2001), Tracer tests in a fractured dolomite 3. Double-porosity, multiple-rate mass transfer processes in convergent flow tracer tests, Water Resources Research, 37, 1143--1154.

Millington, R. J. and J. P. Quirk (1961), Permeability of porous solids, Transactions of the Faraday Society, 57, 1200-1207.

Molins, S. and K. U. Mayer (2007a), Personal Communication. 
Molins, S. and K. U. Mayer (2007b), Coupling between geochemical reactions and multicomponent gas and solute transport in unsaturated media: A reactive transport modeling study, Water Resources Research, 43, W05435, doi:10.1029/2006WR005206.

Molins, S., K. U. Mayer, C. Scheutz, and P. Kjeldsen (2008), Transport and reaction processes affecting the attenuation of landfill gas in cover soils, Journal of Environmental Quality, 37, 459-468.

Nastev, M., R. Therrien, R. Lefebvre, and P. Gelinas (2001), Gas production and migration in landfills and geological materials, Journal of Contaminant Hydrology, 52, 187--211.

Oldenburg, C. M., S. W. Webb, K. Pruess, and G. Moridis (2004), Mixing of stably stratified gases in subsurface reservoirs: A comparison of diffusion models, Transport in Porous Media, $54,323-334$.

Oweis, I. S., D. A. Smith, R. B. Ellwood, and D. S. Greene (1990), Hydraulic characteristics of municipal refuse, Journal of Geotechnical Engineering, 116, 539-553.

Pierce, J., L. LaFountain, and R. Huitric (2004), LFG Generation and Modeling Manual of Practice, Solid Waste Association of North America (SWANA).

Poulsen, T. G., M. Christophersen, P. Moldrup, and P. Kjeldsen (2003), Relating landfill gas emissions to atmospheric pressure using numerical modelling and state-space analysis, Waste Management \& Research, 21, 356-366.

Pruess, K. and A. Battistelli (2002), TMVOC, A numerical simulator for three-phase nonisothermal flows of multicomponent hydrocarbon mixtures in saturated-unsaturated heterogeneous media, Report LBNL-49375.

Pruess, K., C. Oldenburg, and G. Moridis (1999), TOUGH2 User's Guide, Version 2.0, Report $L B N L-43134$.

Qian, X., R. M. Koerner, and D. H. Gray (2002), Geotechnical Aspects of Landfill Design and Construction, Prentice Hall, Upper Saddle River, NJ.

RamaRao, B. S., M. Lavenue, G. de Marsily, and M. G. Marietta (1995), Pilot point methodology for automated calibration of an ensemble of conditionally simulated transmissivity fields 1 . Theory and computational experiments, Water Resources Research, 31, 475-493.

Reinhart, D. R. (1996), Full scale experiences with leachate recirculating landfills: case studies, Waste Management \& Research, 14, 347-365.

Reinhart, D. R., P. T. McCreanor, and T. G. Townsend (2002), The bioreactor landfill: its status and future, Waste Management \& Research, 20, 172-186. 
Rittmann, B. E. and P. L. McCarty (2000), Environmental Biotechnology and Applications, 768 pp., McGraw-Hill.

Sanchez-Villa, X. and J. Xarrera (1997), Directional effects on convergent flow tracer tests, Mathematical Geology, 29, 551-569.

Scharff, H. and J. Jacobs (2006), Applying guidance for methane emission estimation for landfills, Waste Management, 26, 417-429.

Schuetz, C., J. Bogner, J. Chanton, D. Blake, M. Morcet, and P. Kjeldsen (2003), Comparative oxidation and net emissions of methane and selected non-methane organic compounds in landfill cover soils, Environmental Science \& Technology, 37, 5150-5158.

Shan, C. (1995), Analytical solutions for determining vertical air permeability in unsaturated soils, Water Resources Research, 31, 2193-2200.

Spokas, K., J. Bogner, J. P. Chanton, M. Morcet, C. Aran, C. Graff, Y. M. Golvan, and I. Hebe (2006), Methane mass balance at three landfill sites: What is the efficiency of capture by gas collection systems?, Waste Management, 26, 516-525.

Taylor, R. and R. Krishna (1993), Multicomponent Mass Transfer, John Wiley \& Sons, Inc., New York.

Tchobanoglous, G. and H. Theisen (1983), Integrated Solid Waste Management, Engineering Principles and Management Issues, McGrown-Hill, Inc., New York.

Thorstenson, D. C. and D. W. Pollock (1989), Gas-Transport in Unsaturated Zones Multicomponent Systems and the Adequacy of Fick's Laws, Water Resources Research, 25, 477507.

Tolaymat, T. M., R. B. Green, G. R. Hater, M. A. Barlaz, P. Black, D. Bronson, and J. Powell (2010),

Evaluation of landfill gas decay constant for municipal solid waste landfills operated as bioreactors, J. Air Waste Manag. Assoc., 60, 91-97.

USEPA (1994), Seminar publication, Design, operation, and closure of municipal solid waste landfills, EPA/625/R-94/008.

USEPA (1998), Compilation of Air Pollutant Emission Factors, U.S. Environmental Protection Agency, Office of Air Quality Panning and Standards.

USEPA (2003), Example Moisture Mass Balance Calculations for Bioreactor Landfills, EPA456/R-03-007, Office of Air Quality Planning and Standards, Research Triangle, NC.

USEPA (2005), Landfill Gas Emissions Model (LandGEM) Version 3.02 User's Guide, EPA$600 / R-05 / 047$. 
USEPA (2008), Inventory of U.S. Greenhouse Gas Emissions and Sinks: 1990-2006, USEPA \#430-R-08-005.

Walter, G. R. (2003), Fatal flaws in measuring landfill gas generation rates by empirical well testing, Journal of the Air \& Waste Management Association, 53, 461-468.

Warith, M. A., E. Evgin, and P. A. S. Benson (2004), Suitability of shredded tires for use in landfill leachate collection systems, Waste Management, 24, 967-979.

Webb, S. W. and K. Pruess (2003), The use of Fick's law for modeling trace gas diffusion in porous media, Transport in Porous Media, 51, 327-341.

Weeks, E. P. (1978), Field determination of vertical permeability to air in the unsaturated zone, U.S. Geological Survey Professional Paper 1051.

Wen, X. -., C. V. Deutch, and A. S. Cullick (2002), Construction of geostatistical aquifer models intergrating dynamic flow and tracer data using inverse technique, Journal of Hydrology, 255, 151-168.

Wilke, C. R. (1950), Diffusional properties of multicomponent gases, Chemical Engineering Progress, 46, 95-104.

Yazdani, R. (2008), Demonstration of landfill technology for peaking power potential at Yolo County Central Landfill, Yolo County Planning and Public Works Department.

Yazdani, R., M. M.E., B. Han, P. T. Imhoff, P. Chiu, D. Augenstein, M. Kayhanian, and G. Tchobanoglous (2010), Quantifying factors limiting aerobic degradation during aerobic bioreactor landfilling, Environmental Science \& Technology, 44, 6215-6220.

Yildiz, E. D., K. Ünlü, and R. K. Rowe (2004), Modeling leachate quality and quantity in municipal solid waste landfills, Waste Management \& Research, 22, 78-92.

Zison, S. W. (1984), Landfill gas recovery method. 